\title{
OPTIMAL PORTFOLIO CHOICE WITH PREDICTABILITY IN HOUSE PRICES AND TRANSACTION COSTS
}

\author{
Stefano Corradin \\ José L. Fillat \\ Carles Vergara
}




\title{
OPTIMAL PORTFOLIO CHOICE WITH PREDICTABILITY IN HOUSE PRICES AND TRANSACTION COSTS*
}

\author{
Stefano Corradin ${ }^{1}$ \\ José L. Fillat ${ }^{2}$ \\ Carles Vergara ${ }^{3}$
}

\begin{abstract}
Are housing returns predictable? If so, do households take them into account when making their housing consumption and portfolio decisions? We document the existence of housing return predictability in the U.S. at the aggregate, census region, and state level. We study a portfolio choice model in which housing returns are predictable and adjustment costs must be paid when a house is purchased or sold. We show that two state variables affect the agent's decisions: (i) her wealth-to-housing ratio; and (ii) the time-varying expected growth rate of house prices. The agent buys (sells) her housing assets only when the wealth-to-housing ratio reaches an optimal upper (lower) bound. These bounds are time-varying and depend on the expected growth rate of house prices. Finally, we use household level data from the PSID and SIPP surveys to test and support the model's main implications.
\end{abstract}

Keywords: Portfolio choice; predictability; house prices; household finance.

\footnotetext{
* The views expressed in this paper are those of the authors and not necessarily represent the views of the European Central Bank, Federal Reserve Bank of Boston, or Federal Reserve System. We are grateful to Geert Bekaert, Dwight Jaffee and Nancy Wallace. We benefited from discussions with Fernando Alvarez, Dante Amengual, John Cochrane, Morris Davis, Greg Duffee, Darrell Duffie, Janice Eberly, Harry Huizinga, Nuria Mas, Massimo Massa, Manfred Kremer, Arvind Krishnamurthy, John Leahy, Andrew Lo, Jean Imbs, Lasse H. Pedersen, Monika Piazzesi, Stuart Rosenthal, Martin Schneider, Rene M. Stulz, Selale Tuzel, Otto Van Hemert, Stijn Van Nieuwerburgh, Dimitri Vayanos, Annette VissingJorgensen, Neng Wang, Rui Yao, the participants at the University of Amsterdam Real Estate Workshop, the 2009 Summer Real Estate Symposium in San Diego and the XVII Finance Forum of the AEFIN, and the seminar participants at the University of the Basque Country, the University of Navarra, the European Central Bank, and the Goethe University Frankfurt. Jonathan Morse, Roberto Felici and Thomas Kostka provided outstanding research assistance.

1 European Central Bank, DG-Research, Office: EM1607, Kaiserstrasse 29, Frankfurt am Main, D-60311, Germany. E-mail: Stefano.Corradin@ecb.int.

2 Federal Reserve Bank of Boston, 600 Atlantic Ave., Boston, 02118 MA. E-mail: jose.fillat@bos.frb.org.

${ }^{3}$ Assistant Professor of Finance, IESE, Av. Pearson 21, 08034 Barcelona, Spain. Email: cvergara@iese.edu.
} 


\section{Introduction}

Housing plays an important role in the portfolio choices of households because it accounts for an important fraction of their wealth. However, several specific characteristics of housing make portfolio allocation decisions nontrivial. First, housing is a durable consumption good as well as an investment asset. Second, moving to a new house involves high transaction costs; therefore, homeowners would find it optimal to rebalance their housing position less frequently than other financial assets. Third, housing returns present a certain degree of predictability. The main contribution of this paper is to solve a portfolio choice problem that incorporates these three particular characteristics of housing and to test its empirical implications. The paper provides a first step towards understanding the existence of housing returns predictability and its qualitative and quantitative impact on housing consumption and portfolio decisions subject to transaction costs. This study has been articulated in three parts.

First, we motivate and explore predictability in housing returns. Figure 1 depicts the growth in U.S. house prices over the period from 1930 to 2010. The figure shows that most of the growth has happened during a few years of housing market "booms" 1 . Around the end of World War II, house prices rose by $60 \%$ from 1942 to 1947 . More recently, the annual rate of price change increased almost every year from 1998 to 2006, with a cumulative price increase of 85\%. This evidence suggests the existence of two regimes determined by the growth rate in house prices.

\section{[INSERT FIGURE 1 HERE]}

A natural candidate for capturing regular switches between these regimes is the empirical model developed in Hamilton (1990). We use a long time series of data to estimate the parameters of a 2-regime process that assumes that the expected growth of house prices can be either in a high or a low growth regime. We find that a model specification that allows the expected growth of house prices to switch only between two regimes captures sufficiently well the essential dynamics

\footnotetext{
${ }^{1}$ We define a boom in the housing market as the time interval that includes the minimum number of periods with at least three consecutive years of positive yearly returns in the Case-Shiller House Price Index (HPI) and at least one year with a return higher than $5 \%$. The existing literature is not consistent on the definition of housing boom.
} 
of U.S. house prices. We estimate a yearly growth rate of house prices of $-0.49 \%$ during the low growth regimes and a growth rate of $9.25 \%$ during the high regimes. Our analysis also suggests that house prices are most often in a regime of low growth. We also estimate the model at U.S. census division and state level using the repeat sales indexes constructed by the Federal Housing Finance Agency (FHFA). We find that there are important differences in expected growth rates, the spread between the highest and lowest growth rate, and timing across different U.S. census divisions and states. Furthermore, we show that housing returns are more predictable than stock returns. Because housing is a major component of wealth, our empirical findings suggest that it is important to understand how housing returns predictability affects households' consumption and portfolio decisions.

Second, we introduce housing return predictability in a model that studies housing consumption and portfolio choices by an agent in a partial equilibrium framework. We consider the housing market to be subject to sizeable transaction costs in the sense that the agent incurs a cost when selling the house she currently owns to buy a new one, making housing consumption lumpy. In essence, we generalize the model in Grossman and Laroque (1990) (GL henceforth), introducing predictability in housing returns 2 We show that two state variables affect the agent's decisions: (i) the wealth-to-housing ratio; and (ii) the time-varying expected growth rate of house prices. The agent buys (sells) her housing assets only when the wealth-to-housing ratio reaches an optimal upper (lower) bound. These bounds are time-varying and depend on the expected growth rate of house prices and the probability of switching from one regime to the other.

Third, we unveil some interesting implications of the model and test them with household level data on wealth, housing values, and asset holdings available from the Panel Study of Income Dynamics (PSID) from 1984 to 2007, and from the U.S. Census Bureau's Survey of Income and Program Participation (SIPP) from 1997 to 2005 3 We exploit the variation across households at

\footnotetext{
${ }^{2}$ Damgaard, Fuglsbjerg, and Munk (2003) generalize the GL setting allowing for both a perishable and a durable good whose price follows a geometric Brownian motion. Their general setting allows the relation between perishable and durable consumption and the impact of the uncertainty of the durable good price and its correlation with financial asset prices on portfolio behavior to be studied. Additionally, we consider predictability in housing returns and test the model's empirical implications.

${ }^{3}$ The SIPP collects income, asset and demographic information from a sample of approximately 20,000 - 30,000
} 
the time they move to a different house. The variable of interest is the wealth-to-housing ratio of households just before a move. It allows us to identify the threshold levels that trigger the re-optimization of housing wealth. Not surprisingly, we find that the inaction region does exist: the value of the wealth-to-housing ratio that triggers the purchase of a more expensive house is significantly higher than the value that triggers the purchase of a less expensive house. Moreover, we find that there exists an upper bound in the wealth-to-housing ratio that triggers the increase of housing holdings (i.e., moving to a more expensive house). Similarly, there exists a lower bound in the wealth-to-housing ratio that triggers the decrease of housing holdings (i.e., moving to a less expensive house).

We also document time variation of the bounds using house price indexes at state level. One of our main hypotheses predicts that households moving to a more expensive house in a period of expected high house price appreciation had an ex-ante wealth-to-housing ratio that is significantly lower than those moving in a period of expected low appreciation. To capture periods of high house price appreciation at state level, we construct a variable that we call "Hot Housing Market Indicator" (HHMI). The HHMI is a function of the estimated smooth probability of being in a period of high growth rate for each state. This indicator serves as a proxy for the model's second state variable (i.e., the time-varying expected growth rate of house prices). We provide evidence that the indicator does not only affect the likelihood of a housing adjustment but, conditional on an adjustment taking place, it also affects the size of the housing adjustment. With respect to the asset holdings, the model predicts that on average households should hold less risky stock holdings in a period of high house appreciation. The estimated effects of HHMI on stock shares suggest that housing return predictability is an important driver of the link between housing and portfolios.

Our paper follows the literature that studies investment decision problems under fixed adjustment costs 4 The model in Grossman and Laroque (1990) is a milestone in this literature. There are two lines of research that depart from this seminal paper and are related to our paper. First,

households. The main advantages of the SIPP relative to PSID are its large sample size and detailed information about covariates as well as its complete housing history. However, PSID covers a larger period for the variables that we are interested in. Additionally, the survey includes detailed questions about moving.

${ }^{4}$ See Stokey (2009a) for a treatment of stochastic control problems in the presence of fixed adjustment costs. 
the empirical part of our analysis is connected to the literature on $(\mathrm{S}, \mathrm{s})$ models, which focuses on empirically investigating the inaction region and testing the GL model, such as Eberly (1994), Attanasio (2000), Martin (2003) and Bertola, Guiso, and Pistaferri (2005). We are not aware of previous papers that study the joint effect of variability and predictability on the price of a durable good (i.e., housing in our specific case). Second, our model and its main implications are related to papers that focus on particular implications of portfolio choice in the presence of housing such as Flavin and Yamashita (2002), Cocco (2005), Yao and Zhang (2005), Flavin and Nakagawa (2008), Van Hemert (2008) and Stokey (2009b). This strand of literature assumes that house prices evolve stochastically following a random walk process 5 Flavin and Yamashita (2002) use a mean-variance efficiency framework to examine the household's portfolio problem when owner-occupied housing is included in the set of available assets. The authors focus on the impact of the portfolio constraint imposed by the consumption demand for housing on the household's optimal holding of risky stock, but they do not incorporate the house purchase decision as in Grossman and Laroque (1990). Cocco (2005) shows that investment in housing plays a crucial role in explaining the patterns of PSID cross-sectional variation in the composition of wealth and level of stock holding. Because housing investments are risky, younger and poorer homeowners have limited financial wealth to invest in stocks. Yao and Zhang (2005) investigate households' asset allocation and housing decisions in a life-cycle model. Their model predicts that housing investment has a negative effect on stock market participation as in Cocco (2005). Chetty and Szeidl (2011) examine how portfolio allocations change when households buy houses. They provide evidence that housing substantially reduces the amount that households invest in risky stock ${ }^{6}$

The outline of the paper is structured as follows. Section 2 motivates and explores predictability

\footnotetext{
${ }^{5}$ Specifically, Damgaard, Fuglsbjerg, and Munk (2003), Cocco (2005), Yao and Zhang (2005), Flavin and Nakagawa (2008) and Van Hemert (2008) make this assumption.

${ }^{\circ}$ Our paper is also related to the sizeable literature that incorporates stock return predictability into portfolio choice models. Lynch and Balduzzi (2000) examine the re-balancing behavior of an agent in the presence of stock return predictability when transaction costs are non-zero. Brennan, Schwartz, and Lagnado (1997), Barberis (2000), Kim and Omberg (1996) and Campbell and Viceira (1999) analyze the impact of myopic versus dynamic decisionmaking when stock returns are predictable but they refrain from considering the impact of transaction costs. Instead, in this paper, we analyze the impact of housing, as a consumption and investment good, on portfolio choices in the presence of transaction costs on housing and housing return predictability.
} 
in housing returns. Section 3 introduces the model and summarizes the main theoretical implications. In Section 4, we use the results of the estimation exercise to solve the model and show the main results. In Section 5, we describe the PSID and SIPP survey data. In Section 6, we test the main implications arising from the model solution that were presented in Section 3 (i.e., the existence and characteristics of the bounds and the implications of these bounds on the portfolio decisions of the households included in these panels). Finally, Section 7 concludes.

\section{Predictability in Housing Markets}

Are growth rates in housing prices predictable? Answering yes to this question is akin to saying that expected growth rates in housing prices are time-varying. There is a large literature that explores stock return predictability but predictability in housing markets has been largely overlooked 7 The goal of this section is to present evidence on the time variation of expected housing price growth rates. We focus on the U.S. housing market and we explore the census division and the state level data separately.

Hamilton (1990) proposed an empirical approach for identifying time-varying first moments. In particular, one conceives the housing price growth shown in Figure 1 as depending on some $n$-regime process, where the expected value is generally modeled through a Markov chain tracking the particular regime at a given point in time. Although regimes could affect the entire distribution of housing price growth, we consider the case where regimes affect the drift $\mu_{i}$ of the process

$$
\frac{d P}{P}=\mu_{i} d t+\sigma_{p} d Z
$$

where $P$ stands for housing price level, $\mu_{i}$ the drift or expected growth rate if regime $i$ is realized, and $\sigma_{p}$ determines the standard deviation of the growth process. We assume that the process governing the dynamics of the underlying regime $i$ follows a homogeneous first order Markov chain. For example, in the case of two regimes, the expected growth in house prices, $\mu_{i}$, can only take two

\footnotetext{
${ }^{7}$ With the notable exception of Campbell et al. (2009).
} 
values: $\mu_{i}=\mu_{h}$, where $h$ denotes the high growth regime, and $\mu_{i}=\mu_{l}$, where $l$ denotes the low growth regime, and $\mu_{h}>\mu_{l}$. The transition probability matrix of the Markov chain is denoted by $\Lambda$. The diagonals of this matrix represent the unconditional probabilities of staying in the current regime while the off-diagonal terms represent the probability of a regime shift, either from high to low $\left(\lambda_{h l}\right)$, or from low to high $\left(\lambda_{l h}\right)$.

Table 1 reports the parameter estimates of equation (1) using U.S. housing data constructed in Shiller (2005). The sample period is 1925 - 2010 and data frequency is annual. The Case-Shiller HPI time series dates back to 1890, but before 1925 becomes substantially more unreliable. We assume two regimes for the expected growth rate of house prices. We follow the procedure in Hamilton (1990) for estimating the switching probabilities, the process's standard deviation and the values for the two regimes of conditional expected house prices and stock growth rate. The estimated mean of the real annual growth rate is $-0.49 \%$ during the low-growth regimes and $9.25 \%$ during the high-growth regimes. We also estimate the parameters of equation (1) using stock market prices (i.e., Standard\&Poor's 500 index). We obtain a mean of the nominal annual growth rate of $-19.90 \%$ during the low-growth regimes and $12.72 \%$ during the high-growth regimes. Then, we test the null hypothesis that house prices and the stock market follow a martingale against the alternative of a regime switching mechanism. Using a likelihood ratio test, we reject the null hypothesis $\mu_{h}=\mu_{l}$ for housing prices 8 However, we cannot reject the same null hypothesis for the U.S. stock market. Therefore, predictability, as a form of time-varying first moment of returns, is much higher in magnitude in house prices than in stock prices 9 This lends support to the parsimonious 2-regime Markov switching model with only time variation in the expected growth of

\footnotetext{
${ }^{8}$ Tests for the number of regimes are typically difficult to implement because they do not follow standard distributions. Under the null of a single regime in the simple 2-regime model, the parameters of the other regime are not identified and so there are unidentified nuisance parameters. This means that conventional likelihood ratio tests are not asymptotically $\chi^{2}$ distributed. We report a test for linearity in all output, which is based on the likelihood-ratio statistic between the estimated model and the derived linear model. Then, we report the approximate upper bound for the significance level of the LR statistic as derived by Davtes (1977). For an example of this procedure, see Garcia and Perron (1996).

${ }^{9}$ Previous literature documents that regimes on equity returns are mostly identified by volatility (see Hamilton and Lin (1996) and Ang and Bekaert (2002)). Ang and Timmermann (2011) have recently estimated the regime switching model on equity excess returns, which are total returns on the Standard\&Poor's 500 index in excess of T-bills. Their sample period is $1953-2010$ and the data are at the monthly frequency. They cannot reject that the regime-dependent means are equal to each other, $\mu_{h}=\mu_{l}$, but overwhelmingly reject that $\sigma_{h}=\sigma_{l}$.
} 
house prices.

[INSERT TABLE 1 HERE]

A large number of studies find that aggregate stock market returns are predictable. The strength of this predictability, however, has varied considerably over time. The predictable power of an instrument such as the price-dividend ratio for predicting excess aggregate equity returns declined, as documented by Ang and Bekaert (2007), Lettau and van Nieuwerburgh (2008), Welch and Goyal (2008), among others. Ang and Timmermann (2011) claim that the strength of predictability changes over time and is subject to breaks and parameter instability 10 Appendix A.1 shows evidence of house price and stock price predictability using the rent-price and dividend-price ratios, respectively. We present evidence on the linkages between the price-rent ratio and the estimated probabilities of being in a high and low growth rate regime. Under this alternative approach we reach similar results than under the framework based on Hamilton (1990) presented in this section.

Figure 2 shows the nominal returns and the smoothed regime probability, that is the probability that the regime is high-growth regime given all the information present in the data sample, for both the U.S. housing returns and Standard\&Poor's 500 index. For the stock market, the result is consistent with previous literature. Ang and Bekaert (2002) find that equity returns are characterized by two regimes: a regime of high growth and a regime of low growth in which returns are negative. Most of the time, stock prices follow a martingale process but they might experience short-lived bear market periods. Housing return dynamics are markedly different. Our analysis suggests that house prices are most often in a low-growth regime and the probability of being in a high regime is rather low, except in periods of large price appreciation, indicating that high-growth regimes in the U.S. tend to occur relatively infrequently. The likelihood ratio tests mentioned above are consistent with this observation. This fact is also reflected in the estimated, time-invariant, transition probabilities of switching to the alternative regime in the next period: the probability

\footnotetext{
10 Henkel, Martin, and Nardari (2011) use a regime switching VAR with several predictors, including price-dividend ratios and interest rate variables along with stock returns. They find that predictability is very weak during business cycle expansions but is very strong during recessions. Thus, most predictability occurs during market downturns and the regime switching model captures this counter-cyclical predictability by exhibiting significant predictability only in the recession regime.
} 
of moving from a low to a high growth rate regime is only about $3.43 \%$ (i.e., $1-0.9658=0.0343$ ), while the probability of moving from a high to a low growth rate is $24.14 \%$ (see Table 1). Figure 2 also shows that the probability of being in a regime of high growth is greater than $50 \%$ only on two occasions. Those two occasions correspond to World War II and the most recent housing market boom. Regarding the latter, the probability of being in high-growth regime began to grow in 1996 and reached its peak of almost $100 \%$ in 2005 . The persistent high probabilities during this recent period are extraordinary by historical standards and have been followed by a downward correction in aggregate housing prices.

\section{[INSERT FIGURE 2 HERE]}

To account for the geographic heterogeneity in the housing markets, we further analyze house prices at the U.S. census division and state levels. We use quarterly house price indexes provided by the Federal Housing Finance Agency (FHFA) starting in 1975. During the most recent housing market boom, some state housing markets experienced the pattern observed for U.S. at the aggregate level, but others did not. For example, house prices rose by $100 \%$ in California, and then fell by $60 \%$, but they barely moved in Texas. Part of this cross-sectional variation may stem from institutional differences across states but that aspect is beyond the scope of this paper.

We estimate the Markov switching model using house price data at the U.S. census division and U.S. state levels. Table 2 reports the parameter estimates for the U.S. census divisions ${ }^{11}$ 12 Overall, our analysis provides evidence that U.S. census divisions and states markedly differ

\footnotetext{
${ }^{11}$ Census regions and divisions are groupings of states that subdivide the United States. Each of the four census regions is divided into two or more census divisions:

- West Region i) Pacific Division: Hawaii, Alaska, Washington, Oregon, California; ii) Mountain Division: Montana, Idaho, Wyoming, Nevada, Utah, Colorado, Arizona, New Mexico;

- Midwest Region i) West North Central Division: North Dakota, South Dakota, Minnesota, Nebraska, Iowa, Kansas, Missouri; ii) East North Central: Michigan, Wisconsin, Illinois, Indiana, Ohio;

- South Region i) East South Central Division: Kentucky, Tennessee, Mississippi, Alabama; ii) South Atlantic Division: Delaware, Maryland, District of Columbia, Virginia, West Virginia, North Carolina, South Carolina, Georgia, Florida. iii) West South Central Division: Oklahoma, Arkansas, Texas, Louisiana;

- Northeast Region i) New England Division: Maine, New Hampshire, Vermont, Massachusetts, Rhode Island, Connecticut; ii) Middle Atlantic Division: New York, New Jersey, Pennsylvania.

${ }^{12}$ Appendix A.4 presents the results of the estimation at the U.S. state level.
} 
in the levels and spread between their high and low-phase growth rates. We cannot generalize high-growth periods across census division as regimes where house prices markedly grew. For some census divisions, like Pacific (West) and New England (Northeast), the high-growth regime displays annual real growth rates of $8.52 \%$ and $9.36 \%$, respectively, while for others, such as West North Central (Midwest) and East South Central (South), the high-growth regimes are characterized by modest growth in house prices with a annual mean real growth rate of $1.79 \%$ and $1.02 \%$ respectively. Overall, the housing returns for all the census divisions are well captured by a 2-regime switching model and the mean growth rate in each regime is accurately portrayed. Likelihood ratio tests support the hypothesis that the means of the two regimes, $\mu_{l}$ and $\mu_{h}$, are different.

[INSERT TABLE 2 HERE]

The estimated probability of being in a regime of high mean house price growth rates is very different across the U.S. census divisions. Figure 3 depicts the quarterly real housing returns (dotted line) and the inferred smooth probability of being in the regime of high mean growth rates (continuous line) for Pacific (West), New England (Northeast), West South Central (South) and East North Central (Midwest). This figure shows the pronounced cyclicality in the quarterly house prices growth for Pacific and New England. High-growth periods in Pacific and New England tend to occur relatively frequently and tend to be long in duration. The expected duration of a high-growth regime is 5.91 years for Pacific and 3.87 years for New England. West South Central and East North Central have less pronounced cycles and in fact the spread between their high and low growth rates is not substantial. They experience a relatively modest growth with an expected duration of a high-growth regime of 14.12 years for West South Central and of 7.48 years for East North Central.

\section{[INSERT FIGURE 3 HERE]}

To understand the main implications of house price predictability on portfolio decisions, we first examine a model with infrequent housing adjustment in the presence of predictability. Then, we 
develop relevant qualitative implications that we test on data that feature extensive information on housing purchases and measures of housing return predictability at the state level.

\section{The Model}

In this section, we examine the consumption and portfolio choice of an agent in a continuous time economy with a riskless asset, a risky asset and two consumption goods, a perishable and a durable good with uncertain price evolution. The agent in our model has non-separable Cobb-Douglas preferences over housing and non-housing goods. The agent derives utility over a trivial flow of services generated by the house. This specification can be generalized as long as preferences are homothetic. For simplicity, we focus on the Cobb-Douglas implications. The period utility function can be expressed as:

$$
u(C, H)=\frac{1}{1-\gamma}\left(C^{\beta} H^{1-\beta}\right)^{1-\gamma},
$$

where $H$ is the service flow from the house (square unit size), $C$ is other consumption, and $\beta, \gamma \in$ $(0,1)$. The agent has no bequest motive. The period-by-period budget constraint determines that the agent spends her income on consumption of non-housing goods, changing the house size, and investments for the following period in risky and safe assets. Income is composed of the returns of previous investments and a deterministic endowment.

The housing stock depreciates at a physical depreciation rate $\delta$. If the agent does not buy or sell any housing assets, the dynamics of the housing stock follows the process:

$$
d H=-\delta H d t
$$

for a given initial condition $H_{0}=\bar{H}$. We assume that the square foot price of the house, $P$, follows a geometric Brownian motion with time-varying drift,

$$
d P=P \mu_{i} d t+P \sigma_{P}\left(\rho_{P S} d Z_{1}+\sqrt{1-\rho_{P S}^{2}} d Z_{2}\right)
$$


where $\mu_{i}$ is the time-varying drift and $\rho_{P S}$ is the correlation coefficient between the house price, $P$, and value of the risky financial asset, $S$, defined below.

We assume that house price growth is predictable in the sense that $\mu_{i}$ follows a $n$-regime Markov chain and $i$ takes values in the set $1, \ldots, n$. The generator matrix of the Markov chain is $\Lambda=\left[\lambda_{j k}\right]$ for $j, k \in\{1, \ldots, n\}$. Thus, the probability of moving from regime $j$ to $k$ within the time $\Delta t$ is approximately $\lambda_{j k} \Delta t$. We assume that the agent knows with certainty the economy's regime, hence $\mu_{i}$ is observable by the agent at time $t$. The agent in our model has no uncertainty about the model's parameters. Pastor and Veronesi (2003) highlight the importance of learning about mean profitability in stock valuation. Our aim is to first understand how agents make housing and portfolio decisions in the presence of housing return predictability with perfect information and transaction costs. Hence, our agents are endowed with all the information about the current regime 13

Let $W$ define the agent's wealth in units of non-housing consumption such as investments in financial assets (riskless and risky financial assets) and the value of current housing stock:

$$
W=B+\Theta+H P
$$

where $B$ is the wealth held in the riskless asset and $\Theta$ is the amount invested in the risky financial asset, both of them expressed in units of non-housing consumption. The price of the risky asset, $S$, follows a geometric Brownian motion:

$$
d S=S \alpha_{S} d t+S \sigma_{S} d Z_{1}
$$

Given the process for risky asset prices, the housing stock's law of motion, and house price

\footnotetext{
${ }^{13}$ We refrain from introducing uncertainty about expected house appreciation to keep the model as parsimonious as possible while still exploiting the implications of predictability and transaction costs in the portfolio choice problem with housing. Nonetheless, we acknowledge that the agents' information set is ambitiously rich. We leave the introduction of learning about the uncertainty of the state variable as a useful line of research for the future.
} 
dynamics, wealth evolves according to the following process in regime $i$ (for $i=1, \ldots, n$ ):

$$
\begin{aligned}
d W & =\left[r(W-H P)+\Theta\left(\alpha_{S}-r\right)+\left(\mu_{i}-\delta\right) H P-C\right] d t \\
& +\left(\Theta \sigma_{S}+H P \rho_{P S} \sigma_{P}\right) d Z_{1}+H P \sigma_{P} \sqrt{1-\rho_{P S}^{2}} d Z_{2} .
\end{aligned}
$$

The homeowner can sell the house at any time $\tau$. The agent incurs in a transaction cost which is proportional to the value of the house she is selling. Since the quantity of housing changes discontinuously at the stopping time $\tau$, the notation $H\left(\tau^{-}\right)$is used to distinguish the amount of housing immediately prior to the sale from the quantity of housing immediately after the sale, $H(\tau)$. At the instant the house is sold, the homeowner's wealth is $W(\tau)=W\left(\tau^{-}\right)-\epsilon P(\tau) H\left(\tau^{-}\right)$, where $\epsilon P(\tau) H\left(\tau^{-}\right)$is the transaction cost. The homeowner first decides whether it is optimal to instantaneously sell the house by comparing the value function associated with her problem conditional on selling a house (action) with the value function conditional on not selling (inaction). Let $\tau$ define the stopping time where the selling action occurs. In practice, homeowners may be required to sell the current house for exogenous reasons. Marital status changes that involve relocating to a new house and changes in family size are two possible interpretations of the exogenous moves. We refrain from introducing exogenous moving shock 14

The value function of this problem, $V(W(0), P(0), H(0), i)$, satisfies the following Bellman equation in which the consumer chooses optimal consumption of non-housing and housing, asset allocation and optimal stopping time for buying a new house:

$V(W(0), P(0), H(0), i)=\sup _{C, \Theta, H(\tau), \tau} E\left[\int_{0}^{\tau} e^{-\rho t} u(C, H) d t+e^{-\rho \tau} V(W(\tau), P(\tau), H(\tau), i)\right], \quad i=1, \ldots, n$

and $W(\tau)=W\left(\tau^{-}\right)-\epsilon P(\tau) H\left(\tau^{-}\right)$. We can use the homogeneity properties of the value

\footnotetext{
${ }^{14}$ Stokey (2009b) assumes that this shock is Poisson with a constant arrival rate. In her set up, a positive hazard rate for exogenous moves makes housing less attractive and moves more frequent. As result, the inaction region widens and the upper and lower bounds increase. In our empirical analysis, we will include changes in demographic characteristics in assessing our model's qualitative predictions.
} 
function to reduce the problem with four state variables $(W, P, H, i)$ to one with two state variables, $z=W /(P H)$, and $i$, since

$$
V(W, P, H, i)=H^{1-\gamma} P^{\beta(1-\gamma)} V\left(\frac{W}{P H}, 1,1, i\right)=H^{1-\gamma} P^{\beta(1-\gamma)} v(z, i)
$$

Furthermore, let $\hat{c}$ and $\hat{\theta}$ denote the scaled controls $\hat{c}=C /(P H)$ and $\hat{\theta}=\Theta /(P H)$. We refer to the ratio $z$ as the wealth-to-housing ratio.

A solution consists of a value function $v(z, i)$ defined on the state space, where bounds $\underline{z}_{i}$ and $\bar{z}_{i}$ define an inaction region, $z_{i}^{*}$ is the optimal regime-dependent return point, and a consumption policy $\hat{c}^{*}(z, i)$ and portfolio policy $\hat{\theta}^{*}(z, i)$ defined on $\left(\underline{z}_{i}, \bar{z}_{i}\right)$. The function $v(z, i)$ satisfies the HamiltonJacobi-Bellman equation on the inaction region. Value matching and smooth pasting conditions hold at the two bounds, and an optimality condition holds at the return point. Compared to Grossman and Laroque (1990) and Damgaard, Fuglsbjerg, and Munk (2003), the novel feature exploited here is the Markov chain process governing the dynamics of the expected growth rate of house prices. Hence, the model features optimal rules that reflect the possibility for the agent to invest in a different regime of house price growth in the future. The agent has to determine the optimal rule in each regime, while taking into account the optimal rule in the other one. Thus, the model generates richer rules than the standard one-regime models. The following proposition exposes the optimal housing and portfolio choices properties derived from our model.

Proposition 1 The solution of the optimal portfolio choice problem defined above presents the following properties:

1. $v(z, i)$ satisfies

$$
\widetilde{\rho} v(z, i)=\sup _{\hat{c}, \hat{\theta}}\left\{u(\hat{c})+\mathcal{D} v(z, i)+\sum_{j \neq i} \lambda_{i j}(v(z, j)-v(z, i))\right\}, \quad z \in\left(\underline{z}_{i}, \bar{z}_{i}\right),
$$

where 


$$
\begin{aligned}
& \mathcal{D} v(z, i)=\left((z-1)\left(r+\delta-\mu_{i}+\sigma_{P}^{2}(1+\beta(\gamma-1))\right)\right. \\
&+\left.\hat{\theta}\left(\alpha_{S}-r-(1+\beta(\gamma-1)) \rho_{P S} \sigma_{S} \sigma_{P}\right)-\hat{c}\right) v_{z}(z, i) \\
&+ \frac{1}{2}\left((z-1)^{2} \sigma_{P}^{2}-2(z-1) \hat{\theta} \rho_{P S} \sigma_{P} \sigma_{S}+\hat{\theta}^{2} \sigma_{S}^{2}\right) v_{z z}(z, i) \\
& v(z, i)=M_{i} \frac{(z-\epsilon)^{(1-\gamma)}}{1-\gamma}, \quad z \notin\left(\underline{z}_{i}, \bar{z}_{i}\right)
\end{aligned}
$$

and $M_{i}$ is defined as

$$
M_{i}=(1-\gamma) \sup _{z \geq \epsilon} z^{\gamma-1} v(z, i)
$$

for $i=1, \ldots, n$.

2. The return point $z_{i}^{*}$ attains the maximum in

$$
v\left(z^{*}, i\right)=M_{i} \frac{z_{i}^{*(1-\gamma)}}{1-\gamma}, \quad \text { for } \quad i=1, \ldots, n
$$

3. Value matching and smooth pasting conditions hold at the two thresholds $\left(\underline{z}_{i}, \bar{z}_{i}\right)$

$$
\begin{aligned}
& v(\hat{z}, i)=M_{i} \frac{\left(\hat{z}_{i}-\epsilon\right)^{(1-\gamma)}}{1-\gamma}, \\
& v_{z}(\hat{z}, i)=M_{i}\left(\hat{z}_{i}-\epsilon\right)^{-\gamma}
\end{aligned}
$$

for $\hat{z}_{i}=\underline{z}_{i}, \bar{z}_{i}$ and $i=1, \ldots, n$.

4. In a state $z$, where $v(z, i)>M_{i} \frac{(z-\epsilon)^{1-\gamma}}{1-\gamma}$, the agent chooses a optimal consumption $\hat{c}^{*}(z, i)$ and portfolio $\hat{\theta}^{*}(z, i)$ and $\hat{b}^{*}(z, i)$

$$
\begin{aligned}
& \hat{c}^{*}(z, i)=\left(\frac{v_{z}(z, i)}{\beta}\right)^{1 /(\beta(1-\gamma)-1)}, \\
& \hat{\theta}^{*}(z, i)=-\omega \frac{v_{z}(z, i)}{v_{z z}(z, i)}+\frac{\rho_{P S} \sigma_{P}}{\sigma_{S}}(z-1), \\
& \hat{b}^{*}(z, i)=1-\left(1+\hat{\theta}^{*}(z, i)\right) / z
\end{aligned}
$$


for $i=1, \ldots, n$, and the constant $\omega$ is defined as $\omega=\left[\alpha_{S}-r+(1-\beta(1-\gamma)) \rho_{P S} \sigma_{P}\right] / \sigma_{S}^{2}$.

The main model implications that are tested and analyzed in the empirical part of this paper are summarized by the following statements:

1. There exists an inaction region for housing, that is, households do not trade housing continuously. Instead, they wait until their wealth is high (low) enough to increase (decrease) their housing assets. The inaction region is limited by a lower bound $\underline{z}_{i}$ and an upper bound $\bar{z}_{i}$ in each regime $i$, such as $\underline{z}_{i}<\bar{z}_{i}$ for $i=1, \ldots, n$.

2. The upper and lower bounds are not constant, but depend on the regime $i$. In particular, both the upper and lower bounds in periods of high house price growth are below the respective bounds in low-growth periods. With higher mean growth rates, the optimal housing holdings are substantially higher and hence the inaction region is narrower.

3. The portfolio choices of households $\hat{\theta}^{*}(z, i)$ and $\hat{b}^{*}(z, i)$ depend on their individual value of $z$, which in turn depends on the regime $i$. Regarding the risky asset position, the model predicts the following linear relation between asset holdings and the ratio $z$ of total wealth to housing wealth when the ratio $z$ is very close to the bounds $\underline{z}_{i}$ and $\bar{z}_{i}$ :

$$
\hat{\theta}^{*}(z, i) \approx-\frac{\omega}{\gamma} z+\frac{\rho_{P S} \sigma_{P}}{\sigma_{S}}(z-1)
$$

The equality holds when $z=\underline{z}_{i}$ or $z=\bar{z}_{i}$. In either case, equation (18) becomes the linear portfolio rule in Merton (1969), which is equivalent to the equality in (20). The first term on the right-hand side of $(18)$ becomes "less linear" the further $z$ is from $z=\underline{z}_{i}$ and $z=\bar{z}_{i}$, because the coefficient of the relative risk aversion varies with $z$. The lower relative risk aversion when $z$ is close to the upper or lower bounds leads to higher fractions of wealth invested in the risky asset than when $z$ is in the center of the inaction region. The second term is a hedging term. The effect of the hedging term mainly depends on the correlation between housing and equity return and on the term $z-1$. This latter corresponds to the 
liquid wealth-to-housing ratio, $(B+\Theta) /(P H)$. When the correlation between housing and equity returns is positive (negative), the stock market position decreases (increases) to the point where financial wealth-to-housing ratio is null and then increases (decreases).

Figure 4 illustrates the implications of transaction costs, and predictability in housing returns in a 2-regime set up. In this case, the expected housing return can be high (regime 1) or low (regime 2). Consider that an agent has a ratio of total wealth, $W$, to housing wealth, $P H$ equal to 2.5 at the initial time $t=0$. Assume that $t=0$ belongs to a time interval in which the growth of house prices is high. The agent must pay a transaction cost every time she adjusts her housing consumption; therefore, she does not move to a more expensive house until she has not accumulated a sufficient amount of wealth to compensate this transaction cost. When the wealth-to-housing ratio, $W /(P H)$ in the figure, reaches the upper bound, the agent sells her house and purchases a more expensive one in order to reset her wealth-to-housing ratio to its optimal level. In Figure 4 , this event corresponds to point 1 at time $t=\tau_{1}$. As a result, the ratio $W /(P H)$ returns to the optimal level $z_{h}^{*}$, which corresponds to point $1^{*}$. Now assume that the economy moves towards a regime of low growth in house prices shortly after $\tau_{1}$. Note that both the upper and lower bounds in this period of low house price growth are higher than their respective bounds in the period of high growth. The wealth-tohousing ratio evolves over time until it hits the upper bound again (point 2) at time $t=\tau_{2}$. Hence, the agent purchases a more expensive house (point $2^{*}$ ). At time $t=\tau_{3}$ there is a shift to the regime of high expected growth in house prices (point 3). As a result, the upper bound shifts down and the agent moves to a more expensive house (point $3^{*}$ ), which is bigger than in the regime of low expected growth in house prices. The example continues with symmetrical situations in which the agent moves to a less expensive house when her ratio reaches the lower bound (points 4, 5, and 6). The previous hypothetical example provides insights into the paper's main contributions: (i) the portfolio choice implications of three of the main characteristics of housing (i.e., housing being a durable consumption good as well as an investment asset, high transaction costs, and predictability in housing returns); (ii) the testable implications of the wealth-to-housing ratio for households that want to change their housing holdings; and (iii) the testable implications about the overall portfolio 
allocation.

[INSERT FIGURE 4 HERE]

Predictability in housing returns implies a time-varying inaction region as the bounds shift over time adding a second state variable to the GL framework, where housing adjustment occurs only when the wealth-to-housing ratio hits a time-invariant bound. In addition to the wealth-tohousing ratio, the time-varying expected growth rate of house prices also determines the optimal timing for re-balancing the wealth composition 15 The time-varying expected growth rate of house prices causes a shift in the location of the bound where it is optimal to pay the transaction costs for re-sizing the housing holdings. The intuition is as follows. When the expectations of house appreciation are higher, the agent expects to have a lower wealth-to-housing ratio in the next time period due to a regime switch, therefore, she upgrades to a more expensive house even with a relatively lower wealth. On the other side, in times of lower expectations of appreciation, the agent prefers to wait longer until her own wealth increases in order to upgrade to a more expensive house ${ }^{16}$ Hence, our framework generates richer portfolio rules than the GL framework. In particular, risk aversion is also regime-dependent, generating a different portfolio allocation rule for each regime. The portfolio allocation rule reflects the possibility of regime switches in the future. Therefore, the agent has to determine the portfolio rule in each regime, while accounting for the possibility of a future shift in the expected growth rate in house prices.

\section{Numerical Simulations}

It is not possible to find properties of the portfolio choice problem in closed-form when we take into account transaction costs. Consequently, we implement an iterative procedure to find the

\footnotetext{
${ }^{15}$ In Grossman and Laroque (1990), the only state variable is the wealth-to-housing ratio.

16 Davis, Lehnert, and Martin (2008) document that almost all of the decline in the rent-price ratio is attributable either to a steep decline in risk premium or an increase in the expected growth of house prices, or some combination of these two factors. Fillat (2009) presents evidence of a small predictable component in the growth of housing services, which is a proxy for the growth in rents. This alone does not explain entirely the mean reversion of rent-price ratios after a shock. Therefore, the absence of a full explanation in the rent growth motivates the presence of predictability in housing returns.
} 
numerical solution for the problem. A detailed description of this iterative procedure can be found in Appendix A.2.

Table 3 reports the model's parameters. We assume a curvature of the utility function of 2 and a rate of time preference of $2.5 \%$. The parameter $1-\beta$ measures how much the agent values housing consumption relative to the numeraire consumption. It is set at 0.4 , which is consistent with the average proportion of household housing expenditure in the U.S ${ }^{17}$ We assume that the risk-free rate is equal to $1.5 \%$ annually. Using U.S. data over the period 1889-2005, Kocherlakota (1996) reports an average real return on a market index of $7.7 \%$ and a standard deviation of $16.55 \%$. We consider that the estimated house price standard deviation, $\sigma_{P}$, of $4.47 \%$ is too low (see Tables 1 and 2 ), due to the inertia in house price indexes. Instead, we assume a house price standard deviation of 10\%. This is close to that estimated by Campbell and Cocco (2003) and Landvoigt, Piazzesi, and Schneider (2011). Campbell and Cocco (2003) report a house price standard deviation of $11.5 \%$, using house price data from the PSID for the period 1970 through 1992. Landvoigt, Piazzesi, and Schneider (2011) report a house price standard deviation of 10\%, using micro-data on the San Diego Metro area for the period 1997 through 2008. We set the correlation coefficient $\rho_{P S}$ at 0.25. We assume that the cost of selling a house is $5 \%$ of the unit's value. This figure includes the agent's commissions, legal fees, time cost of searching and the direct cost of moving the consumer's possessions. Following previous literature, we set the housing's physical depreciation rate at $2 \%$ per annum.

\section{[INSERT TABLE 3 HERE]}

Figures 5 and 6 are key for showing the three main implications of the model that arise from Proposition 1 and are tested in the empirical section of the paper. Figure 5 displays the difference between the value function, $v(z(t), i)$, and the value of changing housing consumption, $(z(t)-$ $\epsilon)^{1-\gamma} M_{i} /(1-\gamma)$, against the value of the wealth-to-housing ratio, $z(t)$, using the parameter values reported on Tables 1 and 3 . If this difference is positive, then the agent does not move to a more or less expensive house. The agent only moves when this difference is zero, that is, when the

\footnotetext{
${ }^{17}$ While Cocco (2005) sets $1-\beta$ at 0.1, Yao and Zhang (2005) assume that $1-\beta$ equals 0.2 .
} 
value function from not moving given by $v(z(t), i)$ is equal to the value from moving given by $(z(t)-\epsilon)^{1-\gamma} M_{i} /(1-\gamma){ }^{18}$ Thus, agents only move in two situations: (i) when their total wealth is high enough relative to their current house's value so that $z(t)$ reaches the upper bound $\bar{z}_{i}$; or (ii) when their house's value is too high relative to the total wealth and $z(t)$ reaches the lower bound $\underline{z}_{i}$. The inaction region is limited by a lower bound $\underline{z}_{i}$ and an upper bound $\bar{z}_{i}$ in each regime $i$, such as $\underline{z}_{i}<\bar{z}_{i}$ for both the high regime $(i=h)$ and the low regime $(i=l)$. In Section 6.1, we will test the existence of the upper and lower bounds hypothesis and we will study its main implications.

[INSERT FIGURES 5 and 6 HERE]

Figure 5 shows the differences of the solution across regimes. The upper and lower bound are not constant but depend on the regime $i$. We obtain that $\underline{z}_{l}=1.575, \bar{z}_{l}=6.739$, and the ratio chosen when a new house is purchased $z_{l}^{*}=3.870$ for the low regime. Equivalently, we find that $\underline{z}_{h}=0.249, \bar{z}_{h}=1.587$, and $z_{h}^{*}=0.491$ for the high regime (see Table 4). The economic magnitude of the calibrated results is sizeable: during a period of low (high) house appreciation, an average household will decide to buy a more expensive house when the wealth is approximately higher than 6.7 (1.6) times the value of her current house. On the other hand, when her total wealth is approximately less $1.5(0.2)$ times the value of the house, the agent will engage in a transaction to buy a less expensive house. Note that: (i) the upper and lower bounds in the high regime are below their respective upper and lower bounds in the low regime, that is, $\bar{z}_{h}<\bar{z}_{l}$ and $\underline{z}_{h}<\underline{z}_{l}$; (ii) the inaction region for the low regime, $\left[\underline{z}_{l}, \bar{z}_{l}\right]$, is larger than the inaction region for the high regime, $\left[\underline{z}_{h}, \bar{z}_{h}\right]$; (iii) the inaction regions for the two regimes overlap over a range of $z(t)$ values, $\left[\underline{z}_{l}, \bar{z}_{h}\right]$; (iv) the optimal housing wealth on total wealth, $1 / z_{i}^{*}$, for the high (low) regime is 2.035 (0.258), which is lower than the constant ratio of $2.980(0.340), \alpha_{h, i}$, chosen by an agent who faces no transaction costs 19 and (v) the size of upward adjustment and downward adjustment in a high

\footnotetext{
${ }^{18}$ This is equivalent to saying that the values of the upper bounds $\bar{z}_{i}$ and the lower bounds $\underline{z}_{i}$ are determined by the value matching conditions (15) for $i=h, l$, by which the agent is indifferent between not moving and moving. Additionally, the smooth pasting conditions in (16) assure that $v(z(t), i)$ is differentiable on the threshold that triggers the agent to move. As Figure 5 shows, this implies that $v(z(t), i)$ is less concave than $(z(t)-\epsilon)^{1-\gamma} M_{i} /(1-\gamma)$ at these points. However, $v(z(t), i)$ must become more concave than $(z(t)-\epsilon)^{1-\gamma} M_{i} /(1-\gamma)$ somewhere between $\underline{z}_{i}$ and $\bar{z}_{i}$.

${ }^{19}$ Transaction costs make housing more expensive, so the agent who faced those costs would hold less of her wealth in the form of housing.
} 
regime is lower in than in a low regime, $\bar{z}_{h}-z_{h}^{*}<\bar{z}_{l}-z_{l}^{*}$ and $z_{h}^{*}-\underline{z}_{h}<z_{l}^{*}-\underline{z}_{l}$. In Section 6.2 we will empirically test these types of findings related to the effects of the predictability in housing returns on the upper and lower bounds.

Figure 5 shows that our framework features a second channel generating a housing transaction: the regime switching mechanism. A transaction may also occur when the regime switches from high to low and the agent's wealth-to-housing ratio $z(t)$ falls within the region $\left[\underline{z}_{h}=0.249, \underline{z}_{l}=1.575\right]$. Let us assume that $z(t)=0.500$. In this case, it is not optimal to sell during the high regime because her ratio $z(t)$ is not low enough (i.e., $z(t)>\underline{z}_{h}$ ). However, if there is a switch to the low regime, then the lower bound would increase from $\underline{z}_{h}$ to $\underline{z}_{l}$, and, consequently, it would be optimal for the agent to sell reduce her housing holdings because $z(t) \leqslant \underline{z}_{l}$. The other interesting case occurs when there is a regime switch from low to high and $z(t)$ is in the region $\left[\bar{z}_{h}=1.587, \bar{z}_{l}=6.739\right]{ }^{20}$

As one may expect, this regime-switching mechanism generates rich portfolio rules. The upper panel of Figure 6 plots the fraction of wealth invested in risky assets against wealth for the two regimes of expected growth rate of house prices, $\hat{\theta}^{*}(z(t), i) / z(t)$, for $i=h, l$. Each curve is drawn only for the realizations of $z(t)$ within the inaction bounds. We find that it is optimal to increase the stock holdings in the low-growth regime and sharply decrease them in the high-growth regime in order to increase the housing wealth share. Note that the optimal portfolio rules are quite different from the no transaction costs case, where the fraction of wealth invested in each asset is constant. What is the channel that drives the agent's portfolio choices and makes them different from those provided by other models? The model's key mechanism is the coefficient of relative risk aversion, $-\left(z(t) v_{z z}(z(t), i)\right) / v_{z}(z(t), i)$, which varies with $z(t)$ and with the regime $i$ with $i=h, l$. As in Grossman and Laroque (1990) and Damgaard, Fuglsbjerg, and Munk (2003), the lower relative risk aversion when $z(t)$ is close to either the upper or lower bound leads to higher fractions of wealth invested in the risky asset than when $z(t)$ is in the inaction region. Then, because the unconditional probability of switching from a high-growth to low-growth regime is substantial,

\footnotetext{
${ }^{20}$ The location of the bounds depends on the transition probabilities to switch regime at the next period given the current regime. Specifically, for the low regime, the estimated transition probability, $\lambda_{l h}$, is only about $3.43 \%$, while $\lambda_{h l}$ is about $24.14 \%$ for the high regime. As result, the location of the upper bound depends crucially on the probability of a regime switch from high to low.
} 
$\lambda_{h l}=24.14 \%$, the agent becomes more risk averse where the inaction regions for the two regimes overlap over a range of $z(t)$ values, $\left[\underline{z}_{l}, \bar{z}_{h}\right]$. Therefore, the agent invests less in the stock market in that region. Hence, the relative risk aversion after a housing trade associated with a highgrowth regime, $-\left(z_{h}^{*} v_{z z}\left(z_{h}^{*}, h\right)\right) / v_{z}\left(z_{h}^{*}, h\right)$, is higher than that associated with a low-growth regime, $-\left(z_{l}^{*} v_{z z}\left(z_{l}^{*}, l\right)\right) / v_{z}\left(z_{l}^{*}, l\right)$. In our benchmark case, we obtain a relative risk aversion of 2.595 for the high-growth regime and 2.071 for the low-growth regime (see Table 4).

\section{[INSERT TABLE 4 HERE]}

Transaction costs also make housing more expensive, so the agent facing those costs holds less of her wealth in the form of housing. In our benchmark case, due to transaction costs we observe a reduction of $46 \%(32 \%)$ in housing share in the high-growth (low-growth) regime. In a highgrowth regime the optimal housing holding is substantially higher, the inaction region is narrower and housing is quite attractive for investment purposes, but transaction costs have the dramatic effect of lowering the optimal housing wealth to total wealth ratio, $1 / z_{i}^{*}$, making the agent more risk averse after a housing trade. Differently from Grossman and Laroque (1990) and Damgaard, Fuglsbjerg, and Munk (2003), the coefficient of risk aversion depends on the current regime. In summary, the model delivers a regime contingent portfolio rule. Additionally, due to the possibility of a regime change, the portfolio rule optimally reflects the agent's investment set in the alternative regime.

The lower panel plots the fraction of wealth invested in the risk-free asset, $\hat{b}^{*}(z(t), i) / z(t)$. We find that: (i) the agent is a net borrower in both regimes; (ii) she borrows a bigger amount in the high-growth regime (to increase her housing holdings, which are more attractive in the high-growth regime) than in the low-growth regime; and (iii) her borrowing increases with her ratio $z(t)$. In Section 6.3, we will empirically test these findings related to the portfolio choices of households. Appendix A.3 presents a sensitivity analysis of the benchmark model.

In Section 2, we provide evidence that the degree of predictability varies across the U.S. census divisions. The theoretical relevance of the house price dynamics parameters is evident when analyzing the results of the calibration. Due to the shorter time series and the recent boost episode 
(2007 - 2010), house prices growth rates are markedly more negative for the U.S. census divisions than for the U.S. at aggregate level (see Table 1). As result, inaction regions are larger than those calculated in the benchmark case for the low-growth regime (see Table 4). This boost episode was preceded by a long period $1998-2006$ in which house prices dramatically appreciated in the New England and Middle Atlantic (Northeast), South Atlantic (South) and Pacific (West) census divisions. In fact, according to our calibration, we expect these census divisions to be characterized by markedly lower values of the lower and upper bounds, narrower inaction regions, and lower average risky stock holdings in the same period. In Section 6.2 and 6.3 , we will test these implications empirically at U.S. state level. ${ }^{21}$ To capture periods of high house price appreciation at U.S. state level, we construct a variable that we call "Hot Housing Market Indicator" (HHMI). The HHMI is function of the estimated smooth probability of being in a period of high growth rate for each state. This indicator will serve as a proxy for the second state variable of our model.

It is important to recognize that while the optimizing behavior characterized above is that of a hypothetical agent living infinitely, the data we will use later to test the model's predictions are drawn from a cross-section of demographically heterogeneous consumers. Therefore, to assess the descriptive fit of our model, we will include demographic characteristics and changes in demographic characteristics, for example, household head age in two age bands, change in marital status and change in family size, which may absorb determinants other than dynamic variations of the type featured by our representation of a typical agent's problem.

\section{Data}

To test the theoretical predictions of our model, we use household level survey data from the Panel of Income and Study (PSID) from 1984 to 2007, and from the Survey of Income and Program Participation (SIPP) of the U.S. Census Bureau from 1997 to 2005. Both surveys have data on asset holdings and housing wealth. PSID regularly collects information about home values and mortgage debt; occasionally, it also collects information about behavior on savings and wealth.

\footnotetext{
${ }^{21}$ Appendix A.4 provides evidence that the degree of predictability varies across the U.S. states.
} 
SIPP has a detailed inventory of annual real and financial assets and liabilities. It also contains more frequent measures of those assets that are relevant for assistance measures since its main purpose is to evaluate the effectiveness of government transfer programs. PSID is a nationally representative longitudinal sample of approximately 9,000 households. At each moment, SIPP tracks approximately 30,000 households. During the period considered, information was collected from three consecutive groups of households that were interviewed during the years $1996-2000$ (four times), 2001 - 2003 (three times), and 2004 - 2006 (two times), respectively. During its active period, each panel is interviewed every year, while panels of households do not overlap across periods. SIPP over-samples from areas with high poverty concentrations, which should be taken into account when interpreting the results. Its longitudinal features enable the analysis of dynamic characteristics, such as changes in income and in household and family composition, or housing dynamics. Its cross-sectional features allow us to keep track of household wealth. Both surveys allow us to study the empirical implications of the model outlined above. In particular, we focus on the identification that arises when households sell their current house to buy a new one. Unfortunately, neither data set offers a measure of overall transaction costs paid by households when they change their house.

Using the PSID data, we calculate financial wealth as the summation of an individual's house value, their second house value (net of debt), business value (net of debt), other asset:22 (net of debt), stock holdings (net of debt), checking and savings balances, IRAs and annuities less the mortgage principal on the primary residence 23 , and human capital. We delineate these variables into those that are considered risky assets and those that are safe assets. The risky assets are comprised of the stock holdings, IRA and annuity holdings. The safe asset is comprised of other assets (net of debt), checking and savings balances, less the principal on the primary residence. Generally, the variables we utilized from the SIPP data set are net of debt, the sole exception is property value. Using the SIPP data, we calculate risky assets as the summation of equity in stocks and mutual funds, equity in IRAs, and equity in $401 \mathrm{k}$ and thrifts. The safe assets are interest-

\footnotetext{
${ }^{22}$ Other assets include bonds and insurance.

${ }^{23}$ For comparability across waves of surveys, we focus only on the primary mortgage.
} 
earning assets in banks and other institutions less outstanding mortgage balance. The value for financial wealth is calculated by adding the risky asset value to safe asset value, business equity, property value of primary residence, housing equity in second residence and other assets. In both PSID and SIPP data sets, the measure of house value is given by homeowners' estimate of home value. Home value is problematic in that there might be a large amount of measurement error in the figure quoted. However, we would argue that while most homeowners only have a general idea of the value of their home, owners who are near to the bound or have recently bought a house have very precise knowledge of the value of their home. Hence, if households do not own risky stock or safe assets such as checking and savings balances, IRA and annuity holdings, we set these holdings to zero. In addition, we exclude households whose total reported stockholdings are negative. This exclusion does not affect the qualitative results reported below.

We calculate the total wealth of each household including unobservable human capital (human wealth). Following Jagannathan and Wang (1996), we estimate the human capital of each household as capitalized wage income, that is, as the present value of a growing annuity ${ }^{24} 25$

Tables 5 and 6 show the descriptive statistics for the main variables that we use in the empirical analysis. We present statistics for the full sample and also for the selection of households that moved to a bigger or a smaller house (second and third pair of columns, respectively.) We show mean and standard deviations of the relevant variables. The single most important variable is the wealth-

\footnotetext{
${ }^{24}$ We assume that for each household, the wage remains constant at the current real level until age of $65, g=0 \%$, and then the wage ends, as in Heaton and Lucas (2000) and Eberly (1994). The stream of labor income cash flows is discounted back at a real interest rate of five percent per year, $R=5 \%$. We use the current annual total household earned income as the cash flow for the annuity $C F_{t}$. We also assume that households earn income until they retire at the age of 65 . Therefore, we assume that households older than 65 have zero human capital. Under these assumptions, the human capital of each household $i$ of age $n$ (younger than 65 years, that is, $n<65$ ) can be estimated using the following formula:$$
L_{i, t}=\frac{C F_{t}}{R-g}\left[1-\left[\frac{1+g}{1+R}\right]^{(65-n)}\right] .
$$

${ }^{25}$ As Palacios-Huerta (2003) acknowledges, measuring human capital as capitalized wage income has several limitations. First, it does not account for the capital gains of the stock of human capital. Second, this simple measure assumes that labor supply is exogenous. Third, it ignores the worker's skill premia and experience. Fourth, it does not net out the effect of physical capital on labor income and human capital returns. Fifth, this measure does not account for regional differences. We have run different robustness checks on these five limitations for all the results that we present. We have found that the results obtained using the measure of human capital in Jagannathan and Wang (1996) are robust.
} 
to-housing ratio, $z{ }^{26}$ For the PSID sample, we observe that, on average, the value of the house is approximately two-thirds of the total household wealth. This average ratio is lower for movers, not controlling for any other reason to move that is exogenous to the model. Stock holdings are roughly $10.2 \%$ of the financial wealth, and safe assets without debt holdings represent $10.9 \%$ of financial wealth, much higher for households who buy a more expensive house. We also report statistics on stock holdings that do not take into account the retirement assets' (IRA, 401k) impact on financial wealth and on liquid wealth where liquid wealth is total wealth less home equity and other illiquid assets such as cars. We define the dummy Move big (small) to identify households selling the current house to buy a more (less) expensive house in the same U.S. census region. Hence, we report summary statistics for variables that will help us to distinguish between changes in housing that occur because of reasons that are exogenous to the model and changes in housing that occur because individuals have a total wealth-to-housing ratio that is close to the boundary.

\section{[INSERT TABLES 5 and 6 HERE]}

In order to capture exogenous shocks, we define variables to examine changes in demographics from the year before to the year after home purchase. $\Delta$ Family size shows the statistics of changes in family size. $\Delta$ Married is a dummy variable which takes a value of one if the individual gets married. $\Delta$ Employment is a dummy variable which takes a value of one if the individual changes her employment status. During the sample period analyzed using the PSID data, the size of the household (in number of members) decreased by -0.044 . The family size increased for movers to a bigger house, 0.071, while it decreased for movers to a smaller house, -0.235 , meaning that housing consumption is strictly related to the number of members in the household. Marriages also increase, by almost $1.6 \%$, and again this figure is substantially higher for movers. The mean age of the household head is 49.09 years. The mean age of movers is shifted towards a younger population: 40.38 years for household heads moving to a more valuable house and 46.07 years for household heads moving to a less valuable house. The regional composition, in terms of census

\footnotetext{
${ }^{26}$ Although we show statistics for the wealth-to-housing ratio without and with human capital, $z$ and $\widetilde{z}$, respectively, we use the measure with human capital in the rest of the paper.
} 
regions are $15.6 \%$ Northeast, $26.6 \%$ Midwest, $41 \%$ South, and 16.9\% West. The summary statistics using SIPP do not differ substantially. It is worth mentioning the differences in age composition, where the youngest group is more represented in PSID. In terms of moving, the group of movers to a bigger and smaller house is lower in SIPP than in PSID in percentage terms, although we have more observations for this group in SIPP. Geographic composition and other relevant variables are comparable both in levels, standard errors, and also conditional on moving household.

Table 7 provides information on the percentage of movers by current ownership status (owner, renter, or occupied) over total households in the PSID and SIPP surveys across all years. The four columns represent the percentage of households that moved to a new address, that moved to a new address in the same U.S. macro region, that moved to a new address in the same U.S. state, and that moved to a new address and were previously not homeowners. While we can easily identify movers in PSID because it reports explicitly whether there has been a move since the previous interview, we have to identify movers in SIPP keeping track of the households' address identifier. That identification mechanism is what generates differences between SIPP and PSID that were not present in Tables 5 and 6. In the upper panel of Table 7, we observe that the percentage of owners who move is much lower than the percentage of renters, who have a much higher mobility than owners. The percentage of movers to a different U.S. census region or U.S. state is very low among owners. The total inflow of homeowners is different between PSID and SIPP. While households in SIPP entering in home ownership during the sample is $5.47 \%$, more than half of the movers in PSID are new homeowners ${ }^{27}$ Despite reporting data for renters, it is necessary to emphasize that we do not model renters' decisions. Our agent does not have the possibility of renting. In order to consume housing services, the only option is to pay a transaction cost and purchase a new house and derive a flow of services from it. Renting is not part of the model and we select the sample of homeowners only. Therefore, the model is mute about the renters who moved during the sample period.

\section{[INSERT TABLE 7 HERE]}

\footnotetext{
${ }^{27}$ New in the sense that they did not own at $t-1$ but it could be the case that they were owners in the past.
} 


\section{Empirical Results}

We use the household survey data described previously to test the model's predictions. Our main hypothesis can be restated looking at Figure 4 , where a hypothetical path of the wealth-to-housing ratio is depicted as well as the effect of a time-varying growth rate of house prices on the ratio itself. Transaction costs generate an inaction region with upper and lower action bounds. We are able to test whether these bounds are actually different from each other by comparing the wealth-tohousing ratio of households who moved to a more expensive house to the ratio of those who moved to a less expensive house. The ratio before moving defines the upper and lower action bounds, $\bar{z}$ and $\underline{z}$, respectively. When a household decides to engage in the purchase of a new house after hitting the bound, she chooses the value of the new house such that the wealth-to-housing ratio reaches its optimal level. The observed ratio after moving determines the optimal ratio $z^{*}$. The model predicts that the bounds and the optimal level of the wealth-to-housing ratio vary across states depending on the timing of, levels of and spread between their high and low-growth regimes. Hence, the model also predicts that stock holdings are also regime-dependent. We test whether stock holdings are on average lower in markets with stronger growing house prices.

To capture periods of persistent high appreciation in house prices at U.S. state level, we introduce the variable "Hot Housing Market Indicator" (HHMI). This is a binary variable that is calculated using the estimated smooth probabilities from the Markov-switching model on real housing returns using the quarterly FHFA house price indexes for each state and the U.S. aggregate. To go from these estimated probabilities to a binary variable, we assume that the binary variable $H H M I_{k t}$ for the U.S. state $k$ (i.e., $k=$ California) at time $t$ is equal to one when the following two conditions hold:

1. the smooth probability of being in the regime associated with the highest expected real housing return of the U.S. state $k$ is higher than its historical average plus half of its historical standard deviation in $t, t-1, t-2$ and $t-3$ (four quarters in a row);

2. the real housing return of the state $k$ is higher than the expected real housing return in the 
high-growth regime of the U.S. aggregate in $t, t-1, t-2$ and $t-3$ (same four quarters of point 1).

The HHMI is based on these two conditions because they embed two specific pieces of information. The first condition captures the likelihood that there has been a regime switch in the U.S. state $k$ based on a turning point probability. We define the turning point probability when the estimated smooth probability reaches a $90 \%$ statistical level. The logic underlying the first condition is to detect whether a housing market peak relative to its historical average in the state $k$ has been reached and it has lasted at least four quarters in a row. Hence, condition 1 allows us to classify states' house prices according to the degree of cyclicality in their real housing returns ${ }^{28}$ The second condition verifies whether the real housing return in the state $k$ is substantially high when compared to the overall U.S. housing market. Appendix A.4 provides a detailed description of this estimation and the results.

\subsection{Existence of the Upper and Lower Bounds Hypothesis}

The first hypothesis to be tested is the existence of the optimal upper and lower bounds provided by the model in the cases in which transaction costs are taken into consideration. Specifically,

Hypothesis 1. $\underline{z}_{i}<\bar{z}_{i}$. Therefore, $\underline{z}$ is significantly different (and lower) from $\bar{z}$ for a given expected growth rate in house prices in regime $i$.

This hypothesis states that the ex-ante average value for the ratio of total wealth-to-housing holdings $\tilde{z}_{i t}$ for households who own a house and move to a less expensive one $\underline{z}$ is significantly different (and lower) from the ratio of total wealth to housing holdings for households who own a house and move to a more expensive one $\bar{z}$.

To test this hypothesis, we estimate the following reduced-form model, which exploits the

\footnotetext{
${ }^{28}$ The condition that the smooth probability of being in the regime associated with the highest expected real housing return reaches the turning point probability is satisfied in some periods by states such as California and Florida in which housing markets experienced a particularly high appreciation in the same periods. Hence, these periods are generally characterized by high and pronounced appreciation in house prices. Differently, condition 1 is not satisfied by states such as Alabama and Montana whose housing markets have experienced prolonged and continuous high-growth phases that are mainly characterized by modest growth in house prices.
} 
variation across households and years:

$$
\tilde{z}_{i t}=\gamma_{0}+\gamma_{1} \cdot m_{B I G_{i t}}+\gamma_{2} \cdot m_{S M A L L_{i t}}+\Gamma \cdot X_{i t}+u_{i t}
$$

where $\tilde{z}_{i t}$ is the total wealth-to-housing ratio of household $i$ at time $t ; m_{B I G_{i t}}$ is a binary variable equal to one if the household is increasing its housing holdings (i.e., moving to a more expensive house); $m_{S M A L L_{i t}}$ is a binary variable equal to one if the household is decreasing its housing holdings (i.e., moving to a less expensive house); $X_{i t}$ contains a set of control variables that intend to capture changes in housing due to exogenous causes, unrelated to the total wealth-to-housing ratio, and $u_{i t}$ is an error term. The set of controls in $X_{i t}$ includes changes in employment status, changes in family size, changes in marital status, and age controls. All variables control ex-ante changes to examine changes from the year before to the year after home purchase. The regression omits the households who do not move, treating them as a benchmark. Therefore, we check whether $\gamma_{1}$ is significantly positive and different from zero, which means that the total wealth-to-housing ratio of the households who move to a more expensive house is significantly higher than the ratio of those who do not move. We run the pooled regression in equation 22 with year fixed effects and also separate regressions for each year.

\section{[INSERT TABLES 8 AND 9 HERE]}

The results of testing the first hypothesis are shown in Tables 8 and 9 . The first column shows the results for the pooled regression with year fixed effects. It shows that the average value of $\tilde{z}_{i t}$ for families that do not move, $\gamma_{0}$, is 2.166 for PSID and 3.471 for SIPP. It is worth pointing out that the total wealth of the total wealth-to-housing ratio includes the human capital as calculated in Section 5. The ex-ante average value of $\tilde{z}_{i t}$ for households that moved to a bigger house is 2.456 for PSID and 1.677 for SIPP above the non-movers average with a 99\% significance for PSID and SIPP, respectively. Similar results are obtained when running yearly regressions. Note that $\gamma_{2}$ is not significantly different from $\gamma_{0}$ for PSID, but it is for SIPP. Thus, the average total wealthto-housing ratio $\tilde{z}_{i t}$ for non-movers is not significantly different from the ratio for movers to less 
expensive houses. It can be inferred that the distribution of the total wealth-to-housing ratio is skewed to the left and on average, agents are closer to moving down according to our model. We also run a test on the coefficients $\gamma_{1}$ and $\gamma_{2}$ being equal, which is strongly rejected for most of the years. This result supports the obvious hypothesis of the existence of the inaction region in the presence of transaction costs since the test shows that the upper and lower bounds are significantly different from each other. The results of the test also show evidence that the ratio $\tilde{z}_{i t}$ is timevarying, on average. This is a clear effect for non-movers and for households who move to a more expensive house in SIPP. For non-movers, $\gamma_{0}$ is 2.103 in 1997, it goes up to 2.308 in 1999, and it decreases to 1.702 in 2005 . For households that move to a more expensive house, $\gamma_{1}$ is 1.847 in 1997, it increases to 2.424 in 1999, and it decreases to 1.049 in 2005. Similar results hold for the PSID data.

The effect of the regional dummies is statistically significant and economically sizable. The exante average total wealth-to-housing ratio $\tilde{z}_{i t}$ for households living in Northeast (the benchmark) is lower than those living in the South and Midwest but higher than for those living in the West.

\subsection{Effects of the Predictability Hypothesis and the Probability of Moving}

The second set of hypotheses to be tested is related to the effects of predictability of housing returns in the action bounds and the probabilities of moving derived in the portfolio choice problem. Let us state Hypotheses $2 \mathrm{a}$ and $2 \mathrm{~b}$ to test whether the optimal bounds and the probabilities of moving change under the different house price growth regimes.

Hypothesis 2a. $\bar{z}_{h}<\bar{z}_{l}$. The wealth-to-housing ratio defining the upper bound in periods of high price growth, $\bar{z}_{h}$, is significantly lower than the wealth-to-housing ratio that defines the upper bound in periods of low house price growth, $\bar{z}_{l}$. Equivalently, $\underline{z}_{h}<\underline{z}_{l}$ for the lower bound 29

Hypothesis 2b. The probability of increasing (decreasing) housing holdings is higher (lower) in periods of high house price growth than in periods of low growth. Conditionally on moving,

\footnotetext{
${ }^{29}$ Therefore, the wealth-to-housing ratio defining the lower bound in periods of high house price growth, $\underline{z}_{h}$, is significantly different (and lower) from that defining the lower bound in periods of low house price growth, $\underline{z}_{l}$.
} 
households buy more expensive houses in periods of high growth.

To test these hypotheses, we follow two different approaches. Firstly, we develop a difference-indifferences analysis to test Hypothesis 2a. The goal is to capture the interactions between the type of moving (i.e., moving to a more or less expensive house) and the housing market performance at state level using our indicator $H H M I$. Secondly, we estimate a two-stage selection model to test Hypothesis 2b, where the first stage concerns the selection of homeowners who sell the current house to move to a more or less expensive house, and the second stage concerns the size of adjustment. We use PSID data for the difference-in-differences analysis because it covers more than 15 years from 1988 to 2005. Conversely, we use SIPP data for the second test because it includes a higher number of households who sell the current house to move to a more or less expensive house.

\subsubsection{Does predictability affect the action bounds? Difference-in-differences analysis}

Let us consider the following reduced form model:

$$
\begin{aligned}
\tilde{z}_{i t}= & \gamma_{0}+\gamma_{1} \cdot H H M I_{k t}+\gamma_{2} \cdot m_{B I G_{i t}}+\gamma_{3} \cdot m_{S M A L L_{i t}} \\
& +\gamma_{4} \cdot m_{B I G_{i t}} \times H H M I_{k t}+\gamma_{5} \cdot m_{S M A L L_{i t}} \times H H M I_{k t}+\Gamma \cdot X_{i t}+u_{i t},
\end{aligned}
$$

where $\tilde{z}_{i t}$ is each household $i$ 's ex-ante value for the total wealth-to-housing ratio. As in the previous subsection, $m_{B I G_{i t}}$ is a binary variable equal to one if the household is moving to a house with a higher value than that currently owned, while $m_{S M A L L_{i t}}$ is equal to one if the household moves to a house with a lower value than that currently owned. Then, we interact $H H M I_{k t}$ with $m_{B I G_{i t}}$ and $m_{S M A L L_{i t}}$. In this regression, we include the same control variables listed above.

The hypothesis test consists of a difference-in-differences analysis. Table 10 reports its results. We choose households that did not move in cold years, $H H M I_{k t}=0$, as the control group. The positive sign in $\gamma_{1}$ shows that households that moved big (increased her housing holdings)

had a 3.186 higher $\tilde{z}_{i t}$ than households that did not move in a cold year. The negative sign in the coefficient $\gamma_{3}$ confirms that the total wealth-to-housing ratio, on average, is 1.030 lower in hot 
markets than in cold markets. The main results of this specific analysis arise from the terms in which we interact $m_{B I G_{i t}}$ with $H H M I_{k t}$ and $m_{S M A L L_{i t}}$ with $H H M I_{k t}$. The term $m_{B I G_{i t}} \times H H M I_{k t}$ captures the difference between the following two terms: (i) the difference between the average $\tilde{z}_{i t}$ for the upper boundary in cold and hot years; and (ii) the difference between the average $\tilde{z}_{i t}$ for non-movers in cold and hot years. The negative sign in the coefficient $\gamma_{4}$ indicates that the decrease in $\tilde{z}_{i t}$ in the upper boundary in the transition from cold to hot markets is lower than the decrease in $\tilde{z}_{i t}$ for non-movers in the transition from cold to hot markets. However, the coefficient $\gamma_{5}$ associated with $m_{S M A L L_{i t}} \times H H M I_{k t}$ is not significant. These empirical results confirm the model's implications in the sense that housing return predictability affects the total wealth-to-housing ratio and hence the upper bounds suggesting that the inaction region changes over time. Our estimate associated with the lower bounds, $\gamma_{2}$, is not correctly signed and insignificant. These results are consistent with those obtained in the previous test for PSID. Consequently, the empirical results are significant and the coefficients of the control variables are consistent with our previous empirical analysis. Moreover, the regional analysis shows that, compared to the Northeast (benchmark region), households in the Midwest and South present higher total wealth-to-housing ratios and households in the West present lower ratios.

\section{[INSERT TABLE 10 HERE]}

\subsubsection{Does predictability affect the probability of moving and the size of adjustment?} A two-stage selection model

To answer this question, we follow Bertola, Guiso, and Pistaferri (2005) and we implement the selection model introduced by Heckman (1979). We will focus our empirical approach on effects of housing return predictability on the frequency and width of upward and downward adjustment (i.e., increasing or decreasing their amount of housing holdings). We let the upward and downward adjustment of the current housing stock occur when a latent variable $D_{i}^{*}=X_{i t}^{\prime} \varphi+u_{i t}$, is driven to be larger than zero. The assumption that the error term $u_{i t}$ is normally distributed yields the 
probit model:

$$
\operatorname{Pr}\left(D_{i}^{*}>0\right)=\phi\left(X_{i t}^{\prime} \varphi\right)
$$

where $X_{i t}$ is a vector of variables and $\phi\left(X_{i t}^{\prime} \varphi\right)$ is the standard normal cumulative density function evaluated at $X_{i t}^{\prime} \varphi$. In our framework, such a latent variable is interpreted as the distance between the total wealth-to-housing ratio, $z$, and the optimal return point, $z^{*}$. The model predicts that upward (downward) adjustment is more (less) likely to be observed, for a given $z$, when house prices experience high appreciation. We re-introduce our indicator HHMI to capture periods of persistent high house price growth in the state where the households live. In practice, households can sell the current house located in a state and buy a more (less) expensive house in another state. Hence, it would be also important to control for the level of house prices in the state where the household is moving to. This latter variable should affect the likelihood and the size of housing adjustment. However, this exclusion does not affect the qualitative results reported below because we are considering households selling the current house to buy a bigger one in the same U.S. census macro-region and the percentage of movers to a different state is substantially low among owners (see Table 7) 30 Columns 1 and 3 of Table 11 report marginal effect estimates from the probit regressions for increasing and decreasing the amount of housing holdings. After controlling for observable characteristics, the probability of upgrading (downgrading) increases (decreases) with the value of the total wealth-to-housing ratio, $\tilde{z}_{i t}$. Consequently, our second state variable $H H M I_{k t}$ affects positively (negatively) the probability of an upgrading (downgrading) as predicted by our theoretical model. Both coefficients are highly statistically significant and economically important. In addition, households living in the West are more likely to upgrade and downgrade and the economic effect is also substantial.

The probit regression is the first step for testing Hypothesis 2b. Our model also delivers sign predictions for the size of the adjustment conditional on adjusting. It predicts that persistent

\footnotetext{
${ }^{30}$ In our setup, we refrain from introducing the option of selling the house at the price $P$ in the household's current market and buying a more or less expensive one at the price $P^{\prime}$ in the region to which the household relocates in the next move. In this setup, the household's indirect utility depends on six state variables, $V\left(W, P, H, P^{\prime}, j, k\right)$, where $j$ is the regime (i.e., high or low) characterizing house price $P$, while $k$ is the regime (i.e., high or low) characterizing house price $P^{\prime}$. A similar model without house return predictability is analyzed by Flavin and Nakagawa (2008).
} 
higher growth in house prices decreases the size of the adjustment. However, the disturbance of the regression equation for the size of the adjustment depends upon unobserved heterogeneity. We treat the problem adopting Heckman's selectivity corrections in the regression. We use the value of $\tilde{z}_{i t}$ prior to adjustment as a selection variable because theory predicts that it affects the likelihood of adjusting but not the size of adjustment if it occurs. Following Bertola, Guiso, and Pistaferri (2005), we use as independent variable the $\log$ of the adjustment, $\ln \left(\bar{z}-z^{*}\right)$ for upgrading and $\ln \left(z^{*}-\underline{z}\right)$ for downgrading 31 The results of the second stage of the Heckman selectivity regressions are reported in Columns 2 and 432 The most important effect is captured by the variable $H H M I_{k t}$. The effect is statistically significant and economically sizable when households sell the current house to buy a more expensive house. It implies that the distance between the upper bound $\bar{z}_{i}$ and the optimal adjustment point $z^{*}$ is lower in periods of persistent high growth in house prices. In the downward case, the coefficient associated with $H H M I_{k t}$ is not significant but it points in the right direction.

\section{[INSERT TABLE 11 HERE]}

\subsection{Portfolio Choice Hypothesis}

Do households hold more risky stock before moving to a bigger house? To answer this question, we develop the following test, in which we study the holdings of risky securities relative to wealth and their link to the decision to buy a more or less expensive house.

Hypothesis 3. $\Theta_{m_{B I G}} / W_{i t}>\Theta_{i t} / W_{i t}$. Therefore, the risky assets holdings relative to the financial wealth before moving to a bigger house, $\Theta_{m_{B I G}} / W_{i t}$, is significantly different (and higher) from the average risky assets holdings relative to the financial wealth of households who do not move, $\Theta_{i t} / W_{i t}$.

\footnotetext{
${ }^{31}$ In the second stage, we do not include households who sell the current house to buy a more (less) expensive house but whose total wealth-to-housing ratio increases (decreases) between the two purchases. We have two possible explanations. The first is that total wealth is not following the continuous diffusion process assumed by our model but rather positive or negative jumps may be occurring in the total wealth process. The second is that total wealth might be affected by a measurement error.

${ }^{32}$ We implement a standard GLS procedure to calculate appropriate standard errors for the estimated coefficients (see Greene (2008)).
} 
To test Hypothesis 3, we estimate the following reduced form model:

$$
\frac{\Theta_{i t}}{W_{i t}}=\gamma_{0}+\gamma_{1} \cdot m_{B I G_{i t}}+\gamma_{2} \cdot m_{S M A L L_{i t}}+\Gamma \cdot X_{i t}+u_{i t}
$$

The results of the test of Hypothesis 3 are shown in Tables 12 and 13 . We run the pooled regression with year fixed effects and also year by year. The first column shows the results for the pooled data. It shows that the average holdings of risky stock on financial wealth for non-movers is 8.1\% for PSID data and 9.7\% for SIPP data. The average holdings of risky stock relative to financial wealth for households that moved to a more expensive house is $3 \%$ higher, that is $11.1 \%$. For SIPP movers to a more expensive house the risky holdings account for $13.8 \%$ of their financial wealth. Looking at the coefficients year by year in the subsequent columns, we observe that the average holdings of risky stock for non-movers is in the range $[5 \%, 19.7 \%]$ for PSID and $[13.7 \%, 15.7 \%]$ for SIPP. In sum, households that move to more expensive houses have higher risky asset holdings. ${ }^{33}$

\section{[INSERT TABLES 12 and 13 HERE]}

In Appendix A.5, we show similar results for $\widehat{\Theta}_{i t} / \widehat{W}_{i t}$ defined as the stock holdings without accounting for the retirement assets on the liquid wealth (see Tables 22 and 23). Furthermore we provide the equivalent results for the risk-free holdings of households (see Tables 24 and 25 ).

In order to test the effect of housing return predictability on risky stock holdings, we follow Chetty and Szeidl (2011). They use SIPP data to estimate the causal effect of house value on portfolio allocations. They provide evidence that an increase in housing holdings substantially reduces the amount households invest in risky stocks. Our model provides an additional implication:

Hypothesis 4. $\widehat{\Theta\left(\widehat{h i g h}_{i t}\right.} / \widehat{W}_{i t}<\widehat{\Theta(\text { low })}{ }_{i t} / \widehat{W}_{i t}$. On average, households should hold less risky stock holdings in a period of high house appreciation.

To test this hypothesis, we follow the empirical strategy developed by Chetty and Szeidl (2011)

\footnotetext{
${ }^{33}$ Uncertainty around the estimates for the lower bound does not allow us to make a statement about how the level of risky assets in that an investor who has just moved to a less valuable house should have in her portfolio, although we observe that households holds less risk stock before moving to a less expensive house. Only the negative and significant sign for $\gamma_{2}$ in the pooled regression using SIPP data (shown in Table 13 indicates that agents moving to a smaller house hold less risky stock than non-movers and agents moving to a bigger house.
} 
and we extend it to account for housing return predictability. Their goal is to estimate the effect of owning a more expensive house on portfolio choice. Because both portfolio and housing are endogenous choices that are affected by unobserved factors such as background risk (see Cocco (2005) and Davidoff (2010)), previous empirical work (see Heaton and Lucas (2000), Yamashita (2003) and Cocco (2005)) could document the cross-sectional correlation between house values and portfolio choices but they couldn’t identify the casual effect of housing on portfolios.

Chetty and Szeidl (2011) highlight that the key to capturing the effects of housing on portfolio is to distinguish between changes in mortgage debt and changes in home equity wealth. Because property value is the sum of mortgage debt and home equity, changes in property value should reduce the stock share of liquid wealth through the combination of these two components, but home equity increases stock holdings through a wealth effect 34 To characterize the effect on housing return predictability on stock holdings, we include our indicator $H H M I_{k t}$ and we interact $H H M I_{k t}$ with house value and home equity to estimate a specification analogous to that discussed in Chetty and Szeidl (2011):

$$
\begin{aligned}
\frac{\widehat{\Theta}_{i t}}{\widehat{W}_{i t}} & =\gamma_{0}+\gamma_{1} \cdot \text { house value }_{i t}+\gamma_{2} \cdot \text { home equity }_{i t}+\gamma_{3} \cdot H H M I_{k t} \\
& +\gamma_{4} \cdot \text { house value } i t \\
& \times H H M I_{k t}+\gamma_{5} \cdot \text { home equity }_{i t} \times H H M I_{k t}+\Gamma \cdot X_{i t}+u_{i t},
\end{aligned}
$$

where $\widehat{\Theta}_{i t} / \widehat{W}_{i t}$ is the risky share of liquid wealth. Because we do not have information on the risk characteristics of retirement portfolios in SIPP, we follow Chetty and Szeidl (2011) and we do not include retirement assets (i.e., IRA and 401K) in the risky stock holdings in this specification. The

\footnotetext{
${ }^{34}$ Chetty and Szeidl (2011) exploit two instruments to generate variation in home equity and property value: the average house value in the state where the household lives in the current year and the average house value in the state in the year that the household bought the house. Because SIPP data contain information on households who purchase houses in different years and observe portfolio allocations in different years in states, they include state, current year, year of house purchase and age fixed effects in the regression specification below. In addition, we include a 10-piece linear spline for liquid wealth, income, and number of children under 15.

${ }^{35}$ Our specification is similar to that used by Chetty and Szeidl (2011) to examine how the effect of housing on portfolios covaries with the volatility of local housing markets (see Section 4.3 and Table 7 of their paper). To test whether the effects of housing on portfolios differ in high versus low-risk environments, they interact a high-risk indicator with property value and home equity. The high-risk indicator is equal to one when the standard deviation of annual house price growth rates using the OFHEO data by state is above the median volatility of $4.5 \%$.
} 
error term of this regression might capture other sources of heterogeneity in portfolios, including background risk (see Heaton and Lucas (2000)), heterogeneity in risk aversion, or measurement error. To address this concern, we also instrument the house value and home equity using the state price index in the year of home purchase and the state price index at time $t$.

Table 14 reports the results. Columns 1-4 report first stage regressions and Columns 5 and 6 report the two-stage least square estimates ${ }^{36}$ The coefficient estimates in Column 5 imply that a $\$ 100,000$ increase in property value reduces the risky share of liquid wealth approximately by $2.2 \%$, while a $\$ 100,000$ increase in home equity increases it by $3 \%$. The coefficients point in the right directions but they are statistically insignificant. The coefficient on the interaction between home equity and $H H M I_{k t}$ is $-2.7 \%$ and is statistically significant. Hence, consistent with model predictions, housing has a substantial and significant effect on stock holdings during a period of high house appreciation. Column 6 replicates the specification in Column 5 but replaces the dependent variable with an indicator for owning stocks. Consistent with the stock share results, housing has an effect on stock market participation and has a differential effect in low- and high-growth states.

[INSERT TABLE 14 HERE]

\section{Conclusions}

As the recent literature on portfolio choice models with real estate has emphasized, there are important frictions in the housing markets that affect agents' portfolio decisions. For instance, models have considered housing as a durable consumption good as well as an investment asset, or the existence of large transaction costs in housing markets. This paper makes progress in this direction by studying an empirically relevant model that includes predictability in housing returns.

First, we study the existence of predictability in housing returns and we find that the dynamics of housing prices are well captured by a Markov switching model. The recent steep rise of U.S. house prices has received a lot of attention in the media and in the literature, but one interesting

\footnotetext{
${ }^{36}$ The number of observations is lower compared to the previous analysis. Each observation in the cross-sectional sample is for a unique household. As in Chetty and Szeidl (2011), we only use data from the first year in which portfolio allocations and house values are observed.
} 
feature of our analysis is that it documents substantial differences in expected growth rates, spread between highest and lowest growth rates, and timing across U.S. census divisions and U.S. states during the same period. Part of these variations may stem from institutional differences across U.S. states. However, in future work, it would be interesting to study and model the determinants of the distribution of house prices.

Moreover, we set up and solve a novel model for studying how housing return predictability affects housing consumption and portfolio choices. We find that households consider two state variables for making their decisions under predictability in housing returns and transaction costs: the wealth-to-housing holdings ratio and the time-varying mean rate of house price growth. As in the GL model, agents increase (decrease) their housing asset holdings only when their wealthto-housing ratio reaches an optimal upper (lower) bound; consequently, they do not trade housing when their wealth-to-housing ratio is between the upper and lower bounds. One of the main contributions of our model is to show that these bounds are time-varying and decrease when house prices are expected to rise, that is, the bounds are low in periods of high growth in housing prices and high in periods of low growth. We also show that relative risk aversion is different in high and low-growth regimes, which explains the differences in optimal portfolio choices between both regimes.

Finally, we use PSID and SIPP data to test whether the upper and lower inaction bounds are affected by housing return predictability at U.S. state level. Our empirical results show that the high growth in house prices in some U.S. states experienced during the period $1998-2006$ affected the likelihood of housing purchase and increased the investment in housing. Our analysis also suggests that the current downturn of house prices and the substantial amount of mortgage debt can dramatically increase the illiquidity of housing as many households postpone selling their houses. In future work, it would be interesting to explore such interactions when new PSID and SIPP data become available. 


\section{References}

Ang, A., and G. Bekaert. 2002. "International Asset Allocation with Regime Shifts." Review of Financial Studies 15 (4): 1137-1187.

—. 2007. "Stock Return Predictability: Is It There?" Review of Financial Studies 20 (3): $651-707$.

Ang, A., and A. Timmermann. 2011. "Regime Changes and Financial Markets." Working paper 17182, National Bureau Economic Research.

Attanasio, O. 2000. "Consumer Durables and Inertial Behaviour: Estimation and Aggregation (S,s) Rules for Automobile Purchases." Review of Economic Studies 67 (4): 667-696.

Baele, L. 2005. "Volatility Spillover Effects in European Equity Markets." Journal of Financial and Quantitative Analysis 40 (2): 373-401.

Barberis, N. 2000. "Investing for the Long Run When Returns are Predictable." Journal of Finance 55 (1): 225-264.

Bertola, G., L. Guiso, and L. Pistaferri. 2005. "Uncertainty and Consumer Durables Adjustment." Review of Economic Studies 72 (4): 973-1007.

Brennan, M., E. Schwartz, and R. Lagnado. 1997. "Strategic Asset Allocation." Journal of Economic Dynamics and Control 21 (8-9): 1377-1403.

Campbell, J. Y., and J. F. Cocco. 2003. "Household Risk Management and Optimal Mortgage Choice." Quarterly Journal of Economics 118 (4): 1449-1494.

Campbell, J. Y., S. Giglio, and C. Polk. 2010. "Hard Times." Working paper 16222, National Bureau Economic Research.

Campbell, J. Y., and R. J. Shiller. 1988. "The Dividend-Price Ratio and Expectations of Future Dividends and Discount Factors." Review of Financial Studies 1 (3): 195-228.

Campbell, J. Y., and L. M. Viceira. 1999. "Consumption and Portfolio Decisions When Expected Returns are Time Varying." Quarterly Journal of Economics 114 (2): 433-495. 
Campbell, S. D., M. A. Davis, J. Gallin, and R. F. Martin. 2009. "What Moves Housing Markets: A Variance Decomposition of the Rent-Price Ratio." Journal of Urban Economics 66 (2): 90-102.

Chetty, R., and A. Szeidl. 2011. "The Effect of Housing on Portfolio Choice." Working paper, University of California, Berkeley.

Cocco, J. F. 2005. "Portfolio Choice in the Presence of Housing." Review of Financial Studies 18 (2): $535-567$.

Damgaard, A., B. Fuglsbjerg, and C. Munk. 2003. "Optimal Consumption and Investment Strategies with a Perishable and an Indivisible Durable Consumption Good." Journal of Economic Dynamics and Control 28 (2): 209-253.

Davidoff, T. 2010. "Home Equity Commitment and Long-Term Care Insurance Demand." Journal of Public Economics 94 (1): 44-49.

Davis, M. A., A. Lehnert, and R. F. Martin. 2008. "The Rent-Price Ratio for the Aggregate Stock of Owner-Occupied Housing." Review of Income and Wealth 54 (2): 350-359.

Davtes, R. B. 1977. "Hypothesis Testing When a Nuisance Parameter is Present only Under the Alternative." Biometrika 64 (2): 247-254.

Eberly, J. 1994. “Adjustment of Consumers' Durable Stocks: Evidence from Automobile Purchases." Journal of Political Economy 102 (3): 403-436.

Fillat, J. L. 2009. "Housing as a Measure for Long-run Risk in Asset Pricing." Working paper, University of Chicago.

Flavin, M., and S. Nakagawa. 2008. "A Model of Housing in the Presence of Adjustment Costs: A Structural Interpretation of Habit Persistence." American Economic Review 98 (1): 474-495.

Flavin, M., and T. Yamashita. 2002. "Owner-Occupied Housing and the Composition of the Household Portfolio." American Economic Review 92 (1): 345-362.

Garcia, R., and P. Perron. 1996. "An Analysis of the Real Interest Rate Under Regime Shifts." Review of Economics and Statistics 78 (1): 111-125. 
Greene, W. H. 2008. Econometric Analysis. 6th. Prentice Hall.

Grossman, S. J., and G. Laroque. 1990. "Asset Pricing and Optimal Portfolio Choice in the Presence of Illiquid Durable Consumption Goods." Econometrica 58 (1): 22-51.

Hamilton, J. D. 1990. "Analysis of Time Series Subject to Changes in Regime." Journal of Econometrics 45 (1): 39-70.

Hamilton, J.D., and G. Lin. 1996. "Stock Market Volatility and the Business Cycle." Journal of Applied Econometrics 11 (5): 573-593.

Heaton, J., and D. Lucas. 2000. "Portfolio Choice and Asset Prices: The Importance of Entrepreneurial Risk." Journal of Finance 55 (3): 1163-1198.

Heckman, James J. 1979. "Sample Selection Bias as a Specification Error." Econometrica 47 (1): $153-161$.

Henkel, S. J., J. S. Martin, and F. Nardari. 2011. "Time-Varying Short-Horizon Predictability." Journal of Financial Economics 99 (3): 560-580.

Jagannathan, R., and Z. Wang. 1996. "The Conditional CAPM and the Cross-Section of Expected Returns." Journal of Finance 51 (1): 3-53.

Kim, T. S., and E. Omberg. 1996. "Dynamic Nonmyopic Portfolio Behavior." Review of Financial Studies 9 (1): 141-161.

Kocherlakota, N. R. 1996. "The Equity Premium: It's Still a Puzzle." Journal of Economic Literature 34 (1): 42-71.

Landvoigt, T., M. Piazzesi, and M. Schneider. 2011. "Housing Market(s) in San Diego." Working paper, University of Stanford.

Lettau, M., and S. van Nieuwerburgh. 2008. "Reconciling the Return Predictability Evidence." Review of Financial Studies 21 (4): 1607-1652.

Lynch, A. W., and P. Balduzzi. 2000. "Predictability and Transaction Costs: The Impact on Rebalancing Rules and Behavior." Journal of Finance 55 (5): 2285-2309. 
Martin, R. F. 2003. "Consumption, Durable Goods, and Transaction Costs." Working paper, Board of Governors of the Federal Reserve System.

Merton, R. C. 1969. "Lifetime Portfolio Selection Under Uncertainty: The Continuous-Time Case." Review of Economics and Statistics 51 (3): 247-257.

Palacios-Huerta, I. 2003. "The Robustness of the Conditional CAPM with Human Capital." Journal of Financial Econometrics 1 (2): 272-289.

Pastor, L., and P. Veronesi. 2003. "Stock Valuation and Learning about Profitability." Journal of Finance 58 (5): 1749-1789.

Shiller, R. J. 2005. Irrational Exuberance. 2nd. Princeton University Press.

Stokey, N. L. 2009a. The Economics of Inaction, Stochastic Control Models with Fixed Costs. Princeton University Press.

—. 2009b. "Moving Costs, Nondurable Consumption and Portfolio Choice." Journal of Economic Theory 144 (6): 2419-2439.

Van Hemert, O. 2008. "Life-cycle Housing and Portfolio Choice with Bond Markets." Working paper, New York University, Stern Business School.

Welch, I., and A. Goyal. 2008. "A Comprehensive Look at the Empirical Performance of Equity Premium Prediction." Review of Financial Studies 21 (4): 1455-1508.

Yamashita, T. 2003. "Owner-Occupied Housing and Investment in Stocks: An Empirical Test." Journal of Urban Economics 53 (2): 220-237.

Yao, R., and H. H. Zhang. 2005. "Optimal Consumption and Portfolio Choices with Risky Housing and Borrowing Constraints." Review of Financial Studies 18 (1): 197-239. 
Figures and Tables

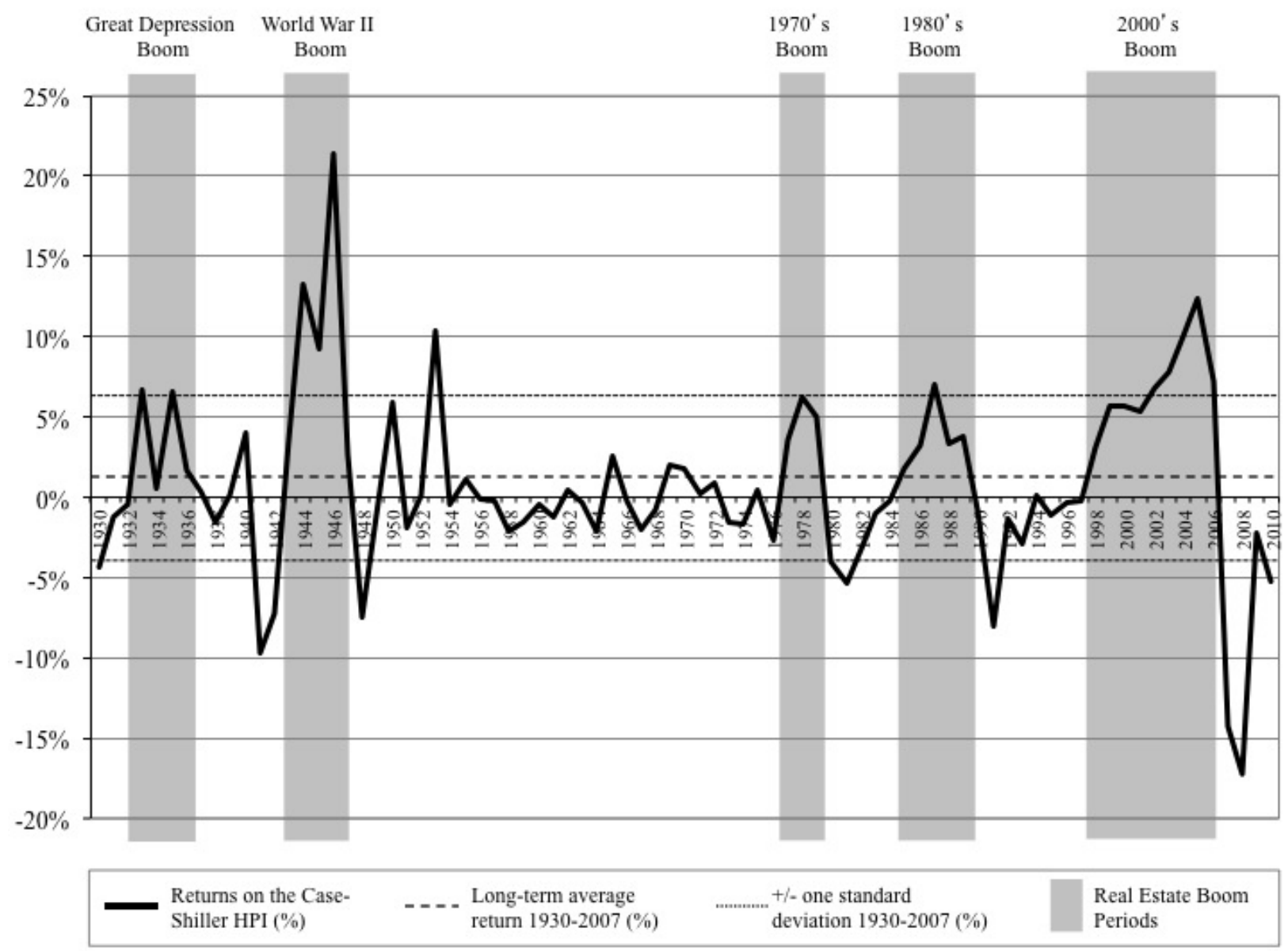

Figure 1: Case-Shiller U.S. Home Price Index (\% annual change) and periods of real estate boom. A boom in the housing market is defined as the time interval that includes the minimum number of periods with at least three consecutive years of positive yearly returns in the Case-Shiller House Price Index (HPI) and at least one year with a return higher than 5\%. 


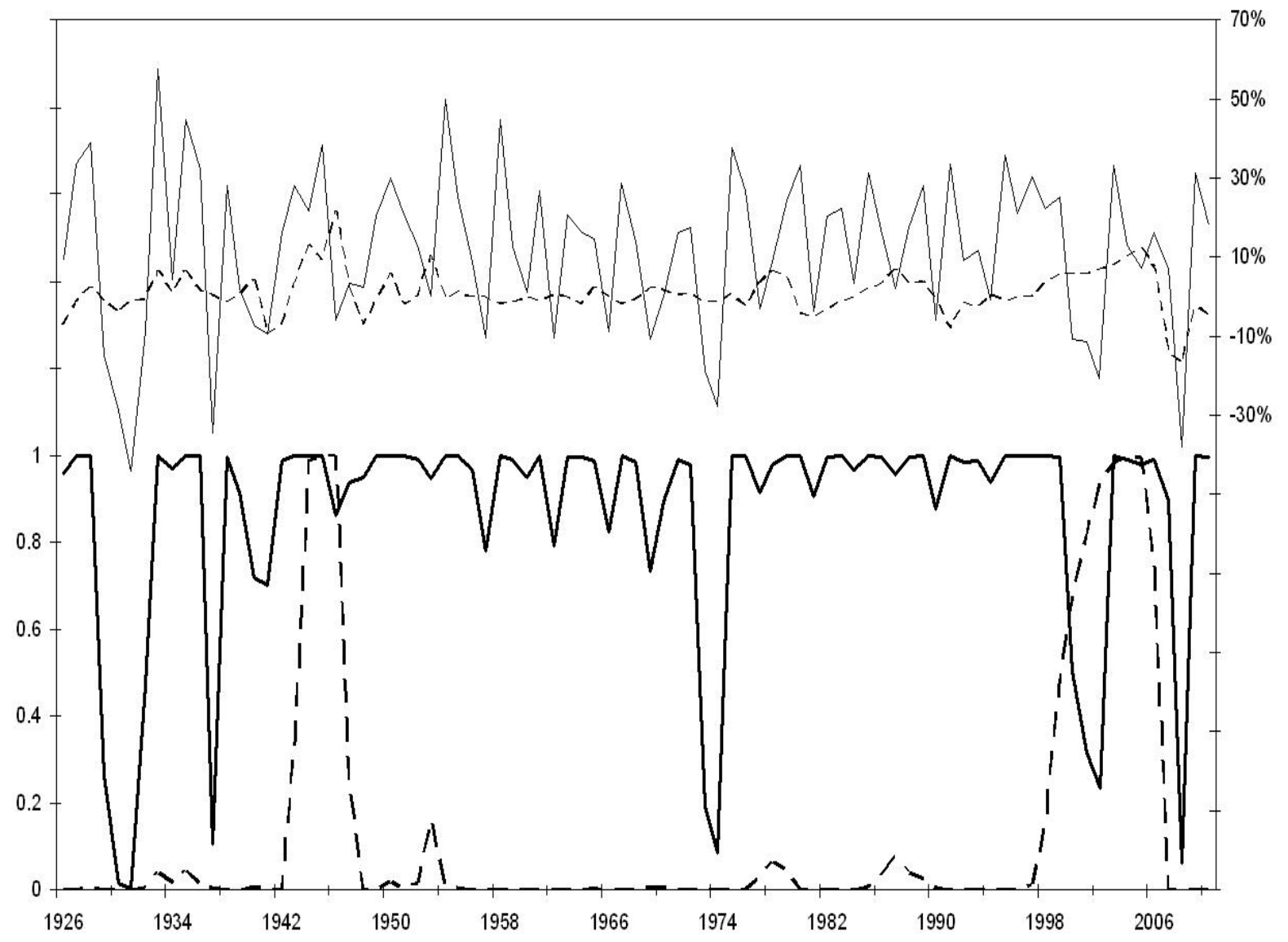

Figure 2: Returns and probabilities of being in a high regime for U.S. housing and stock markets. The top part of the figure shows returns on housing prices (dotted line; right-hand scale) and stock market prices (continuous line; right-hand scale). The bottom part of the figure shows the smoothed probability of being in a regime of high growth in housing prices (dotted line; right-hand scale) and stock market prices (continuous line; right-hand scale). 

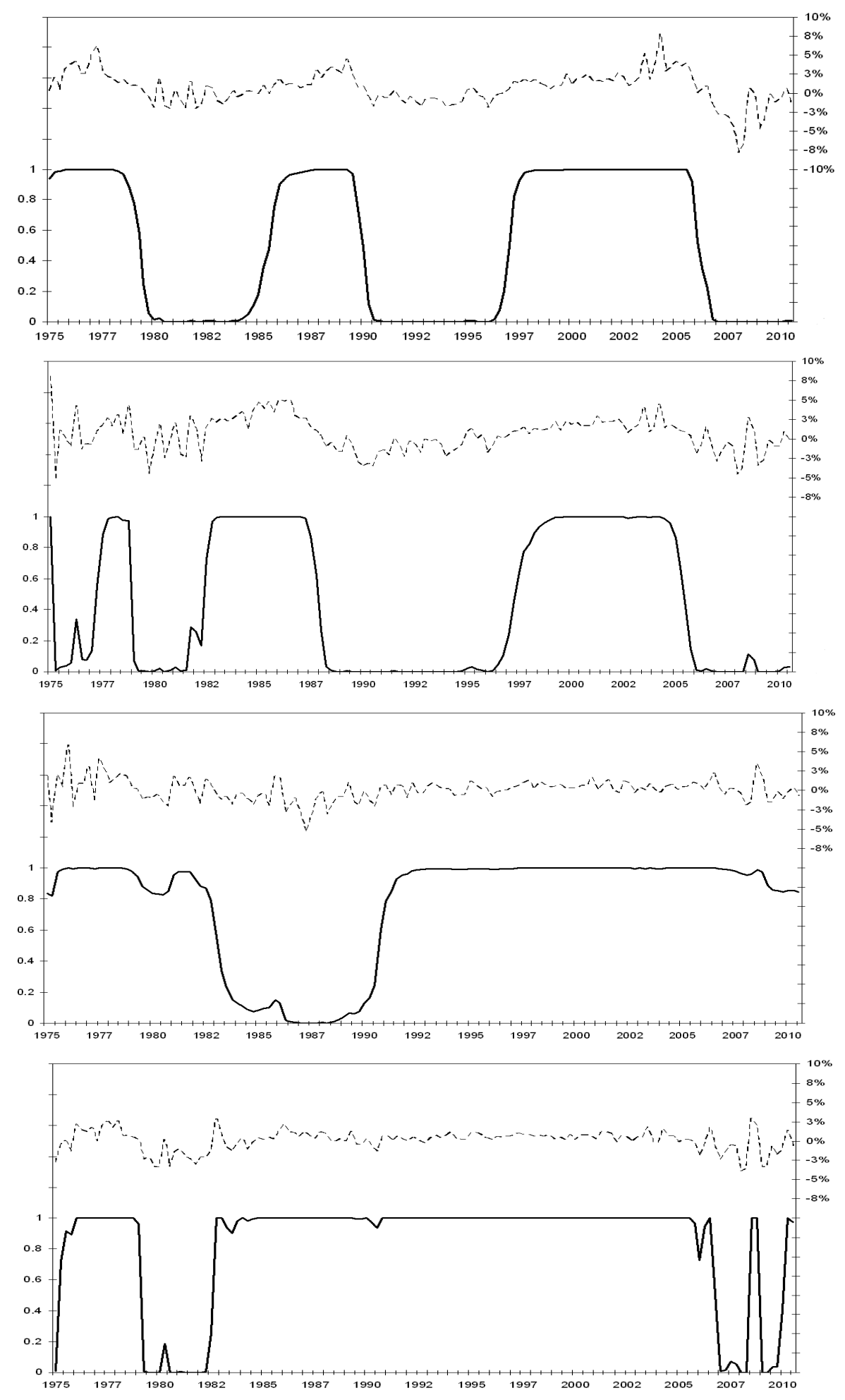

Figure 3: Probability of being in a high regime of house price returns and house price returns. U.S. census divisions. Probabilities of being in a high regime in continuous lines and values on the left-hand vertical axis. Housing returns in dotted lines and values according to the right-hand vertical axis. Graphs shown in the following order: Pacific (West) (Top), New England (Northeast), West South Central (South) and East North Central (Midwest) (Bottom). 


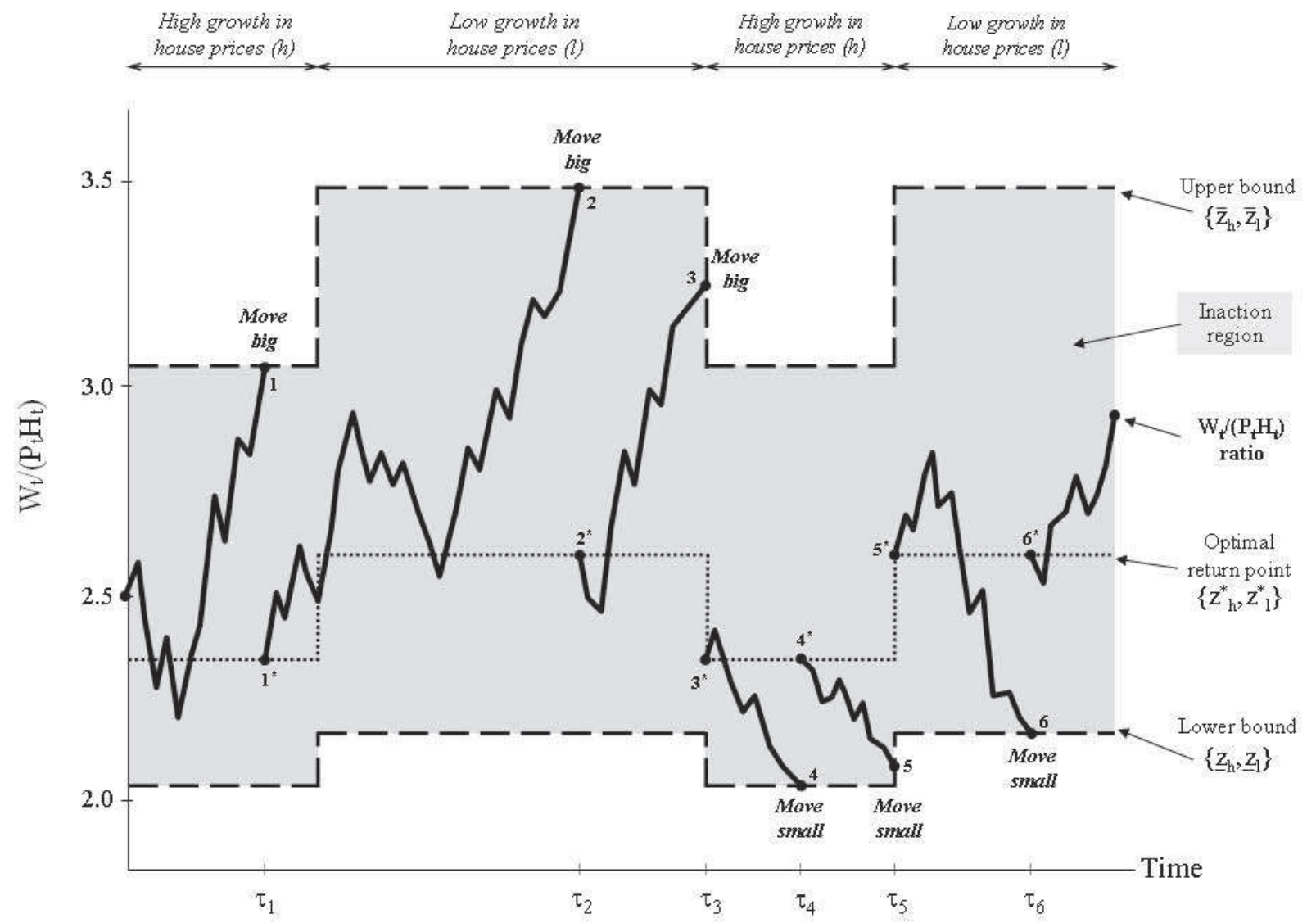

Figure 4: Illustration. Hypothetical path of wealth-to-housing ratio and upper and lower bounds associated with the two regimes. Changes in the expected growth of prices cause households to buy or sell the house. When the ratio hits a bound, the benefits of re-sizing the house outweighs the transaction costs. 


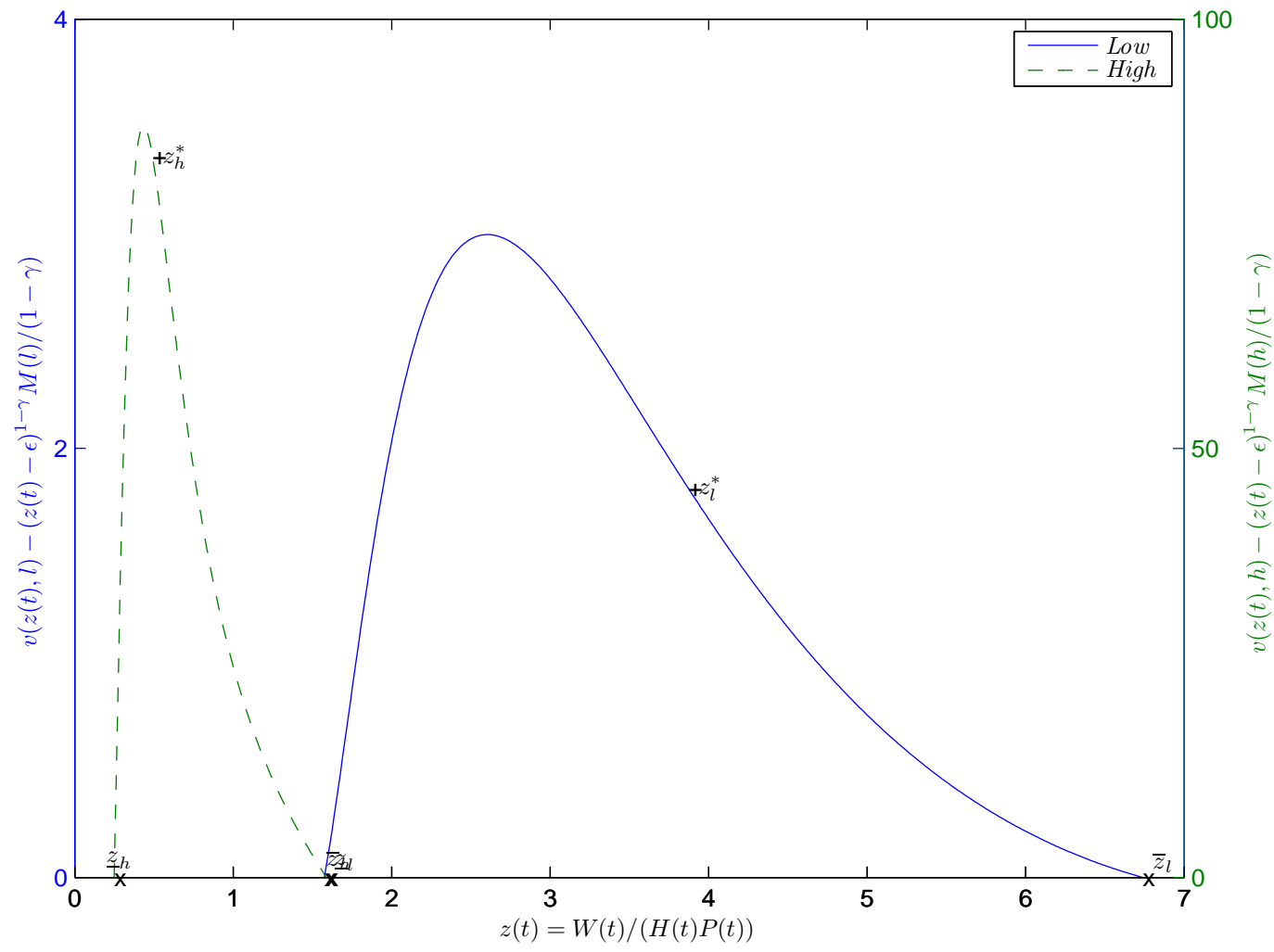

Figure 5: Value function and value of changing the home. The difference between the value function, $v(z(t), i)$, and the value of changing housing consumption, $(z(t)-\epsilon)^{1-\gamma} M_{i} /(1-\gamma)$, is plotted against $z(t)$, where $z(t)=W(t) /(H(t) P(t))$. The dotted line represents the high-growth regime (right-hand scale), while the continuous line represents the low-growth regime (left-hand scale). $\mathrm{x}(+)$ indicates the location of $z(t)$ at the point when a new purchase becomes optimal in the high (low) regime. $\bar{z}_{h}$ and $\underline{z}_{h}$ represent the upper and lower bound in the high regime. $\bar{z}_{l}$ and $\underline{z}_{l}$ represent the upper and lower bound in the low regime. $z_{h}^{*}\left(z_{l}^{*}\right)$ indicates the locations of $z(t)$ just after the purchase of a new durable in the high (low) regime. 

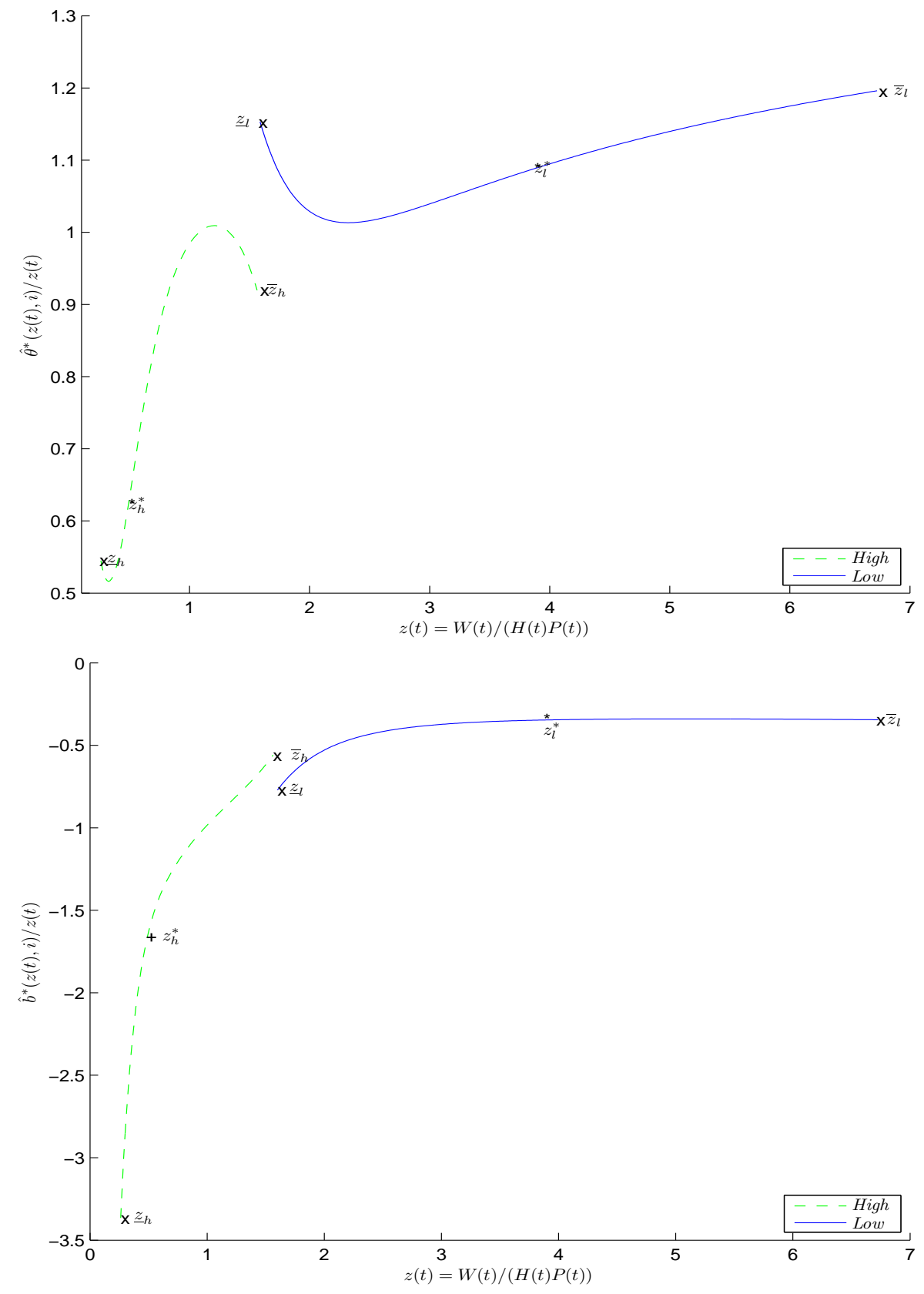

Figure 6: Risky asset and risk-free asset. Relative risk aversion and portfolio allocation as a function of $z(t)$, where $W(t) /(H(t) P(t))$ : Share of risky stock $\hat{\theta}(z(t), i) / z(t)$ (top) and share of risk-free stock $\hat{b}(z(t), i) / z(t)$ (bottom). The dotted line represents the high regime, while the continuous line is the low regime. 
Table 1: Parameter values for the house price and stock market process. Estimation of the parameters of the house price process using a discrete Markov regime process. The growth of house prices in each regime $i$ is denoted by $\mu_{i}$ and its standard deviation is denoted by $\sigma$. In 2-regime processes, $i$ can be either $i=l$ (low-growth regime) or $i=h$ (high-growth regime). Column 1 shows the parameters for the U.S. house prices; Columns 2 and 3 show the results for the stock markets. The likelihood test is used to test the null hypothesis that house prices and the stock market follow a martingale against the alternative of a regime switching mechanism. All parameters are reported on an annual basis. Source: Shiller (2005). Period: 1926-2010.

\begin{tabular}{|c|c|c|c|}
\hline & House Prices & $\begin{array}{c}\text { Stock Markets } \\
\text { Real }\end{array}$ & $\begin{array}{l}\text { Stock Markets } \\
\text { Nominal }\end{array}$ \\
\hline & (1) & $(2)$ & $(3)$ \\
\hline$\mu_{l}$ & $\begin{array}{l}-0.0049 \\
(0.0056)\end{array}$ & $\begin{array}{l}-0.1625 \\
(0.0616)\end{array}$ & $\begin{array}{l}-0.1990 \\
(0.0804)\end{array}$ \\
\hline$\mu_{h}$ & $\begin{array}{c}0.0925 \\
(0.0176)\end{array}$ & $\begin{array}{c}0.1217 \\
(0.0413)\end{array}$ & $\begin{array}{c}0.1272 \\
(0.0312)\end{array}$ \\
\hline$\sigma$ & $\begin{array}{c}0.0447 \\
(0.0036)\end{array}$ & $\begin{array}{c}0.1413 \\
(0.0216)\end{array}$ & $\begin{array}{c}0.1473 \\
(0.0187)\end{array}$ \\
\hline$\lambda_{l l}$ & $\begin{array}{c}0.9658 \\
(0.0249)\end{array}$ & $\begin{array}{c}0.3504 \\
(0.1544)\end{array}$ & $\begin{array}{l}0.3515 \\
(0.1661)\end{array}$ \\
\hline$\lambda_{h l}$ & $\begin{array}{c}0.2414 \\
(0.1494)\end{array}$ & $\begin{array}{c}0.2453 \\
(0.1589)\end{array}$ & $\begin{array}{c}0.1243 \\
(0.0985)\end{array}$ \\
\hline $\begin{array}{l}\text { LR-test } \chi^{2}: \mu_{l}=\mu_{h} \\
\text { P-value }\end{array}$ & $\begin{array}{l}14.326 \\
0.0119\end{array}$ & $\begin{array}{c}2.729 \\
0.9526\end{array}$ & $\begin{array}{c}5.115 \\
0.4739\end{array}$ \\
\hline
\end{tabular}


Table 2: Parameter values for the house prices process - U.S. census divisions. Estimation of the parameters of the house price process using a discrete Markov regime process. The growth of house prices in each regime $i$ is denoted by $\mu_{i}$ and its standard deviation is denoted by $\sigma_{P}$. In 2-regime processes, $i$ can be either $i=l$ (low-growth regime) or $i=h$ (high-growth regime). The unconditional probability of moving from regime $i$ to regime $j$ is denoted by $\lambda_{i j}$. Columns 1-9 show the parameters for the nine U.S. census divisions. The likelihood test is used to test the null hypothesis that house prices follow a martingale against the alternative of a regime switching mechanism. All parameters are reported on an annual basis. Source: OFHEO. Period: $1975-2010$.

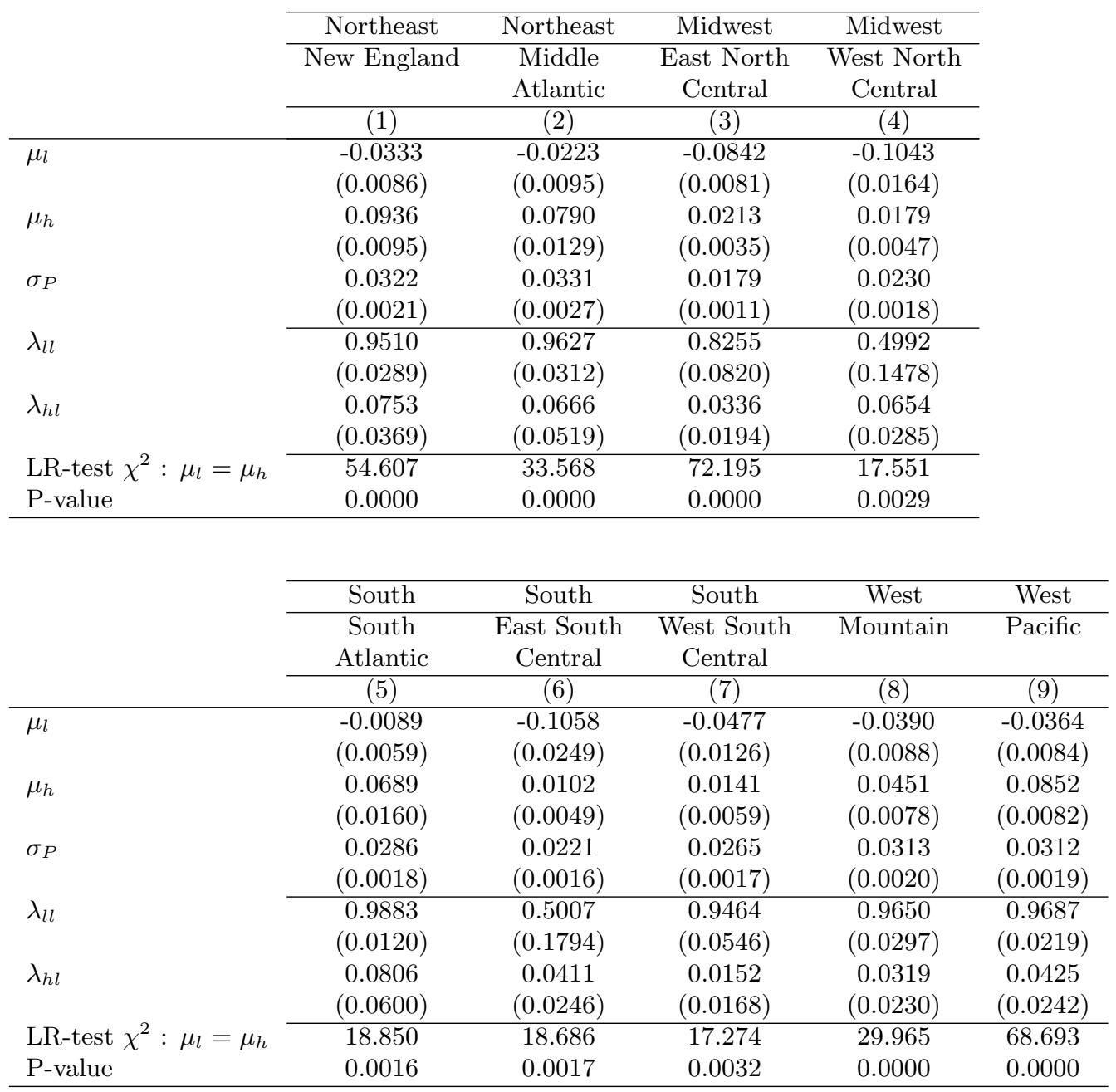


Table 3: Parameter used for benchmark calibration.

\begin{tabular}{lcc}
\hline Variable & Symbol & Value \\
\hline Curvature of the utility function & $\gamma$ & 2 \\
House flow services & $1-\beta$ & 0.4 \\
Time preference & $\rho$ & 0.025 \\
Risk free rate & $r$ & 0.015 \\
House depreciation & $\delta$ & 0.02 \\
Transaction cost & $\epsilon$ & 0.05 \\
Risky asset drift & $\alpha_{S}$ & 0.077 \\
Standard deviation risky asset & $\sigma_{S}$ & 0.1655 \\
Correlation house price - risky asset & $\rho_{P S}$ & 0.25 \\
\hline
\end{tabular}


Table 4: Numerical results. Columns 1, 2 and 3 display the lower bound, the optimal return point and the upper bound, respectively. The optimal return point represents the wealth-to-housing ratio immediately after a housing purchase. Column 4 is the optimal housing-to-wealth ratio without transaction costs and Column 5 is the corresponding ratio with transaction costs immediately after a housing purchase. Column 6 is the relative risk aversion just after a housing purchase, and Column 7 is the average holding of the risky asset, estimated just after a housing purchase. The first row in the table represents the benchmark case, described previously in this section. Finally, we report the model results when we use the estimated house prices parameters for the nine U.S. census divisions.

\begin{tabular}{|c|c|c|c|c|c|c|c|c|}
\hline & Regime & (1) & $(2)$ & (3) & $(4)$ & $(5)$ & (6) & $(7)$ \\
\hline & $i$ & $\underline{z}_{i}$ & $z_{i}^{*}$ & $\bar{z}_{i}$ & $\alpha_{h, i}$ & $1 / z_{i}^{*}$ & $R R A\left(z_{i}^{*}\right)$ & $\frac{E\left(\frac{\hat{\theta}^{*}\left(z^{*}, i\right)}{z^{*}}\right)}{E\left(\tau_{i}\right)}$ \\
\hline \multirow{2}{*}{$\begin{array}{c}\text { U.S. aggregate } \\
(1930-2010)\end{array}$} & High & 0.249 & 0.491 & 1.587 & 2.980 & 2.035 & 2.595 & 0.730 \\
\hline & Low & 1.575 & 3.870 & 6.739 & 0.340 & 0.258 & 2.071 & 1.098 \\
\hline \multicolumn{9}{|l|}{$\begin{array}{l}\text { U.S. census divisions } \\
(1975-2010)\end{array}$} \\
\hline \multicolumn{9}{|l|}{ Northeast } \\
\hline \multirow[t]{2}{*}{ New England } & High & 0.254 & 0.470 & 1.171 & 3.111 & 2.124 & 2.740 & 0.703 \\
\hline & Low & 1.770 & 4.613 & 6.741 & 0.281 & 0.216 & 2.072 & 1.092 \\
\hline \multirow[t]{2}{*}{ Middle Atlantic } & High & 0.284 & 0.652 & 1.377 & 2.371 & 1.531 & 2.519 & 0.789 \\
\hline & Low & 1.809 & 3.831 & 6.743 & 0.288 & 0.260 & 2.106 & 1.090 \\
\hline \multicolumn{9}{|l|}{ Midwest } \\
\hline \multirow[t]{2}{*}{ East North Central } & High & 1.297 & 2.250 & 5.972 & 0.511 & 0.444 & 2.163 & 1.067 \\
\hline & Low & 2.849 & 7.207 & 12.443 & 0.160 & 0.138 & 2.022 & 1.138 \\
\hline \multirow[t]{2}{*}{ West North Central } & High & 1.520 & 2.459 & 6.874 & 0.406 & 0.370 & 2.140 & 1.080 \\
\hline & Low & 2.545 & 7.643 & 17.240 & 0.140 & 0.103 & 2.023 & 1.135 \\
\hline \multicolumn{9}{|l|}{ South } \\
\hline \multirow[t]{2}{*}{ South Atlantic } & High & 0.570 & 0.997 & 2.396 & 1.865 & 1.002 & 2.319 & 0.921 \\
\hline & Low & 2.066 & 3.601 & 6.748 & 0.307 & 0.277 & 2.125 & 1.086 \\
\hline \multirow[t]{2}{*}{ East South Central } & High & 1.675 & 3.799 & 6.178 & 0.405 & 0.263 & 2.052 & 1.100 \\
\hline & Low & 2.638 & 8.897 & 16.743 & 0.138 & 0.112 & 2.014 & 1.147 \\
\hline \multirow[t]{2}{*}{ West South Central } & High & 1.620 & 2.906 & 5.865 & 0.434 & 0.344 & 2.120 & 1.081 \\
\hline & Low & 2.686 & 5.590 & 9.137 & 0.204 & 0.178 & 2.030 & 1.127 \\
\hline \multicolumn{9}{|l|}{ West } \\
\hline \multirow[t]{2}{*}{ Mountain } & High & 0.890 & 1.425 & 2.992 & 0.979 & 0.701 & 2.289 & 0.965 \\
\hline & Low & 2.055 & 5.151 & 7.712 & 0.227 & 0.194 & 2.054 & 1.109 \\
\hline \multirow[t]{2}{*}{ Pacific } & High & 0.329 & 0.624 & 1.686 & 2.703 & 1.602 & 2.526 & 0.828 \\
\hline & Low & 1.863 & 4.676 & 7.508 & 0.259 & 0.213 & 2.071 & 1.103 \\
\hline
\end{tabular}


Table 5: Descriptive statistics - PSID. Statistics for the main variables used in our analysis from PSID data. The variables Move big and Move small correspond to the individuals who moved to a house having a higher and lower value, respectively. Full sample refers to all the individuals in the sample, irrespective of their moving situation. The ratio $z=W /(P \cdot H)$ corresponds to the ratio of financial wealth net of debt over housing value without considering human capital as part of the wealth. The ratio $\widetilde{z}=(W+L) /(P \cdot H)$ corresponds to the ratio of total wealth with human capital $L$ and net of debt over housing value. $\Delta$ Family size shows the statistics of changes in family size. $\Delta$ Married is one if the individual gets married, zero otherwise. $\Delta$ Employment is one if the individual changes employment status, zero otherwise. Age corresponds to the age of the household head. Northeast, Midwest, South and West are U.S. macro-region dummies.

\begin{tabular}{lcccccc}
\hline & \multicolumn{2}{c}{ Full sample } & \multicolumn{2}{c}{ Move big } & \multicolumn{2}{c}{ Move small } \\
& Mean & Std. err. & Mean & Std. err. & Mean & Std. err. \\
\hline$z=W /(P H)$ & 1.388 & 1.645 & 1.322 & 1.780 & 1.257 & 1.640 \\
$\widetilde{z}=(W+L) /(P H)$ & 8.956 & 10.453 & 13.463 & 15.069 & 8.928 & 10.691 \\
Stock share $(\%$ financial wealth) $\Theta / W$ & 0.102 & 0.225 & 0.124 & 0.248 & 0.107 & 0.200 \\
Stock (without retirement assets) share & 0.056 & 0.146 & 0.065 & 0.181 & 0.059 & 0.155 \\
(\% financial wealth) $\widehat{\Theta} / W$ & & & & & & \\
Stock (without retirement assets) share & 0.189 & 0.339 & 0.176 & 0.321 & 0.192 & 0.344 \\
(\% liquid wealth) $\widehat{\Theta} / \widehat{W}$ & & & & & & \\
Safe asset share & -1.051 & 2.199 & -1.644 & 2.679 & -1.682 & 2.903 \\
(\% financial wealth) $B / W$ & & & & & & \\
Safe asset (without debt) share & 0.109 & 0.246 & 0.141 & 0.247 & 0.107 & 0.181 \\
(\% financial wealth) $\widehat{B} / W$ & & & & & & 0.000 \\
Move big $W$ & 0.063 & 0.243 & 1.000 & 0.000 & 0.000 & 0.000 \\
Move small & 0.023 & 0.149 & 0.000 & 0.000 & 1.000 & 0.000 \\
$\Delta$ Family & -0.044 & 0.667 & 0.071 & 0.917 & -0.235 & 1.150 \\
$\Delta$ Married & 0.016 & 0.126 & 0.067 & 0.250 & 0.033 & 0.179 \\
$\Delta$ Employment & 0.148 & 0.356 & 0.101 & 0.301 & 0.217 & 0.413 \\
Age & 49.094 & 15.020 & 40.386 & 12.954 & 46.070 & 15.426 \\
Midwest & 0.266 & 0.442 & 0.269 & 0.444 & 0.270 & 0.444 \\
South & 0.409 & 0.492 & 0.389 & 0.488 & 0.425 & 0.495 \\
West & 0.169 & 0.374 & 0.207 & 0.405 & 0.206 & 0.405 \\
Northeast & 0.156 & 0.363 & 0.135 & 0.342 & 0.099 & 0.299 \\
\hline Num. Obs. & 20189 & & 1273 & & 456 & \\
\hline & & & & & \\
\end{tabular}


Table 6: Descriptive statistics - SIPP. Statistics for the main variables used in our analysis from SIPP data. The variables Move big and Move small correspond to the individuals who moved to a house having a higher and lower value, respectively. Full sample refers to all the individuals in the sample, irrespective of their moving situation. The ratio $z=W /(P \cdot H)$ corresponds to the ratio of financial wealth net of debt over housing value without considering human capital as part of the wealth. The ratio $\widetilde{z}=(W+L) /(P \cdot H)$ corresponds to the ratio of total wealth with human capital $L$ and net of debt over housing value. $\Delta$ Family size shows the statistics of changes in family size. $\Delta$ Married is one if the individual gets married, zero otherwise. $\Delta$ Employment is one if the individual changes employment status, zero otherwise. Age corresponds to the age of the household head. Northeast, Midwest, South and West are U.S. macro-region dummies.

\begin{tabular}{lcccccc}
\hline & \multicolumn{2}{c}{ Full sample } & \multicolumn{2}{c}{ Move big } & \multicolumn{2}{c}{ Move small } \\
& Mean & Std. err. & Mean & Std. err. & Mean & Std. err. \\
\hline$z=W /(P H)$ & 1.376 & 1.636 & 1.360 & 1.776 & 1.213 & 1.451 \\
$\widetilde{z}=(W+L) /(P H)$ & 5.944 & 7.153 & 9.019 & 8.932 & 5.099 & 5.894 \\
Stock share $(\%$ financial wealth) $\Theta / W$ & 0.180 & 0.372 & 0.221 & 0.392 & 0.143 & 0.327 \\
Stock (without retirement assets) share & 0.030 & 9.224 & 0.075 & 0.186 & 0.052 & 0.190 \\
(\% financial wealth) $\widehat{\Theta} / W$ & & & & & & \\
Stock (without retirement assets) share & 0.120 & 0.254 & 0.159 & 0.281 & 0.136 & 0.268 \\
(\% liquid wealth) $\widehat{\Theta} / \widehat{W}$ & & & & & & \\
Safe asset share & -0.779 & 2.187 & -1.035 & 2.268 & -0.929 & 2.181 \\
(\% financial wealth) $B / W$ & & & & & \\
Safe asset (without debt) share & & & & \\
(\% financial wealth) $\widehat{B} / W$ & 0.052 & 6.887 & 0.085 & 0.208 & 0.072 & 0.157 \\
Move big & & & & & & 0.000 \\
Move small & 0.017 & 0.129 & 1.000 & 0.000 & 0.000 & 0.000 \\
$\Delta$ Family & 0.009 & 0.092 & 0.000 & 0.000 & 1.000 & 0.859 \\
$\Delta$ Married & -0.015 & 0.508 & 0.077 & 0.728 & -0.091 & 0.215 \\
$\Delta$ Employment & 0.011 & 0.106 & 0.011 & 0.105 & 0.048 & 0.334 \\
Age & 0.069 & 0.253 & 0.097 & 0.297 & 0.127 & 0.263 \\
Midwest & 52.987 & 15.741 & 43.802 & 12.979 & 49.436 & 15.263 \\
South & 0.272 & 0.445 & 0.279 & 0.449 & 0.249 & 0.433 \\
West & 0.362 & 0.481 & 0.317 & 0.466 & 0.385 & 0.487 \\
Northeast & 0.185 & 0.389 & 0.260 & 0.439 & 0.226 & 0.419 \\
\hline Num. Obs. & 0.180 & 0.384 & 0.144 & 0.351 & 0.139 & 0.347 \\
\hline & 105877 & & 1797 & & 911 & \\
\hline
\end{tabular}


Table 7: Movers. Percentage of households that moved over total households in the PSID and SIPP surveys across all years. Column 1 captures the percentage of households that changed address. Column 2 captures the percentage of households that moved to a new address in the same U.S. macro region. Column 3 captures the percentage of households that moved to a new address in the same state. Column 4 shows the percentage of movers that were not owners in the preceding period.

(a) PSID data

\begin{tabular}{lcccc}
\hline Status & Move & Same U.S. macro region & Same U.S. state & Not Owner at $t-1$ \\
\cline { 2 - 5 } & $(1)$ & $(2)$ & $(3)$ & $(4)$ \\
\hline Owner & $15.43 \%$ & $14.82 \%$ & $14.19 \%$ & $3.79 \%$ \\
Renter & $28.70 \%$ & $27.03 \%$ & $25.26 \%$ & $25.31 \%$ \\
Occupied & $4.15 \%$ & $3.87 \%$ & $3.56 \%$ & $3.63 \%$ \\
\hline
\end{tabular}

(b) SIPP data

\begin{tabular}{lcccc}
\hline Status & Move & Same U.S. macro region & Same U.S. state & Not Owner at $t-1$ \\
\cline { 2 - 5 } & $(1)$ & $(2)$ & $(3)$ & $(4)$ \\
\hline Owner & $13.55 \%$ & $12.74 \%$ & $12.00 \%$ & $5.47 \%$ \\
Renter & $35.16 \%$ & $33.55 \%$ & $32.17 \%$ & $32.67 \%$ \\
Occupied & $3.49 \%$ & $3.31 \%$ & $3.09 \%$ & $3.06 \%$ \\
\hline
\end{tabular}


Table 8: Test of Hypothesis 1 - PSID. Coefficients are estimated by using a standard OLS model and ex-ante (i.e., before moving) values of $\tilde{z}_{i t}$ as endogenous variable. $m_{B I G_{i t}}\left(m_{S M A L L_{i t}}\right)$ is a dummy variable equal to one if the family is increasing (decreasing) its housing holdings (i.e., moving to a bigger (smaller) house). Standard errors are reported in parentheses. ${ }^{* * *}$ denotes significance at the $1 \%$ level, ${ }^{* *}$ at the $5 \%$ level, and ${ }^{*}$ at the $10 \%$ level. The pooled regressions include year dummies. Source: PSID. Period: $1984-2005$.

\begin{tabular}{|c|c|c|c|c|c|c|c|c|}
\hline & All & 1984 & 1989 & 1994 & 1999 & 2001 & 2003 & 2005 \\
\hline \multirow[t]{2}{*}{ constant $\left(\gamma_{0}\right)$} & $2.166^{* * *}$ & $1.949^{* * *}$ & 0.831 & 1.022 & $2.006^{* * *}$ & $2.056^{* * *}$ & $1.361^{* *}$ & $1.682^{* * *}$ \\
\hline & $(0.233)$ & $(0.542)$ & $(0.502)$ & $(0.524)$ & $(0.455)$ & $(0.444)$ & $(0.425)$ & $(0.404)$ \\
\hline \multirow[t]{2}{*}{$m_{B I G}\left(\gamma_{1}\right)$} & $2.456^{* * *}$ & $4.166^{* * *}$ & $4.206^{* * *}$ & 1.667 & $4.305^{* * *}$ & $1.922^{* * *}$ & $2.016^{* * *}$ & $1.732^{* * *}$ \\
\hline & $(0.235)$ & $(0.792)$ & $(0.830)$ & $(0.912)$ & $(0.631)$ & $(0.563)$ & $(0.489)$ & $(0.466)$ \\
\hline \multirow[t]{2}{*}{$m_{S M A L L}\left(\gamma_{2}\right)$} & -0.438 & 0.487 & 0.066 & -2.739 & -1.118 & 0.027 & 0.687 & -0.656 \\
\hline & $(0.378)$ & $(1.430)$ & $(1.529)$ & $(1.503)$ & $(0.961)$ & $(0.787)$ & $(0.872)$ & $(0.726)$ \\
\hline \multirow[t]{2}{*}{$\Delta$ Family } & $-0.352^{* * *}$ & 0.128 & -0.164 & -0.226 & $-0.732^{* * *}$ & -0.289 & -0.365 & -0.179 \\
\hline & $(0.086)$ & $(0.282)$ & $(0.296)$ & $(0.359)$ & $(0.208)$ & $(0.197)$ & $(0.191)$ & $(0.179)$ \\
\hline \multirow[t]{2}{*}{$\Delta$ Married } & -0.041 & 0.696 & -1.488 & $-3.944^{*}$ & 0.934 & -0.866 & 0.665 & 1.372 \\
\hline & $(0.451)$ & $(1.509)$ & $(1.722)$ & $(1.751)$ & $(1.070)$ & $(1.052)$ & $(0.978)$ & $(0.928)$ \\
\hline \multirow[t]{2}{*}{$\Delta$ Employment } & 0.135 & -0.444 & 0.342 & 0.292 & -0.254 & 0.398 & 0.494 & $0.789^{*}$ \\
\hline & $(0.161)$ & $(0.433)$ & $(0.433)$ & $(0.464)$ & $(0.449)$ & $(0.413)$ & $(0.422)$ & $(0.383)$ \\
\hline \multirow[t]{2}{*}{$A g e_{y<30}$} & $10.844^{* * *}$ & $13.521^{* * *}$ & $11.650^{* * *}$ & $12.299^{* * *}$ & $11.731^{* * *}$ & $11.079^{* * *}$ & $8.796 * * *$ & $7.070^{* * *}$ \\
\hline & $(0.220)$ & $(0.576)$ & (0.609) & $(0.688)$ & (0.619) & $(0.580)$ & $(0.553)$ & (0.491) \\
\hline \multirow[t]{2}{*}{$A g e_{30}<y<40$} & $8.706^{* * *}$ & $9.064^{* * *}$ & $9.656^{* * *}$ & $10.327^{* * *}$ & $9.006 * * *$ & $8.875 * * *$ & $7.447^{* * *}$ & $6.645^{* * *}$ \\
\hline & $(0.168)$ & $(0.485)$ & $(0.453)$ & $(0.489)$ & $(0.436)$ & $(0.438)$ & $(0.423)$ & $(0.404)$ \\
\hline \multirow[t]{2}{*}{$\mathrm{Age}_{40<y<50}$} & $7.555^{* * *}$ & $7.620^{* * *}$ & $8.843^{* * *}$ & $8.171^{* * *}$ & $7.737^{* * *}$ & $7.626^{* * *}$ & $7.097^{* * *}$ & $6.083^{* * *}$ \\
\hline & (0.163) & $(0.547)$ & $(0.486)$ & $(0.482)$ & $(0.406)$ & $(0.400)$ & $(0.386)$ & $(0.365)$ \\
\hline \multirow[t]{2}{*}{$A g e_{50}<y<60$} & $4.355^{* * *}$ & $5.097 * * *$ & $3.769 * * *$ & $5.202 * * *$ & $4.426 * * *$ & $4.747 * * *$ & $3.786^{* * *}$ & $3.481^{* * *}$ \\
\hline & (0.174) & $(0.506)$ & $(0.511)$ & $(0.581)$ & $(0.473)$ & $(0.440)$ & $(0.409)$ & $(0.373)$ \\
\hline \multirow[t]{2}{*}{ Midwest } & $1.424^{* * *}$ & 0.127 & $2.673^{* * *}$ & $2.540^{* * *}$ & $1.582^{* * *}$ & 0.842 & $1.626^{* * *}$ & $1.037^{*}$ \\
\hline & (0.178) & $(0.522)$ & $(0.510)$ & $(0.529)$ & $(0.468)$ & $(0.451)$ & $(0.432)$ & (0.409) \\
\hline \multirow[t]{2}{*}{ South } & $2.211^{* * *}$ & $2.233^{* * *}$ & $3.313^{* * *}$ & $2.789 * * *$ & $1.713^{* * *}$ & $1.696^{* * *}$ & $2.302^{* * *}$ & $1.833^{* * *}$ \\
\hline & $(0.167)$ & $(0.483)$ & $(0.468)$ & $(0.500)$ & (0.439) & $(0.424)$ & $(0.404)$ & $(0.381)$ \\
\hline \multirow[t]{2}{*}{ West } & $-1.198 * * *$ & $-1.637^{* *}$ & -0.139 & -0.351 & $-1.407^{* *}$ & $-1.755^{* * *}$ & $-1.192^{*}$ & $-1.530^{* * *}$ \\
\hline & (0.197) & $(0.584)$ & $(0.572)$ & $(0.607)$ & $(0.513)$ & $(0.495)$ & $(0.469)$ & $(0.438)$ \\
\hline$R^{2}$ & 0.593 & 0.628 & 0.630 & 0.612 & 0.608 & 0.591 & 0.561 & 0.539 \\
\hline Num. Obs. & 20189 & 2507 & 2585 & 2457 & 3078 & 3191 & 3190 & 3181 \\
\hline
\end{tabular}


Table 9: Test of Hypothesis 1 - SIPP. Coefficients are estimated by using a standard OLS model and ex-ante (i.e., before moving) values of $\tilde{z}_{i t}$ as endogenous variable. $m_{B I G_{i t}}\left(m_{S M A L L_{i t}}\right)$ is a dummy variable equal to one if the family is increasing (decreasing) its housing holdings (i.e., moving to a bigger (smaller) house). Standard errors are reported in parentheses. ${ }^{* *}$ denotes significance at the $1 \%$ level, ${ }^{* *}$ at the $5 \%$ level, and ${ }^{*}$ at the $10 \%$ level. The pooled regressions include year dummies. Source: SIPP. Period: 1997-2005.

\begin{tabular}{|c|c|c|c|c|c|c|c|}
\hline & All & 1997 & 1998 & 1999 & 2002 & 2003 & 2005 \\
\hline \multirow[t]{2}{*}{ constant $\left(\gamma_{0}\right)$} & $3.471^{* * *}$ & $2.103^{* * *}$ & $2.214^{* * *}$ & $2.308^{* * *}$ & $2.111^{* * *}$ & $1.875^{* * *}$ & $1.702^{* * *}$ \\
\hline & $(0.530)$ & $(0.143)$ & $(0.141)$ & $(0.135)$ & $(0.132)$ & $(0.142)$ & (0.108) \\
\hline \multirow{2}{*}{$m_{B I G}\left(\gamma_{1}\right)$} & $1.677^{* * *}$ & $1.847^{* * *}$ & $1.988^{* * *}$ & $2.424^{* * *}$ & $1.415^{* * *}$ & $1.512^{* * *}$ & $1.049 * * *$ \\
\hline & $(0.153)$ & $(0.439)$ & $(0.396)$ & $(0.384)$ & $(0.379)$ & $(0.388)$ & $(0.286)$ \\
\hline \multirow[t]{2}{*}{$m_{S M A L L}\left(\gamma_{2}\right)$} & $-1.278^{* * *}$ & $-1.577^{* *}$ & $-1.603^{* *}$ & $-1.339 *$ & $-1.483^{* *}$ & -0.987 & -0.818 \\
\hline & $(0.213)$ & $(0.570)$ & $(0.561)$ & $(0.543)$ & $(0.482)$ & $(0.579)$ & $(0.418)$ \\
\hline \multirow[t]{2}{*}{$\Delta$ Family } & $-0.371^{* * *}$ & $-0.572^{* * *}$ & $-0.369^{* * *}$ & $-0.383^{* *}$ & $-0.297^{* *}$ & $-0.478^{* * *}$ & $-0.211^{* *}$ \\
\hline & $(0.040)$ & $(0.105)$ & $(0.102)$ & $(0.117)$ & $(0.095)$ & $(0.123)$ & $(0.070)$ \\
\hline \multirow[t]{2}{*}{$\Delta$ Married } & -0.137 & -0.447 & 0.567 & $-1.832^{* *}$ & -0.333 & 0.124 & 0.371 \\
\hline & (0.193) & $(0.500)$ & $(0.502)$ & $(0.607)$ & $(0.417)$ & $(0.613)$ & (0.338) \\
\hline \multirow[t]{2}{*}{$\Delta$ Employment } & $-0.659 * * *$ & $-0.945 * * *$ & $-0.549^{*}$ & $-0.907 * * *$ & $-0.712^{* * *}$ & $-0.592^{* *}$ & $-0.470 * * *$ \\
\hline & $(0.078)$ & $(0.264)$ & $(0.251)$ & $(0.240)$ & $(0.159)$ & $(0.188)$ & (0.128) \\
\hline \multirow[t]{2}{*}{$A g e_{y<30}$} & $7.439 * * *$ & $8.339^{* * *}$ & $8.125^{* * *}$ & $7.580^{* * *}$ & $7.513^{* * *}$ & $7.406^{* * *}$ & $6.081^{* * *}$ \\
\hline & (0.089) & $(0.237)$ & $(0.240)$ & $(0.231)$ & $(0.210)$ & $(0.232)$ & (0.167) \\
\hline \multirow[t]{2}{*}{$A g e_{30}<y<40$} & $6.604^{* * *}$ & $7.220^{* * *}$ & $6.978^{* * *}$ & $6.780^{* * *}$ & $6.442^{* * *}$ & $6.517^{* * *}$ & $5.793^{* * *}$ \\
\hline & $(0.057)$ & $(0.150)$ & $(0.149)$ & $(0.144)$ & $(0.142)$ & $(0.153)$ & $(0.112)$ \\
\hline \multirow[t]{2}{*}{ Age $_{40<y<50}$} & $5.659 * * *$ & $6.138^{* * *}$ & $6.032^{* * *}$ & $6.190 * * *$ & $5.405^{* * *}$ & $5.347^{* * *}$ & $4.983^{* * *}$ \\
\hline & $(0.053)$ & $(0.143)$ & $(0.140)$ & (0.133) & $(0.129)$ & (0.139) & (0.101) \\
\hline \multirow[t]{2}{*}{ Age $50<y<60$} & $3.134^{* * *}$ & $3.221^{* * *}$ & $3.304^{* * *}$ & $3.177^{* * *}$ & $3.278^{* * *}$ & $3.051^{* * *}$ & 0.000 \\
\hline & $(0.057)$ & $(0.158)$ & $(0.152)$ & $(0.143)$ & $(0.137)$ & $(0.148)$ & $()$. \\
\hline \multirow[t]{2}{*}{ Midwest } & $0.865^{* * *}$ & $1.155^{* * *}$ & $0.931^{* * *}$ & $0.648^{* * *}$ & $0.638^{* * *}$ & $0.836^{* * *}$ & 0.939 *** \\
\hline & $(0.060)$ & $(0.158)$ & $(0.155)$ & $(0.148)$ & $(0.145)$ & $(0.157)$ & (0.117) \\
\hline \multirow[t]{2}{*}{ South } & $0.491^{* * *}$ & $0.561^{* * *}$ & $0.360^{*}$ & $0.382^{* *}$ & $0.502^{* * *}$ & $0.587^{* * *}$ & $0.546^{* * *}$ \\
\hline & $(0.057)$ & $(0.150)$ & $(0.148)$ & $(0.142)$ & $(0.137)$ & $(0.147)$ & (0.112) \\
\hline \multirow[t]{2}{*}{ West } & $-0.918 * * *$ & $-0.698 * * *$ & $-0.909 * * *$ & $-1.119 * * *$ & $-1.185^{* * *}$ & $-0.793 * * *$ & $-0.824^{* * *}$ \\
\hline & $(0.065)$ & $(0.174)$ & $(0.171)$ & $(0.162)$ & $(0.157)$ & $(0.168)$ & $(0.127)$ \\
\hline$R^{2}$ & 0.516 & 0.506 & 0.518 & 0.543 & 0.538 & 0.494 & 0.508 \\
\hline Num. Obs. & 105216 & 18340 & 17095 & 16398 & 15572 & 15327 & 22484 \\
\hline
\end{tabular}


Table 10: Test of Hypothesis 2a. Difference-in-differences regressions. Coefficients estimated using a standard OLS model with ex-ante (i.e., before moving) values of $\tilde{z}_{i t} . m_{B I G_{i t}}\left(m_{S M A L L_{i t}}\right)$ is a dummy variable equal to one if the family is increasing (decreasing) its housing holdings (i.e., moving to a bigger (smaller) house). HHMI is an indicator capturing periods of persistent high appreciation in house prices at U.S. state level. Standard errors are reported in parentheses. ${ }^{* * *}$ denotes significance at the $1 \%$ level, ${ }^{* *}$ at the $5 \%$ level, and ${ }^{*}$ at the $10 \%$ level. The regression includes year dummies. Source: PSID. Period: $1989-2005$.

\begin{tabular}{lc}
\hline & All years \\
\hline constant $\left(\gamma_{0}\right)$ & $2.198^{* * *}$ \\
& $(0.254)$ \\
$m_{B I G}\left(\gamma_{1}\right)$ & $3.186^{* * *}$ \\
& $(0.319)$ \\
$m_{S M A L L}\left(\gamma_{2}\right)$ & 0.404 \\
HHMI $\left(\gamma_{3}\right)$ & $(0.336)$ \\
& $-1.030^{* * *}$ \\
$m_{B I G} \times H H M I\left(\gamma_{4}\right)$ & $(0.203)$ \\
& $-2.726^{* * *}$ \\
$m_{S M A L L} \times H H M I\left(\gamma_{5}\right)$ & $(0.604)$ \\
& -0.893 \\
$\Delta$ Family & $(0.980)$ \\
& $-0.321^{* * *}$ \\
$\Delta$ Married & $(0.095)$ \\
& $3.611^{* * *}$ \\
$\Delta$ Employment & $(0.496)$ \\
& $0.705^{* * *}$ \\
Age $e_{y<30}$ & $(0.182)$ \\
Age $e_{30<y<40}$ & $6.735^{* * *}$ \\
& $(0.251)$ \\
Age $_{40<y<50}$ & $5.374^{* * *}$ \\
& $(0.189)$ \\
Age $_{50<y<60}$ & $4.623^{* * *}$ \\
Midwest & $(0.179)$ \\
& $2.429^{* * *}$ \\
South & $(0.196)$ \\
& $0.754^{* * *}$ \\
West & $(0.209)$ \\
& $1.676^{* * *}$ \\
$R^{2}$ & $(0.196)$ \\
Num. Obs. & $-0.491^{*}$ \\
& $(0.219)$ \\
\hline & 0.416 \\
& 17280 \\
\hline
\end{tabular}


Table 11: Test of Hypothesis 2b. Probit for the upgrading and downgrading of housing and Heckman selectivity model. Columns 1 and 3 report marginal effect estimates from the probit regressions for increasing and decreasing the amount of housing holdings. Columns 2 and 4 report estimates on the log of the adjustment $\ln \left(\bar{z}-z^{*}\right)$ for upgrading and $\ln \left(z^{*}-\underline{z}\right)$ for downgrading. HHMI is an indicator capturing periods of persistent high appreciation in house prices at U.S. state level. Standard errors are reported in parentheses. All the regressions include a constant and year dummies. ${ }^{* * *}$ denotes significance at the $1 \%$ level, ${ }^{* *}$ at the $5 \%$ level, and ${ }^{*}$ at the $10 \%$ level. Source: SIPP. Period: 1997-2005.

\begin{tabular}{|c|c|c|c|c|}
\hline & $\begin{array}{c}\text { Probability } \\
\text { Upward adjustment } \\
\operatorname{Pr}\left(D^{*}>0\right) \\
(1)\end{array}$ & $\begin{array}{c}\text { Size } \\
\begin{array}{c}\text { Upward adjustment } \\
\ln \left(\bar{z}-z^{*}\right)\end{array} \\
(2)\end{array}$ & $\begin{array}{c}\text { Probability } \\
\text { Downward adjustment } \\
\operatorname{Pr}\left(D^{*}>0\right) \\
(3)\end{array}$ & $\begin{array}{c}\text { Size } \\
\begin{array}{c}\text { Downward adjustment } \\
\ln \left(z^{*}-\underline{z}\right)\end{array} \\
(4)\end{array}$ \\
\hline$\tilde{z}$ & $\begin{array}{r}0.0004^{* * *} \\
(0.0000)\end{array}$ & & $\begin{array}{r}-0.0004^{* * *} \\
(0.0001)\end{array}$ & \\
\hline HHMI & $\begin{array}{r}0.0027^{* *} \\
(0.0012)\end{array}$ & $\begin{array}{r}-0.5993^{* * *} \\
(0.2002)\end{array}$ & $\begin{array}{r}-0.0020^{* * *} \\
(0.0008)\end{array}$ & $\begin{array}{r}-0.2172 \\
(0.1449)\end{array}$ \\
\hline$\Delta$ Family & $\begin{array}{r}0.0038^{* * *} \\
(0.0006)\end{array}$ & $\begin{array}{r}-0.4285^{* * *} \\
(0.0967)\end{array}$ & $\begin{array}{r}-0.0009^{* *} \\
(0.0005)\end{array}$ & $\begin{array}{r}0.3752^{* * *} \\
(0.0601)\end{array}$ \\
\hline$\Delta$ Married & $\begin{array}{r}0.0045 \\
(0.0043)\end{array}$ & $\begin{array}{r}-0.1686 \\
(0.5692)\end{array}$ & $\begin{array}{r}0.0218^{* * *} \\
(0.0050)\end{array}$ & $\begin{array}{r}1.7076^{* * *} \\
(0.5525)\end{array}$ \\
\hline$\Delta$ Employment & $\begin{array}{r}0.0034^{* *} \\
(0.0014)\end{array}$ & $\begin{array}{r}-0.2586 \\
(0.2247)\end{array}$ & $\begin{array}{r}0.0058^{* * *} \\
(0.0013)\end{array}$ & $\begin{array}{r}0.1571 \\
(0.1899)\end{array}$ \\
\hline $\operatorname{Age}_{y<30}$ & $\begin{array}{r}0.0383^{* * *} \\
(0.0038)\end{array}$ & $\begin{array}{r}-0.8666^{* *} \\
(0.3701)\end{array}$ & $\begin{array}{r}0.0132^{* * * *} \\
(0.0024)\end{array}$ & $\begin{array}{r}2.1391^{* * *} \\
(0.2287)\end{array}$ \\
\hline Age $_{30<y<40}$ & $\begin{array}{r}0.0274^{* * *} \\
(0.0021)\end{array}$ & $\begin{array}{r}-0.4313 \\
(0.3160)\end{array}$ & $\begin{array}{r}0.0062^{* * *} \\
(0.0012)\end{array}$ & $\begin{array}{r}1.8772^{* * *} \\
(0.1410)\end{array}$ \\
\hline Age $_{40<y<50}$ & $\begin{array}{r}0.0126^{* * *} \\
(0.0015)\end{array}$ & $\begin{array}{r}0.3936 \\
(0.2563)\end{array}$ & $\begin{array}{r}0.0038^{* * * *} \\
(0.0010)\end{array}$ & $\begin{array}{r}1.5645^{* * *} \\
(0.1203)\end{array}$ \\
\hline Age $_{50<y<60}$ & $\begin{array}{r}0.0071^{* * *} \\
(0.0015)\end{array}$ & $\begin{array}{r}0.6013^{* *} \\
(0.2628)\end{array}$ & $\begin{array}{r}0.0036^{* * *} \\
(0.0010)\end{array}$ & $\begin{array}{r}1.1182^{* * *} \\
(0.1288)\end{array}$ \\
\hline Midwest & $\begin{array}{r}0.0037^{* * *} \\
(0.0013)\end{array}$ & $\begin{array}{r}-0.3112 \\
(0.2193)\end{array}$ & $\begin{array}{r}0.0008 \\
(0.0009)\end{array}$ & $\begin{array}{r}0.5697^{* * *} \\
(0.1239)\end{array}$ \\
\hline West & $\begin{array}{r}0.0099^{* * * *} \\
(0.0016)\end{array}$ & $\begin{array}{r}-1.1554^{* * *} \\
(0.2324)\end{array}$ & $\begin{array}{r}0.0033^{* * * *} \\
(0.0011)\end{array}$ & $\begin{array}{r}0.4282^{* * *} \\
(0.1515)\end{array}$ \\
\hline South & $\begin{array}{r}0.0018 \\
(0.0011)\end{array}$ & $\begin{array}{r}-0.1812 \\
(0.2069)\end{array}$ & $\begin{array}{r}0.0022^{* *} \\
(0.0009)\end{array}$ & $\begin{array}{r}0.7181^{* * *} \\
(0.1274)\end{array}$ \\
\hline$R^{2}$ & & 0.346 & & 0.265 \\
\hline Num. Obs. & 105813 & 1361 & 105813 & 537 \\
\hline
\end{tabular}


Table 12: Test of Hypothesis 3 - PSID. Coefficients estimated using a standard OLS model and ex-ante (i.e., before moving) values of the ratio of total risky stock holdings relative to financial wealth, $\Theta_{i t} / W_{i t} . m_{B I G_{i t}}$ $\left(m_{S M A L L_{i t}}\right)$ is a dummy variable equal to one if the family is increasing (decreasing) its housing holdings (i.e., moving to a bigger (smaller) house). Standard errors are reported in parentheses. ${ }^{* * *}$ denotes significance at the $1 \%$ level, ** at the $5 \%$ level, and ${ }^{*}$ at the $10 \%$ level. The pooled regressions include year dummies. Source: PSID. Period: $1984-2005$.

\begin{tabular}{|c|c|c|c|c|c|c|c|c|}
\hline & All & 1984 & 1989 & 1994 & 1999 & 2001 & 2003 & 2005 \\
\hline \multirow[t]{2}{*}{ constant $\left(\gamma_{0}\right)$} & $0.081^{* * *}$ & $0.050^{* * *}$ & $0.064^{* * *}$ & $0.128^{* * *}$ & $0.197^{* * *}$ & $0.185^{* * *}$ & $0.157^{* * *}$ & $0.187^{* * *}$ \\
\hline & $(0.006)$ & $(0.006)$ & $(0.007)$ & $(0.012)$ & $(0.013)$ & $(0.012)$ & $(0.019)$ & $(0.012)$ \\
\hline \multirow[t]{2}{*}{$m_{B I G}\left(\gamma_{1}\right)$} & $0.030 * * *$ & -0.008 & $0.037^{* *}$ & $0.089^{* * *}$ & $0.035^{*}$ & $0.035^{*}$ & 0.016 & $0.042^{* *}$ \\
\hline & $(0.007)$ & $(0.009)$ & $(0.012)$ & $(0.021)$ & $(0.018)$ & $(0.015)$ & $(0.022)$ & $(0.014)$ \\
\hline \multirow[t]{2}{*}{$m_{S M A L L}\left(\gamma_{2}\right)$} & 0.006 & -0.007 & 0.017 & -0.000 & -0.008 & 0.031 & 0.037 & -0.021 \\
\hline & $(0.010)$ & $(0.017)$ & $(0.023)$ & $(0.035)$ & $(0.027)$ & $(0.022)$ & $(0.039)$ & $(0.021)$ \\
\hline \multirow[t]{2}{*}{$\Delta$ Family } & 0.003 & 0.001 & $0.010^{*}$ & 0.008 & 0.008 & 0.005 & -0.003 & 0.000 \\
\hline & $(0.002)$ & $(0.003)$ & $(0.004)$ & $(0.008)$ & $(0.006)$ & $(0.005)$ & $(0.009)$ & $(0.005)$ \\
\hline \multirow[t]{2}{*}{$\Delta$ Married } & -0.004 & -0.010 & -0.043 & -0.056 & 0.005 & -0.039 & 0.045 & 0.024 \\
\hline & $(0.013)$ & $(0.018)$ & $(0.025)$ & $(0.040)$ & $(0.030)$ & $(0.029)$ & $(0.044)$ & $(0.027)$ \\
\hline \multirow[t]{2}{*}{$\Delta$ Employment } & $-0.030 * * *$ & -0.006 & -0.011 & $-0.025^{*}$ & $-0.034^{* *}$ & $-0.031^{* *}$ & $-0.055^{* *}$ & $-0.033^{* *}$ \\
\hline & $(0.004)$ & $(0.005)$ & $(0.006)$ & $(0.011)$ & $(0.013)$ & $(0.011)$ & $(0.019)$ & (0.011) \\
\hline \multirow[t]{2}{*}{$A g e_{y<30}$} & $-0.070^{* * *}$ & $-0.019 * *$ & $-0.027^{* *}$ & $-0.060^{* * *}$ & $-0.105^{* * *}$ & $-0.084^{* * *}$ & $-0.093^{* * *}$ & $-0.096^{* * *}$ \\
\hline & $(0.006)$ & $(0.007)$ & $(0.009)$ & $(0.016)$ & $(0.017)$ & $(0.016)$ & $(0.025)$ & (0.014) \\
\hline \multirow[t]{2}{*}{$A g e_{30}<y<40$} & $-0.040 * * *$ & -0.001 & $-0.018^{* *}$ & -0.020 & $-0.049 * * *$ & $-0.058 * * *$ & $-0.053^{* *}$ & $-0.069 * * *$ \\
\hline & $(0.005)$ & $(0.006)$ & $(0.007)$ & $(0.011)$ & $(0.012)$ & $(0.012)$ & $(0.019)$ & $(0.012)$ \\
\hline \multirow[t]{2}{*}{$\mathrm{Age}_{40<y<50}$} & $-0.021^{* * *}$ & -0.010 & -0.011 & 0.001 & -0.010 & $-0.030 * *$ & -0.032 & $-0.045^{* * *}$ \\
\hline & $(0.005)$ & $(0.007)$ & $(0.007)$ & $(0.011)$ & $(0.011)$ & $(0.011)$ & $(0.017)$ & (0.011) \\
\hline \multirow[t]{2}{*}{$A g e_{50}<y<60$} & 0.002 & 0.007 & -0.006 & 0.007 & 0.003 & 0.004 & -0.005 & -0.004 \\
\hline & $(0.005)$ & $(0.006)$ & $(0.008)$ & $(0.013)$ & $(0.013)$ & $(0.012)$ & $(0.018)$ & $(0.011)$ \\
\hline \multirow[t]{2}{*}{ Midwest } & -0.007 & -0.003 & $0.016^{*}$ & -0.009 & -0.015 & -0.014 & 0.007 & $-0.024^{*}$ \\
\hline & $(0.005)$ & $(0.006)$ & $(0.008)$ & $(0.012)$ & $(0.013)$ & $(0.012)$ & $(0.019)$ & $(0.012)$ \\
\hline \multirow[t]{2}{*}{ South } & $-0.038^{* * *}$ & $-0.025 * * *$ & $-0.014^{*}$ & $-0.040^{* * *}$ & $-0.067 * * *$ & $-0.051^{* * *}$ & -0.018 & $-0.046^{* * *}$ \\
\hline & $(0.005)$ & $(0.006)$ & $(0.007)$ & $(0.012)$ & $(0.012)$ & $(0.012)$ & $(0.018)$ & (0.011) \\
\hline \multirow[t]{2}{*}{ West } & -0.010 & -0.001 & 0.008 & -0.007 & -0.027 & -0.006 & 0.012 & $-0.038^{* *}$ \\
\hline & $(0.005)$ & $(0.007)$ & $(0.008)$ & $(0.014)$ & $(0.014)$ & $(0.014)$ & $(0.021)$ & $(0.013)$ \\
\hline$R^{2}$ & 0.206 & 0.121 & 0.169 & 0.216 & 0.285 & 0.279 & 0.122 & 0.265 \\
\hline Num. Obs. & 20172 & 2491 & 2582 & 2459 & 3078 & 3191 & 3190 & 3181 \\
\hline
\end{tabular}


Table 13: Test of Hypothesis 3 - SIPP. Coefficients estimated using a standard OLS model and ex-ante (i.e., before moving) values of the ratio of total risky stock holdings relative to financial wealth, $\Theta_{i t} / W_{i t} . m_{B I G_{i t}}$ $\left(m_{S M A L L_{i t}}\right)$ is a dummy variable equal to one if the family is increasing (decreasing) its housing holdings (i.e., moving to a bigger (smaller) house). Standard errors are reported in parentheses. ${ }^{* * *}$ denotes significance at the $1 \%$ level, ${ }^{* *}$ at the $5 \%$ level, and ${ }^{*}$ at the $10 \%$ level. The pooled regressions include year dummies. Source: SIPP. Period: 1997-2005

\begin{tabular}{|c|c|c|c|c|c|c|c|}
\hline & All & 1997 & 1998 & 1999 & 2002 & 2003 & 2005 \\
\hline \multirow[t]{2}{*}{ constant $\left(\gamma_{0}\right)$} & $0.097^{* * *}$ & $0.138^{* * *}$ & $0.141^{* * *}$ & $0.157^{* * *}$ & $0.150^{* * *}$ & $0.148^{* * *}$ & $0.137^{* * *}$ \\
\hline & $(0.027)$ & $(0.006)$ & $(0.006)$ & $(0.007)$ & $(0.008)$ & $(0.008)$ & $(0.006)$ \\
\hline \multirow[t]{2}{*}{$m_{B I G}\left(\gamma_{1}\right)$} & $0.041^{* * *}$ & $0.055^{* *}$ & $0.052^{* *}$ & $0.075^{* * *}$ & 0.017 & 0.022 & $0.032^{*}$ \\
\hline & $(0.008)$ & $(0.019)$ & $(0.018)$ & $(0.019)$ & $(0.022)$ & $(0.021)$ & $(0.016)$ \\
\hline \multirow[t]{2}{*}{$m_{S M A L L}\left(\gamma_{2}\right)$} & $-0.032^{* *}$ & -0.006 & -0.017 & $-0.072^{* *}$ & -0.033 & -0.046 & -0.022 \\
\hline & $(0.011)$ & $(0.025)$ & $(0.026)$ & $(0.028)$ & $(0.028)$ & $(0.031)$ & $(0.024)$ \\
\hline \multirow[t]{2}{*}{$\Delta$ Family } & $0.005^{* *}$ & $0.010^{*}$ & $0.024^{* * *}$ & -0.000 & -0.005 & -0.004 & 0.002 \\
\hline & $(0.002)$ & $(0.005)$ & $(0.005)$ & $(0.006)$ & $(0.006)$ & $(0.007)$ & $(0.004)$ \\
\hline \multirow[t]{2}{*}{$\Delta$ Married } & -0.009 & -0.020 & -0.018 & -0.018 & -0.024 & -0.022 & 0.025 \\
\hline & $(0.010)$ & $(0.022)$ & $(0.023)$ & $(0.031)$ & $(0.024)$ & $(0.033)$ & $(0.019)$ \\
\hline \multirow[t]{2}{*}{$\Delta$ Employment } & $-0.016^{* * *}$ & -0.022 & -0.006 & 0.010 & $-0.030 * * *$ & $-0.020^{*}$ & $-0.017^{*}$ \\
\hline & $(0.004)$ & $(0.012)$ & $(0.011)$ & $(0.012)$ & $(0.009)$ & $(0.010)$ & $(0.007)$ \\
\hline \multirow[t]{2}{*}{$A g e_{y<30}$} & $0.011^{*}$ & -0.002 & $-0.063^{* * *}$ & -0.002 & $0.050 * * *$ & $0.050 * * *$ & $0.032^{* * *}$ \\
\hline & $(0.005)$ & $(0.010)$ & (0.011) & $(0.012)$ & $(0.012)$ & $(0.013)$ & (0.009) \\
\hline \multirow[t]{2}{*}{$A g e_{30}<y<40$} & $0.069^{* * *}$ & $0.056^{* * *}$ & 0.003 & $0.069^{* * *}$ & $0.092^{* * *}$ & $0.082^{* * *}$ & $0.110^{* * *}$ \\
\hline & $(0.003)$ & $(0.007)$ & $(0.007)$ & $(0.007)$ & $(0.008)$ & $(0.008)$ & $(0.006)$ \\
\hline \multirow[t]{2}{*}{ Age $40<y<50$} & $0.076^{* * *}$ & $0.066^{* * *}$ & $0.016^{*}$ & $0.074^{* * *}$ & $0.102^{* * *}$ & $0.088^{* * *}$ & $0.105^{* * *}$ \\
\hline & $(0.003)$ & $(0.006)$ & $(0.006)$ & $(0.007)$ & $(0.007)$ & $(0.008)$ & $(0.006)$ \\
\hline \multirow[t]{2}{*}{$\operatorname{Age}_{50<y<60}$} & $0.075^{* * *}$ & $0.061^{* * *}$ & $0.030 * * *$ & $0.070^{* * *}$ & $0.106^{* * *}$ & $0.087^{* * *}$ & $0.092^{* * *}$ \\
\hline & (0.003) & $(0.007)$ & (0.007) & (0.007) & $(0.008)$ & $(0.008)$ & $(0.006)$ \\
\hline \multirow[t]{2}{*}{ Midwest } & $0.021^{* * *}$ & 0.008 & 0.004 & 0.007 & $0.031^{* * *}$ & $0.030 * * *$ & $0.042^{* * *}$ \\
\hline & $(0.003)$ & (0.007) & $(0.007)$ & (0.008) & $(0.008)$ & (0.009) & $(0.007)$ \\
\hline \multirow[t]{2}{*}{ South } & $-0.020 * * *$ & $-0.025^{* * *}$ & $-0.018^{* *}$ & $-0.034^{* * *}$ & $-0.022^{* *}$ & -0.013 & -0.008 \\
\hline & $(0.003)$ & $(0.007)$ & $(0.007)$ & $(0.007)$ & $(0.008)$ & $(0.008)$ & $(0.006)$ \\
\hline \multirow[t]{2}{*}{ West } & $-0.008^{*}$ & -0.002 & 0.004 & -0.001 & -0.017 & $-0.024 * *$ & -0.009 \\
\hline & $(0.003)$ & $(0.008)$ & $(0.008)$ & $(0.008)$ & $(0.009)$ & $(0.009)$ & $(0.007)$ \\
\hline$R^{2}$ & 0.261 & 0.232 & 0.179 & 0.273 & 0.284 & 0.263 & 0.314 \\
\hline Num. Obs. & 105154 & 18322 & 17086 & 16386 & 15564 & 15319 & 22477 \\
\hline
\end{tabular}


Table 14: Test of Hypothesis 4 - IV Estimates. Columns (1) - (4) report OLS estimates of the first stage effect of the house price index in the year of purchase, the house price index in the current year and the interactions between these two indices and HHMI on the house value, home equity and the interactions between the HHMI and the house value and home equity. Column (5) reports estimates of the effect of these variables and $H H M I$ on stock share of liquid wealth without including retirement assets in the stock holdings. Column (6) reports estimates of the effect of these variables and HHMI on an indicator for holding stocks. All specifications include the following set of controls: fixed effects of state residence, household head's age, current year, and the year of purchase, as well as 10-piece linear spline for liquid wealth, income, and number of children below 15 years. Standard errors are reported in parentheses. ${ }^{* * *}$ denotes significance at the $1 \%$ level, ${ }^{* *}$ at the $5 \%$ level, and ${ }^{*}$ at the $10 \%$ level. Source: SIPP. Period: $1997-2005$.

\begin{tabular}{|c|c|c|c|c|c|c|}
\hline & $\begin{array}{c}\text { House Value } \\
\text { (1) }\end{array}$ & $\begin{array}{c}\text { Home Equity } \\
\text { (2) }\end{array}$ & $\begin{array}{c}\text { House value } \\
\times H H M I \\
\text { (3) }\end{array}$ & $\begin{array}{c}\text { Home equity } \\
\times H H M I \\
\quad(4)\end{array}$ & $\begin{array}{c}\text { Stockshare } \\
\text { liquid wealth } \\
(5)\end{array}$ & $\begin{array}{c}\text { Stockholder } \\
\text { (6) }\end{array}$ \\
\hline $\begin{array}{l}\text { OFHEO state house price } \\
\text { index of year purchase (1) }\end{array}$ & $\begin{array}{r}-109.703 \\
(70.483)\end{array}$ & $\begin{array}{r}-557.959^{* * *} \\
(63.026)\end{array}$ & $\begin{array}{r}-22.024 \\
(48.995)\end{array}$ & $\begin{array}{r}158.493^{* * *} \\
(41.758)\end{array}$ & & \\
\hline $\begin{array}{l}\text { OFHEO state house price } \\
\text { index current year }(2)\end{array}$ & $\begin{array}{r}2289.516^{* * *} \\
(101.550)\end{array}$ & $\begin{array}{r}1837.614^{* * *} \\
(90.805)\end{array}$ & $\begin{array}{r}956.072^{* * *} \\
(70.590)\end{array}$ & $\begin{array}{r}420.418^{* * *} \\
(60.163)\end{array}$ & & \\
\hline $\begin{array}{l}(1) \times H H M I \\
(2) \times H H M I\end{array}$ & $\begin{array}{r}64.756 \\
(101.462) \\
-209.274^{* *} \\
(102.699)\end{array}$ & $\begin{array}{r}-214.393 * * \\
(90.727) \\
-109.653 \\
(91.832)\end{array}$ & $\begin{array}{r}-79.232 \\
(70.529) \\
1508.566^{* * *} \\
(71.389)\end{array}$ & $\begin{array}{r}-1968.013^{* * *} \\
(60.111) \\
1617.337^{* * *} \\
(60.844)\end{array}$ & & \\
\hline$H H M I$ & $\begin{array}{r}9531.251 \\
(9986.046)\end{array}$ & $\begin{array}{r}23718.845^{* * *} \\
(8929.453)\end{array}$ & $\begin{array}{r}73798.365^{* * *} \\
(6941.584)\end{array}$ & $\begin{array}{r}111318.538^{* * *} \\
(5916235)\end{array}$ & $\begin{array}{r}3.254 \\
(2593)\end{array}$ & $\begin{array}{r}0.024 \\
(0.047)\end{array}$ \\
\hline House value $(\times \$ 100000)$ & & & & & $\begin{array}{r}-2.165 \\
(2.594)\end{array}$ & $\begin{aligned}-0.090^{*} \\
(0.046)\end{aligned}$ \\
\hline Home equity $(\times \$ 100000)$ & & & & & $\begin{array}{r}2.974 \\
(2.767)\end{array}$ & $\begin{array}{r}0.082^{*} \\
(0.049)\end{array}$ \\
\hline $\begin{array}{l}\text { House value } \\
\times H H M I(\times \$ 100000)\end{array}$ & & & & & $\begin{array}{r}0.138 \\
(1.475)\end{array}$ & $\begin{array}{r}0.026 \\
(0.026)\end{array}$ \\
\hline $\begin{array}{l}\text { Home equity } \\
\times H H M I(\times \$ 100000)\end{array}$ & & & & & $\begin{array}{r}-2.690^{* *} \\
(1.255)\end{array}$ & $\begin{array}{r}-0.052^{* *} \\
(0.022)\end{array}$ \\
\hline$R^{2}$ & 0.422 & 0.321 & 0.717 & 0.571 & 0.166 & 0.262 \\
\hline Num. Obs. & 43977 & 43977 & 43977 & 43977 & 43977 & 43977 \\
\hline
\end{tabular}




\section{Appendices}

\section{A.1 Robustness for the Predictability in House Prices}

In this section, we present some robustness results for the predictability in house prices. The most common starting point to test the existence of predictability is Campbell and Shiller (1988). It presents the discounted identity that relates log-linearized stock returns with dividend price ratios and dividend growth

$$
p_{t}-d_{t}=\alpha+E_{t} \sum_{j=1}^{\infty} \rho^{j-1}\left(\Delta d_{t+k}-r_{t+j}\right)+E_{t} \lim _{j \rightarrow \infty}\left(p_{t+j}-d_{t+j}\right) .
$$

Price-rent ratios only move if they forecast future returns, if they forecast future rent growth, or if there is a bubble. There is a bubble when the price-rent ratio grows at a faster rate than the discount rate. Our analysis focuses on how future returns and rent growth rates are explained by current rent-price ratios, in the absence of bubbles for the sake of simplicity $[37$ The objective of this section is to motivate the time variation of expected housing returns and, in particular, to show the relation between the two-state model presented above and the traditional predictability regressions studied in the literature. In addition, we show that the predictability regressions on the rent-price ratio (or dividend-price ratio for stocks) support the hypothesis of a significantly higher degree of predictability of housing returns relative to stock returns. Equation (27) motivates the return predictability regression, which consists of regressing returns on the lagged price-rent ratio, or the dividend growth predictability, by regressing rent growth on lagged price-rent ratio

$$
r_{t+1}-\bar{r}=\kappa_{0}+\kappa_{r}\left(p_{t}-d_{t}\right)+\varepsilon_{t+1}^{r} \Delta d_{t+1}-\bar{d}=\kappa_{0}+\kappa_{d}\left(p_{t}-d_{t}\right)+\varepsilon_{t+1}^{d} .
$$

The price-rent ratios have been computed as in Campbell et al. (2009) using annualized quarterly data from 1978 to 2001 on house prices from the Federal Housing Finance Agency (FHFA) and

\footnotetext{
${ }^{37}$ Note that if the price dividend ratio is stationary, or bounded, or it does not explode faster than $\rho^{-1}$, then the last term disappears and we are back to equation (27). If we impose that there are no bubbles, this last term would be zero.
} 
rents from the Bureau of Labor Statistics (BLS). We use the annualized 3-month Treasury Bill as a risk-free rate to obtain excess returns. Returns are defined as the change in the house price index plus the rent-price ratio adjusted by the price growth.

Table 15 presents the results of the predictability regressions. We regress future housing returns, for different horizons, on current rent-price ratios. We observe that the rent-price ratio has a strong predictive power on future housing returns. The predictive power of rent-price ratios is stronger than that of price-dividends ratio in predicting stock returns. At the aggregate level, a 1\% variation in the rent-price ratio implies a $3.79 \%$ variation in a one-year horizon return. For longer horizons, results are even stronger. As we increase the horizon, the coefficient of the rent-price ratios, $\left(d_{t}-p_{t}\right)$, which forecasts future housing returns, becomes higher and more statistically significant 38 When forecasting 4- and 5-year returns, a $1 \%$ increase in rent-price ratios implies an increase of $41 \%$ and $46 \%$, respectively, in housing returns at the aggregate level. Similar results appear at the U.S. census macro region level. We also find that house price changes are more predictable than stock prices at all horizons for this particular sample. Table 15 shows that stock return predictability explained by price-dividend ratios is less than half the predictability that we observe in housing returns. The data used for stock predictability are the CRSP returns on the value-weighted market portfolio 39 Panel A in Table 15 uses the subsample data from 1926 to 2000, avoiding the last decade of bubble-like behavior. Panel B shows that including the 2000's decade does not erode the predictive power of price dividend ratios for future stock returns. This is not surprising, since market prices did not experience the same price growth as residential real estate markets did. The right-hand column of the table shows that rent growth rates do not predict future returns. This is the case for both housing and stock returns, reinforcing the idea that housing return predictability is due to movements in rent-price or dividend-price ratios, respectively. The evidence presented

\footnotetext{
${ }^{38}$ The explanation for this phenomenon, in the absence of the bubble term, is that the $\left(d_{t}-p_{t}\right)$ ratios are highly persistent. When estimating an $A R(1)$ to rent-price ratios for the sample, we cannot reject non-stationarity, supporting the idea of bubble-like behavior during the last few years. On the other hand, for the trimmed data set, the autocorrelation coefficient of the rent-price ratios series is 0.93 for annual data. Obviously, this results in a larger $R^{2}$ as well.

${ }^{39}$ NYSE/Amex/Nasdaq/Arca value-weighted market index. Dividend-price series are constructed from the returns and the ex-dividend returns series.
} 
in Table 15 and above motivates the assumption of predictability in housing returns and not in stock returns. We do observe evidence of stock return predictability to a lesser extent. Modeling stock returns with a predictable component results in an additional state variable. For the sake of simplicity, we refrain from doing so and we focus on the role of housing return predictability in portfolio choice and housing tenure decisions.

[INSERT TABLE 15 HERE]

Figure 7 shows the rent-price ratio, with a 4-year lead as the regressions suggest, and the probability of home price growth being in the high state. The sample size of the rent-price ratio is substantially shorter but for the period in which the two of them overlap, the peaks in the probability of the high state correspond to peaks in the rent-price ratio time series. The correlation is positive for most of the sample except for the last few observations. This is in line with the inability of the rent-price ratios to explain expected returns that may be explained only by future expected appreciation. Our partial-equilibrium approach does not allow us to address the origin of a bubble-like outcome.

\section{[INSERT FIGURE 7 HERE]}

Results are very similar at the Metropolitan Statistical Area (MSA) level. Interestingly, the predictability results do not hold if we include the last period of house price increases, or the housing bubble for the data set used in Table 15. We also show results with an alternative data source for which predictability results hold also for the full sample. In the full sample, including the last 7 years, price-rent ratios seem to follow non-stationary behavior which implies that the last term in equation (27) might not converge to zero fast enough. When current prices are explained by growing expectations of future prices, little power is left for price-dividend ratios or dividend growth to explain future price changes. Campbell, Giglio, and Polk (2010) present a similar argument justifying the exclusion of recent years. House price growth is serially correlated. The first order autocorrelation is $71.3 \%$. One could argue that most of the predictive power comes from the high 
autocorrelation of price growth and the low variation in rents may have a relatively low contribution to predictability.

To check the robustness of the data used for this analysis, we focus on two data sets. The first is from Campbell et al. (2009) and uses annualized quarterly data from 1978 to 2001 on house prices from the Federal Housing Finance Agency (FHFA) and rents from the Bureau of Labor Statistics (BLS). The second source for price-rent series is constructed with residential investment values in the Flow of Funds and rents from National Income and Product accounts. Both sets produce similar results for the sample used in the paper. In this Appendix, we show results for the entire sample, which includes the last 6 years, and we also present detailed results at the MSA level (only for the first data set, for which we have MSA level data available). Results are robust to the data set used, to the regional level considered, but not to the sample size. However, there is a sign change when we use data from the recent episode of house prices bubble. As we explain in section 2, this is due to the non-stationarity of rent-price ratio during the recent years. When current price growth is explained by future price growth, predictability power of rent-price ratio disappears.

Table 16 shows the results of the same predictability regressions in Table 15 with Flow of Funds and NIPA data.

\section{[INSERT TABLE 16 HERE]}

In Table 17 we use the entire sample available for both data sets. As mentioned above, there is a substantial change in the results when considering the last years of the housing bubble.

[INSERT TABLE 17 HERE]

Table 18 provides results at the MSA level. In general, each region shows results that are consistent with the aggregate results, except some exceptions such as Denver or Miami.

$$
\text { [INSERT TABLE } 18 \text { HERE] }
$$

Finally, Table 19 shows evidence of the loss of explanatory power when fluctuations in rents are ignored. The coefficient estimates show a significant decline with respect to those including rents 
in the predictive regression, which indicates that the main source of predictive power is not the high autocorrelation in price growth, but the dynamics of rent-price ratios.

[INSERT TABLE 19 HERE]

\section{A.2 Derivation of the Model}

\section{A.2.1 Model Without Transaction Costs $(\epsilon=0)$}

The value function is defined by

$$
\bar{V}(W(0), P(0), i)=\sup _{C, \Theta, H} E\left[\int_{0}^{\infty} e^{-\rho t} u(C, H) d t\right], \quad i=1, \ldots, n .
$$

The associated Hamilton-Jacobi-Bellman equation is the following in the regime $i$ :

$$
\rho \bar{V}(\cdot, i)=\sup _{C, \Theta, H}\left\{U(C, H)+\mathcal{D} \bar{V}(\cdot, i)+\sum_{i \neq j} \lambda_{i j}(\bar{V}(\cdot, j)-\bar{V}(\cdot, i))\right\}
$$

where

$$
\begin{aligned}
\mathcal{D} \bar{V}(\cdot, i) & =\left[r(W-H P)+\Theta\left(\alpha_{S}-r\right)+\left(\mu_{i}-\delta\right) H P-C\right] \bar{V}_{W}(\cdot, i) \\
& +\mu_{i} P_{t} \bar{V}_{P}(\cdot, i)+\frac{1}{2}\left(\Theta^{2} \sigma_{S}^{2}+2 H P \Theta \rho_{P S} \sigma_{S} \sigma_{P}+H^{2} P^{2} \sigma_{P}^{2}\right) \bar{V}_{W W}(\cdot, i) \\
& +\frac{1}{2} P^{2} \sigma_{P}^{2} \bar{V}_{P P}(\cdot, i)+\left(\Theta P \rho_{P S} \sigma_{S} \sigma_{P}+H P^{2} \sigma_{P}^{2}\right) \bar{V}_{W P}(\cdot, i), \quad i=1, \ldots, n
\end{aligned}
$$

We can use the homogeneity properties of the value function to reduce the problem with three state variables $(W, P, i)$ to one with two state variables, $x=W / P$ and $i$, since

$$
\bar{V}(W, P, i)=P^{\beta(1-\gamma)} \bar{V}\left(\frac{W}{P}, 1, i\right)=P^{\beta(1-\gamma)} \bar{v}(x, i), \quad i=1, \ldots, n .
$$


Let us introduce the scaled controls $\bar{c}=C / P$ and $\bar{\theta}=\Theta / P$. Substituting and simplifying we obtain

$$
\bar{\rho}_{i} \bar{v}(x, i)=\sup _{\bar{c}, \bar{\theta}, H}\left\{U(\bar{c}, H)+\mathcal{D} \bar{v}(x, i)+\sum_{i \neq j} \lambda_{i j}(\bar{v}(x, j)-\bar{v}(x, i))\right\},
$$

where

$$
\begin{aligned}
\mathcal{D} \bar{v}(x, i)= & \left((x-H)\left(r-\mu_{i}+\sigma_{P}^{2}(1+\beta(\gamma-1))\right)+\bar{\theta}\left(\alpha_{S}-r-(1+\beta(\gamma-1)) \rho_{P S} \sigma_{S} \sigma_{P}\right)-\bar{c}\right) \bar{v}_{x}(x, i) \\
& +\frac{1}{2}\left((x-H)^{2} \sigma_{P}^{2}-2(x-H) \bar{\theta} \rho_{P S} \sigma_{P} \sigma_{S}+\bar{\theta}^{2} \sigma_{S}^{2}\right) \bar{v}_{x x}(x, i), \quad i=1, \ldots, n .
\end{aligned}
$$

Let

$$
\bar{\rho}_{i}=0.5\left(-2 \rho+\beta(-1+\gamma)\left(-2 \alpha_{i}+(1+\beta(\gamma-1)) \sigma_{P}^{2}\right), \quad i=1, \ldots, n\right.
$$

We derive explicit expressions for both the value function and the optimal policies. We first guess that the optimal controls are given by

$$
\bar{c}^{*}(x, i)=\alpha_{c, i} x, \quad H^{*}(x, i)=\alpha_{h, i} x / P, \quad \bar{\theta}^{*}(x, i)=\alpha_{\theta, i} x
$$

and the value function for the no transaction costs problem is given by

$$
\bar{v}(x, i)=\alpha_{v, i} \frac{x_{t}^{1-\gamma}}{1-\gamma}
$$

where $i=1, \ldots, n$. Then, we verify that the value function and the candidate control policies are the optimal policies for the no transaction costs case.

\section{A.2.2 Model With Transaction Costs $(\epsilon>0)$}

The value function is defined by

$V(W(0), P(0), H(0), i)=\sup _{C, \Theta, H(\tau), \tau} E\left[\int_{0}^{\tau} e^{-\rho t} u(C, H) d t+e^{-\rho \tau} V(W(\tau), P(\tau), H(\tau), i)\right], \quad i=1, \ldots, n$. 
We first solve the problem in the inaction region and then we try to characterize the upper and lower bounds of the inaction region and the optimal return point between them. The associated Hamilton-Jacobi-Bellman equation in the regime $i$ is the following 40

$$
\rho V(\cdot, l)=\sup _{C, \Theta}\left\{U(C, H)+\mathcal{D} V(\cdot, i)+\sum_{i \neq j} \lambda_{i j}(V(\cdot, j)-V(\cdot, i))\right\},
$$

where

$$
\begin{aligned}
\mathcal{D} V(\cdot, i) & =\left[r(W-H P)+\Theta\left(\alpha_{S}-r\right)+\left(\mu_{i}-\delta\right) H P-C\right] V_{W}(\cdot, i) \\
& +\mu_{i} P V_{P}(\cdot, i)-\delta H V_{H}(\cdot, i)+\frac{1}{2}\left(\Theta^{2} \sigma_{S}^{2}+2 H P \Theta \rho_{P S} \sigma_{S} \sigma_{P}+H^{2} P^{2} \sigma_{P}^{2}\right) V_{W W}(\cdot, i) \\
& +\frac{1}{2} P^{2} \sigma_{P}^{2} V_{P P}(\cdot, i)+\left(\Theta P \rho_{P S} \sigma_{S} \sigma_{P}+H P^{2} \sigma_{P}^{2}\right) V_{W P}(\cdot, i), \quad i=1, \ldots, n .
\end{aligned}
$$

The component $\lambda_{i j}(V(\cdot, j)-V(\cdot, i))$ reflects the impact of the house price drift switch on the value functions. This term is the product of the instantaneous probability of a regime shift and the change in value function occurring after a regime switch. We can use the homogeneity properties of the value function to reduce the problem with four state variables $(W, P, H, i)$ to one with two state variables, $z=W /(P H)$ and $i$ since

$$
V(W, P, H, i)=H^{1-\gamma} P^{\beta(1-\gamma)} V\left(\frac{W}{P H}, 1,1, i\right)=H^{1-\gamma} P^{\beta(1-\gamma)} v(z, i), \quad i=h, l .
$$

Let us introduce the scaled controls $\hat{c}=C /(P H)$ and $\hat{\theta}=\Theta /(P H)$. Substituting and simplifying, we obtain

$$
\widetilde{\rho}_{i} v(z, i)=\sup _{\hat{c}, \hat{\theta}}\left\{u(\hat{c})+\mathcal{D} v(z, i)+\sum_{i \neq j} \lambda_{i j}(v(z, j)-v(z, i))\right\},
$$

where

$$
u(\hat{c})=\frac{\hat{c}^{\beta(1-\gamma)}}{1-\gamma},
$$

\footnotetext{
${ }^{40}$ Thereafter, the notation $V(\cdot, i)$ refers to $V(W, P, H, i)$.
} 


$$
\begin{aligned}
\mathcal{D} v(z, i)= & \left((z-1)\left(r+\delta-\mu_{i}+\sigma_{P}^{2}(1+\beta(\gamma-1))\right)\right. \\
& \left.+\hat{\theta}\left(\alpha_{S}-r-(1+\beta(\gamma-1)) \rho_{P S} \sigma_{S} \sigma_{P}\right)-\hat{c}\right) v_{z}(z, i) \\
& +\frac{1}{2}\left((z-1)^{2} \sigma_{P}^{2}-2(z-1) \hat{\theta} \rho_{P S} \sigma_{P} \sigma_{S}+\hat{\theta}^{2} \sigma_{S}^{2}\right) v_{z z}(z, i), \quad i=1, \ldots, n .
\end{aligned}
$$

Let

$$
\widetilde{\rho}_{i}=0.5\left(-2 \rho-2(\gamma-1)\left(\mu_{i}-\delta+\beta(\gamma-1)(1+\beta(\gamma-1)) \sigma_{P}^{2}\right), \quad i=1, \ldots, n\right.
$$

The first-order conditions are

$$
\begin{aligned}
& \hat{c}^{*}(z, i)=\left(\frac{v_{z}(z, i)}{\beta}\right)^{1 /(\beta(1-\gamma)-1)}, \\
& \hat{\theta}^{*}(z, i)=-\left(\alpha_{S}-r\right) \frac{v_{z}(z, i)}{\sigma_{S}^{2} v_{z z}(z, i)}-(1-\beta(1-\gamma)) \rho_{P S} \sigma_{P} \frac{v_{z}(z, i)}{\sigma_{S}^{2} v_{z z}(z, i)}+(z-1) \frac{\rho_{P S} \sigma_{P}}{\sigma_{S}},
\end{aligned}
$$

for $i=1, \ldots, n$.

We need to identify the properties of the inaction region. It follows from 38 that

$V(W(0), P(0), H(0), i)=$

$\sup _{C, \Theta, H(\tau), \tau} E\left[\int_{0}^{\tau} e^{-\rho \tau} u\left(C, H(0) e^{-\delta t}\right) d t+e^{-\rho \tau} V\left(W\left(\tau^{-}\right)-\epsilon P(\tau) H\left(\tau^{-}\right), P(\tau), H(\tau), i\right)\right], \quad i=1, \ldots, n$.

We get

$$
\begin{aligned}
& P(0)^{\beta(1-\gamma)} H(0)^{1-\gamma} v(z(0), i)= \\
& \sup _{\hat{c}, \hat{\theta}, H(\tau), \tau} E\left[\int_{0}^{\tau} e^{-\rho \tau} \frac{P(\tau)^{\beta(1-\gamma)}\left(\hat{c} H(0) e^{-\delta t}\right)^{1-\gamma}}{1-\gamma} d t+e^{-\rho \tau} P(\tau)^{\beta(1-\gamma)} H(\tau)^{1-\gamma} v(z(\tau), i)\right], \quad i=1, \ldots, n .
\end{aligned}
$$


Following Damgaard, Fuglsbjerg, and Munk (2003), let

$$
\begin{array}{r}
e^{-\rho \tau} P(\tau)^{\beta(1-\gamma)} H(\tau)^{1-\gamma} v(z(\tau), i)= \\
e^{-\rho \tau} P(\tau)^{\beta(1-\gamma)} H\left(\tau^{-}\right)^{1-\gamma}\left(\frac{H\left(\tau^{-}\right)}{H(\tau)}\right)^{\gamma-1} v\left(\frac{W\left(\tau^{-}\right)-\epsilon P(\tau) H\left(\tau^{-}\right)}{P(\tau) H(\tau)}, i\right)= \\
e^{-\rho \tau} P(\tau)^{\beta(1-\gamma)} H\left(\tau^{-}\right)^{1-\gamma}\left(\frac{H\left(\tau^{-}\right)}{H(\tau)}\right)^{\gamma-1} v\left(\frac{H\left(\tau^{-}\right)}{H(\tau)}\left(\frac{W\left(\tau^{-}\right)}{P(\tau) H\left(\tau^{-}\right)}-\epsilon\right), i\right)
\end{array}
$$

and we can derive

$e^{-\rho \tau} P(\tau)^{\beta(1-\gamma)}\left(H(0) e^{-\delta \tau}\right)^{1-\gamma}\left(z\left(\tau^{-}\right)-\epsilon\right)^{1-\gamma}\left(\frac{H\left(\tau^{-}\right)}{H(\tau)}\left(z\left(\tau^{-}\right)-\epsilon\right)\right)^{\gamma-1} v\left(\frac{H\left(\tau^{-}\right)}{H(\tau)}\left(z\left(\tau^{-}\right)-\epsilon\right), i\right)$

for $i=1, \ldots, n$. Let us re-express our Bellman equation

$$
\begin{aligned}
& P^{\beta(1-\gamma)} v(z(0), i)= \\
& \sup _{\bar{c}, \bar{\theta}, \tau} E\left[\int_{0}^{\tau} e^{-\hat{\rho} \tau} \frac{P(\tau)^{\beta(1-\gamma)} \bar{c}^{1-\gamma}}{1-\gamma} d t+e^{-\hat{\rho} \tau} P(\tau)^{\beta(1-\gamma)} M_{i} \frac{\left(z\left(\tau^{-}\right)-\epsilon\right)^{1-\gamma}}{1-\gamma}\right],
\end{aligned}
$$

where

$$
\begin{aligned}
M_{i} & =\sup _{H(\tau) \leq H e^{-\delta \tau}\left(z\left(\tau^{-}\right) \epsilon\right) / \epsilon}(1-\gamma)\left(\frac{H\left(\tau^{-}\right)}{H(\tau)}\left(z\left(\tau^{-}\right)-\epsilon\right)\right)^{\gamma-1} v\left(\frac{H\left(\tau^{-}\right)}{H(\tau)}\left(z_{\tau-}-\epsilon\right), i\right) \\
& =(1-\gamma) \sup _{z \geq \epsilon} z^{\gamma-1} v(z, i), \quad i=1, \ldots, n,
\end{aligned}
$$

and $\hat{\rho}=\rho+\delta(1-\gamma)$.

\section{A.2.3 Algorithm for the Numerical Resolution}

We modify the Grossman Laroque algorithm to solve our problem. The algorithm is a stepwise numerical procedure to find the optimal values $\left(M_{i}, \underline{z}_{i}, \bar{z}_{i}, z_{i}^{*}\right)$ for $i=1, \ldots, n$ :

1. Guess $M_{i}=M_{i, 0}$ for $i=1, \ldots, n$. 
2. Solve the free bound problem as follows:

(i) Guess $\underline{z}_{i, 0}$ for $i=1, \ldots, n$;

(ii) Solve the ODEs Eq. 10 using as initial conditions the four equations defined by Eq. 15 until the value-matching conditions are satisfied. We adopt a finite difference scheme to solve the system of ODEs;

(iii) If the smooth pasting conditions specified by Eq. (16) are satisfied, then the candidate value functions $v_{M_{i, 0}}(z, i)$ for $i=1, \ldots, n$ are found, otherwise repeat steps (i) and (ii).

3. Compute the implied $M_{i, 0}^{*}=(1-\gamma) \sup _{z} z^{\gamma-1} v_{M_{i, 0}}(z, i)=(1-\gamma) z_{i}^{*(\gamma-1)} v\left(z_{i}^{*}, i\right)$ using Eq. (13). If $M_{i, 0}^{*}=M_{i, 0}$ for each $i=1, \ldots, n$, the problem is solved, otherwise go to step 1 .

As a starting point, we use the solution to the problem of no transaction costs, $\epsilon=0$. That solution consists of the optimal housing-to-wealth ratio $\alpha_{h, i}$, the optimal risky assets ratio $\alpha_{\theta, i}$ and the optimal numeraire consumption ratio $\alpha_{c, i}$, for $i=1, \ldots, n$. The first set of iterations uses a fixed portfolio policy. For initial values of $M_{i}$ and $z_{i}^{*}$, we use $M_{i}=\alpha_{v, i}$ and $z_{i}^{*}=1 / \alpha_{h, i}$, where $i=1, \ldots, n$. However, there is little to guide the initial estimations about $\underline{z}_{i}$ and $\bar{z}_{i}$, except to require $\underline{z}_{i}<z_{i}^{*}$ and $\bar{z}_{i}>z_{i}^{*}$. After the iterative procedure has converged, the solution is used to construct

an approximation to the policy function $\hat{\theta}^{*}(z, i)$. Then, we adopt a value iteration procedure to obtain $\left(\underline{z}_{i}, \bar{z}_{i}, M_{i}, z_{i}^{*}\right)$ for $i=1, \ldots, n$.

\section{A.3 Sensitivity Analysis}

Table 20 presents a sensitivity analysis of the model. It shows the sensitivity of three key variables of the model $\left(\underline{z}_{i}, z_{i}^{*}, \bar{z}_{i}\right)$ to four scenarios with deviations of four parameters from the benchmark model. Moreover, Column (4) is the optimal housing-to-wealth ratio without transaction costs, $\alpha^{h}(i)$, and Column (5) is the corresponding ratio with transaction costs immediately after a housing purchase, $1 / z_{i}^{*}$. Column (6) is the relative risk aversion just after housing purchase, $R R A\left(z_{i}^{*}\right)$, and Column (7) is the average holding of the risky asset, estimated just after a housing purchase, $E\left(\hat{\theta}^{*}\left(z^{*}, i\right) / z_{i}^{*}\right) / E\left(\tau_{i}\right)$. 


\section{[INSERT TABLE 20 HERE]}

Scenario A illustrates how a change in the correlation between the house price and the risky asset affects the optimal behavior. The optimal level $z_{i}^{*}$ decreases in both regimes, meaning that

housing consumption increases. In addition, the lower and upper bounds decrease as well. As the correlation decreases, housing becomes more effective as a hedge to diversify away the stock market risk, which leads to an increase in housing holdings. Furthermore, holding risky assets becomes more attractive. In scenario B, we consider the sensitivity of our results to changes in the transaction costs parameter $\epsilon$. We find that a rise in transaction costs tends to widen the inaction region and shift it to the right in both regimes. Increasing $\epsilon$ also decreases the optimal housing holding. In scenario $\mathrm{C}$, we vary the curvature coefficient $\gamma$ from 2 to 3 . As expected, the average holding of risky assets falls from 0.730 to 0.536 in the high regime and from 1.098 to 0.730 in the low regime; it is only substantially lower than the benchmark case in the high regime. Scenario D shows that a decrease in house price volatility $\sigma_{P}$ leads to a narrower inaction region and a substantial increase in housing consumption. Moreover, housing is quite attractive for investment purposes in the high regime, decreasing the average holding of risky assets from 0.730 to 0.629 .

\section{A.4 Estimation of the "Hot Housing Market Indicator" (HHMI)}

This Appendix provides a detailed description of the "Hot Housing Market Indicator" (HHMI). To capture periods of persistent high appreciation in house prices at U.S. state level, we introduce this as a binary variable that is calculated using the estimated smooth probabilities from the Markovswitching model on real housing returns using the quarterly house price indexes for each state and the U.S. aggregate. To go from these estimated probabilities to a binary variable, we assume that the binary variable $H H M I_{k t}$ for the U.S. state $k$ (i.e., $k=$ California) at time $t$ is equal to 1 when the following two conditions hold:

1. the smooth probability of being in the regime associated with the highest expected real housing return of the U.S. state $k$ is higher than its historical average plus half of its historical 
standard deviation in $t, t-1, t-2$ and $t-3$ (four quarters in a row);

2. the real housing return of the state $k$ is higher than the expected real housing return in the high-growth regime of U.S. aggregate in $t, t-1, t-2$ and $t-3$ (same four quarters of point 1).

The HHMI is based on these two conditions because they embed two specific pieces of information. The first condition captures the likelihood that there has been a regime switch in the U.S. state $k$ based on a turning point probability. We define the turning point probability when the estimated smooth probability reaches a $90 \%$ statistical level. The logic underlying the first condition is to detect whether a housing market peak relative to its historical average in the state $k$ has been reached and it has lasted at least four quarters in a row.

Ideally, to infer the smooth probability of being in the regime with the highest expected real housing return, the longest time series should be used. We estimate the Markov switching model on the housing price indexes (HPI) published by the Office of Federal Housing Enterprise Oversight (OFHEO) at U.S. state level. The index is a weighted repeat sales index that measures average price changes in repeat sales or refinancing on the same properties and weights them. The price information is obtained from repeat mortgage transactions on single-family properties whose mortgages have been purchased or securitized by Fannie Mae or Freddie Mac since the first quarter of 1975. While the housing price data has been criticized for its construction, to our knowledge it is the best data available to the public at the state level. Subsequently, we work with the growth rates of the housing price data, so issues related to bias in the level estimates are not relevant. The house price indexes data are nominal. We deflate the data using core PCE inflation, which measures inflation in the personal consumption expenditure basket less food and energy.

The house price indexes are available from 1975, but in our estimation we use only data beginning in the first quarter of 1986 for some U.S. states. Figure 1 shows that HPI data at state level are extremely noisy for a number of states before the mid-eighties. From the perspective of the Markov switching model, the noise in the series is not necessarily a problem in terms of estimation, but makes the regime classification uninformative when the time variation is very large, as 
is the case for the HPI data. The noise abates considerably for most states after the mid-eighties. Therefore, we estimate the Markov switching model on the subsample 1986(1) - 2010(4) for some U.S. states using a volatility threshold criteria. If the house price index volatility of a U.S. state in the subsample 1975(1) - 1985(4) is double the house price index volatility of the same U.S. state in the subsample 1986(1) - 2010(4), we estimate the Markov switching model on the subsample 1986(1) - 2010(4) for that U.S. state. We have checked our results for robustness by (i) changing the volatility threshold; and (ii) moving the start date to the first quarter of 1985, and have found that the results are robust.

\section{[INSERT FIGURE 8 HERE]}

An important issue in estimating regime switching models is specifying the number of regimes. This is often difficult to determine from data and as far as possible the choice should be based on economic arguments (see Ang and Timmermann (2011)). It is not uncommon to simply fix the number of regimes at some value, typically two or three, rather than basing the decision on econometric tests. The reason is that tests for the number of regimes are typically difficult to implement because they do not follow standard distributions. Because we aim to infer periods where house prices grew markedly at U.S. state level and house price indexes have recently experienced a sharp appreciation immediately followed by a sharp depreciation, we estimate a 3-regime specification. In this case, the growth of house prices in each regime $i$ is denoted by $\mu_{i}$ and $i$ can be either $i=l$ (low-growth regime), $i=m$ (medium-growth regime) or $i=h$ (high-growth regime).

Table 21 reports the parameter estimates for the U.S. states. Overall, our analysis suggests that U.S. states differ markedly in the level of and spread between the high and low-phase growth rates. Using a likelihood ratio test, we test the null hypothesis that house prices follow a martingale against the alternative of a regime switching mechanism. Then, we provide the Regime Classification Measure (RCM) which captures the quality of a model's regime qualification performance developed by Ang and Bekaert (2002). They argue that a good regime-switching model should be able to classify regimes sharply. This is the case when the smoothed (ex-post) regime probabilities $p_{i}$ are close to either one or zero. Inferior models, however, will exhibit $p_{i}$ values closer to $1 / k$, where $k$ is 
the number of regimes. A perfect model will be associated with a RCM close to zero, while a model that cannot distinguish between regimes at all will produce a RCM close to 100. Ang and Bekaert's (2002) generalization of this formula to the multiple state case has many undesirable features ${ }^{41}$ We therefore adopt the measure adapted by Baele (2005):

$$
R C M=100 \times\left(1-\frac{k}{k-1} \frac{1}{T} \sum_{t=1}^{T} \sum_{i=1}^{k}\left(p_{i, t}-\frac{1}{\kappa}\right)^{2}\right)
$$

lies between 0 and 100, where the latter means that the model cannot distinguish between the regimes. Therefore, lower RCM values denote better regime classification. Overall, a 3-regime specification allows a clear regime-classification of the HPI data.

\section{[INSERT TABLE 21 HERE]}

According to the second condition of HHMI, the real housing return of the state $k$ has to be higher than the expected real housing return in the high-growth regime of U.S. aggregate for four quarters in a row. A natural candidate of the expected real housing return at U.S. aggregate level is the expected growth rate in the high regime we estimated using the long Case-Shiller HPI time series dating back to 1925 . The estimated mean of the real annual growth rate is $9.25 \%$ during the high-growth regimes. Although, OFHEO's HPI data and the house price indexes produced by Case-Shiller are constructed using the same basic methodology, important differences between the indexes remain. The two models use different data sources and implement the mechanics of the basic algorithm in distinct ways 42 Therefore, it is not appropriate to use the estimated mean of $9.25 \%$ as a threshold. The OFHEO's HPI is a good estimate of the typical price appreciation of singlefamily houses, whereas the Case-Shiller index is a good estimate of the capital appreciation that would result from owning a representative sample of U.S. homes. The HPI tends to underrepresent high-priced homes; it also tends to underrepresent low-priced homes. The reason is that Fannie and Freddie only purchase conventional loans, which typically exclude smaller-sized mortgages that are

\footnotetext{
${ }^{41}$ More specifically, their measure produces small RCMs as soon as one regime has a very low probability, even if the model cannot distinguish between the other regimes.

42 Both use the repeat-valuations framework initially proposed in the 1960 s
} 
insured by the Veterans Administration and the Federal Housing Administration 43 These and the previous exclusions imply that the HPI is best interpreted as measuring aggregate price appreciation for a broad middle segment of the U.S. stock of single-family homes. As a consequence of its value weighting, the Case-Shiller index growth rate systematically differs from the HPI growth rate. For example, Case-Shiller index growth consistently exceeds HPI growth, starting in 1998. Over the subsequent six years, it does so by as much as four percentage points in some quarters. Then, HPI growth consistently exceeds Case-Shiller index growth starting in the first quarter of 2006 when house prices started to markedly depreciate. Alternatively, we can obtain our threshold using the regime classification inferred by our 2-regime model using the long Case-Shiller HPI time series. Based on the smooth probabilities, only the period $2000-2006$ is associated with a high growth phase over the period 1975 - 2010. We calculate a mean annual real growth rate of $6.87 \%$ during high regimes using the HPI at U.S. aggregate level 44 Accordingly, we use this as our threshold.

\section{A.5 Risk-free security holdings}

Analogously to Hypothesis 3, we can test the impact of hitting the bounds that trigger a housing purchase on the risk-free shares of the agent's financial wealth.

Hypothesis 5. $B_{m_{B I G}} / W_{i t}>B_{i t} / W_{i t}$ and $B_{m_{S M A L L}} / W_{i t}<B_{i t} / W_{i t}$. Therefore, the optimal holding of risk-free assets before moving to a more (less) expensive house $B_{m_{B I G}} / W_{i t}\left(B_{m_{S M A L L}} / W_{i t}\right)$ is significantly different and higher (lower) from the average holding of risk-free assets of the households who do not move $B_{i t} / W_{i t}$.

To test Hypothesis 5, we estimate the following reduced form model:

$$
\frac{B_{i t}}{W_{i t}}=\gamma_{0}+\gamma_{1} \cdot m_{B I G_{i t}}+\gamma_{2} \cdot m_{S M A L L_{i t}}+\Gamma \cdot X_{i t}+u_{i t}
$$

\footnotetext{
${ }^{43}$ Also excluded from the HPI are condominiums, co-ops, and other multifamily homes.

${ }^{44}$ We have also checked our results for a 3-regime specification on the Case-Shiller HPI for robustness. The period $2000-2006$ is still associated with a high-growth phase. Specifically, we obtain (standard errors in parenthesis) $\mu_{l}=-0.1484$ (0.0334), $\mu_{m}=-0.0004$ (0.0047), $\mu_{h}=0.0944(0.0145), \sigma_{P}=0.0375(0.0030), \lambda_{l l}=0.4206(0.3210)$, $\lambda_{m m}=0.9674(0.0233), \lambda_{l h}=0.1019(0.1008)$ and $\lambda_{m h}=0.1167(0.1244)$. The low regime is associated with sharp house price depreciation, starting in 2006.
} 
Tables 24 and 25 show the results of the test of Hypothesis 5. The first column shows the results for the pooled data for all the years. It shows that households who move to a less valuable house hold on average $32.5 \%$ less safe assets relative to wealth than non-movers for PSID data. Because the safe asset position accounts for the mortgage balance, the result provides evidence that households moving to less valuable houses have more leverage as predicted by the model. However, empirical estimates are only consistent in some years with the model's predictions that households holds more safe assets before moving to a more valuable house. Instead, the mover to a more valuable house holds $16.9 \%$ more in SIPP. This coefficient ranges from being not significantly different from zero to as much as $50.3 \%$ in 1999.

[INSERT TABLES 24 and 25 HERE] 


\section{Figures and Tables of the Appendix}

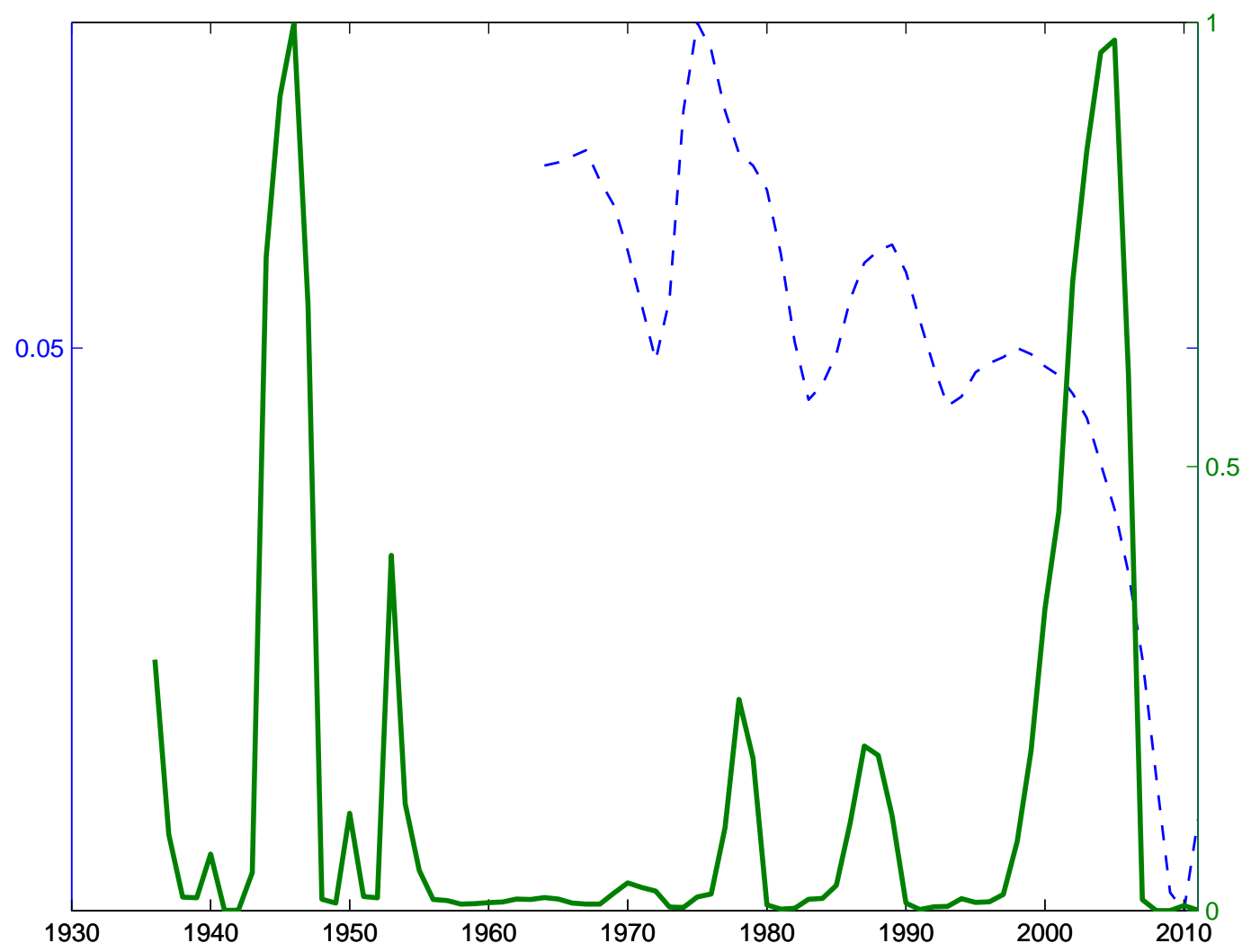

Figure 7: Probability of being in a regime of high house price growth vs. rent-price ratio. The bold line represents the smoothed probability of being in a high regime, on the right axis. The dashed line represents the rent-price ratio, on the left axis. 


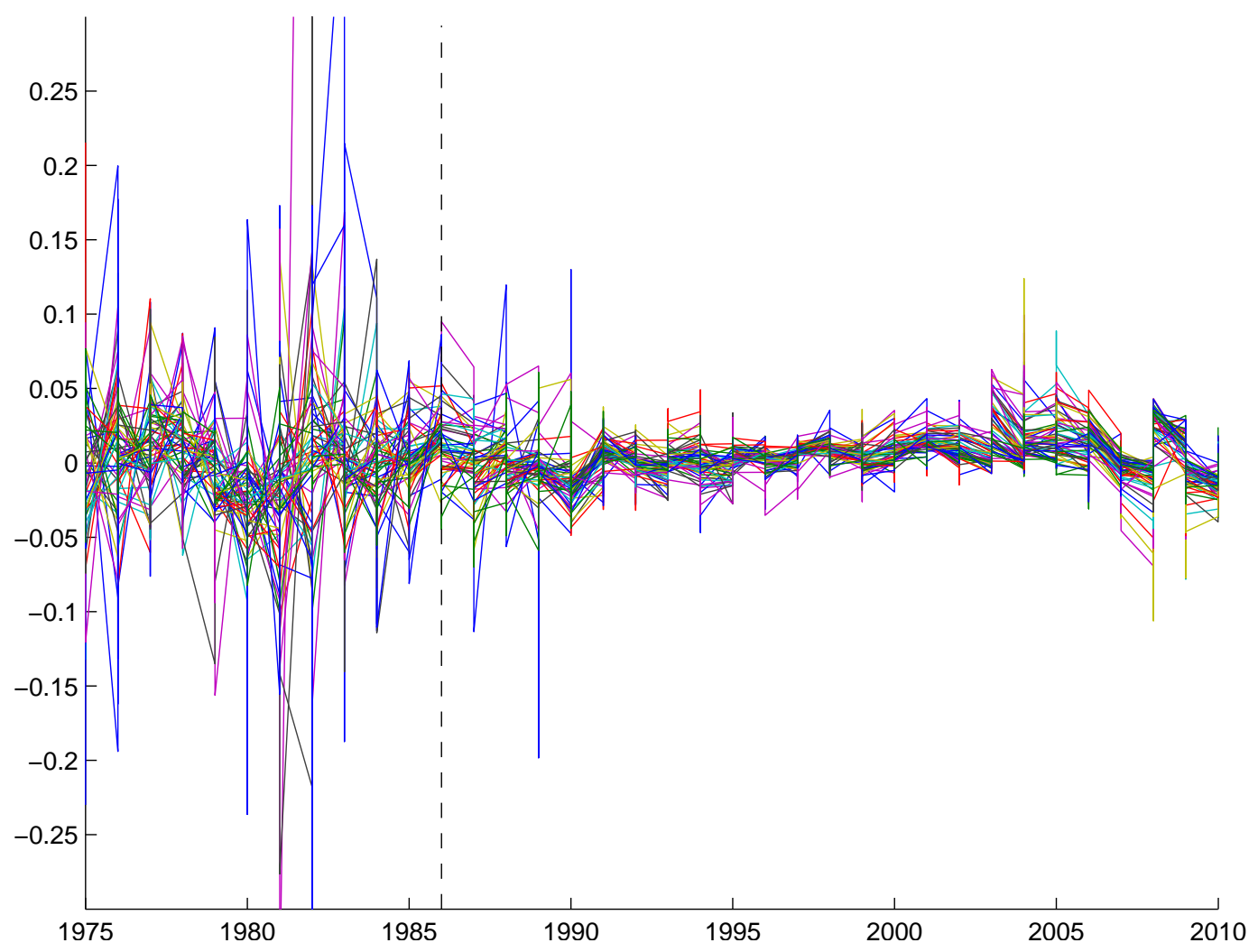

Figure 8: Housing returns - U.S. states. This figure shows the growth rates in OFHEO house price indexes for the U.S. states for the period $1975-2010$. The vertical line marks $1986-Q 1$. 
Table 15: Predictability of excess returns and dividend growth with rent-price ratios. Predictability regressions with 4-lag Newey-West corrected standard errors. Data source: annualized price-rent data annualized quarterly data on house prices from the Federal Housing Finance Agency (FHFA) and rents from the Bureau of Labor Statistics (BLS). Stock returns data source: CRSP NYSE/Amex/Nasdaq/Arca value-weighted market index from 1926 to 2000. Panel A shows the regressions using data up to year 2000. Panel B shows the same regressions using the full samples, which include the 2001-2007 period.

Panel A

\begin{tabular}{|c|c|c|c|c|c|c|c|}
\hline & \multirow[b]{3}{*}{ Horizon } & \multicolumn{6}{|c|}{ Panel A } \\
\hline & & \multicolumn{3}{|c|}{ Excess Returns } & \multicolumn{3}{|c|}{ Dividend growth } \\
\hline & & $\beta$ & t-stat & $R^{2}$ & $\beta$ & t-stat & $R^{2}$ \\
\hline \multirow{3}{*}{ U.S. } & $\mathrm{k}=1$ & 3.97 & 1.47 & 0.06 & 6.54 & 3.60 & 0.38 \\
\hline & $\mathrm{k}=4$ & 41.45 & 14.37 & 0.76 & 10.11 & 2.12 & 0.13 \\
\hline & $\mathrm{k}=5$ & 46.30 & 8.61 & 0.82 & 5.67 & 1.31 & 0.03 \\
\hline \multirow{3}{*}{ Midwest } & $\mathrm{k}=1$ & 1.29 & 0.55 & 0.01 & 2.53 & 1.57 & 0.22 \\
\hline & $\mathrm{k}=4$ & 28.92 & 3.13 & 0.43 & 7.64 & 2.19 & 0.27 \\
\hline & $\mathrm{k}=5$ & 38.03 & 4.07 & 0.53 & 7.21 & 2.21 & 0.22 \\
\hline \multirow{3}{*}{ Northeast } & $\mathrm{k}=1$ & 0.68 & 0.34 & 0.00 & -0.97 & -1.06 & 0.06 \\
\hline & $\mathrm{k}=4$ & 20.30 & 2.53 & 0.27 & 3.18 & 1.09 & 0.09 \\
\hline & $\mathrm{k}=5$ & 30.79 & 2.96 & 0.46 & 5.65 & 1.80 & 0.23 \\
\hline \multirow{3}{*}{ South } & $\mathrm{k}=1$ & 3.52 & 1.48 & 0.09 & 1.55 & 1.09 & 0.05 \\
\hline & $\mathrm{k}=4$ & 26.78 & 4.91 & 0.61 & -2.25 & -0.57 & 0.02 \\
\hline & $\mathrm{k}=5$ & 34.11 & 5.64 & 0.68 & -4.30 & -0.89 & 0.06 \\
\hline \multirow{3}{*}{ West } & $\mathrm{k}=1$ & 0.30 & 0.20 & 0.00 & 1.36 & 1.02 & 0.04 \\
\hline & $\mathrm{k}=4$ & 21.92 & 5.60 & 0.56 & -5.97 & -2.71 & 0.08 \\
\hline & $\mathrm{k}=5$ & 28.23 & 5.75 & 0.70 & -10.61 & -3.71 & 0.20 \\
\hline \multirow{6}{*}{ Stocks } & $\mathrm{k}=1$ & 3.92 & 3.08 & 0.08 & -3.23 & -1.88 & 0.05 \\
\hline & $\mathrm{k}=4$ & 17.71 & 3.25 & 0.27 & -0.01 & -0.67 & 0.00 \\
\hline & $\mathrm{k}=5$ & 20.40 & 3.39 & 0.28 & 0.00 & 0.03 & 0.00 \\
\hline & & \multicolumn{6}{|c|}{ Panel B } \\
\hline & & \multicolumn{3}{|c|}{ Excess Returns } & \multicolumn{3}{|c|}{ Dividend growth } \\
\hline & Horizon & $\beta$ & t-stat & $R^{2}$ & $\beta$ & t-stat & $R^{2}$ \\
\hline \multirow{3}{*}{ U.S. } & $\mathrm{k}=1$ & -3.37 & -2.14 & 0.16 & 0.40 & 0.53 & 0.01 \\
\hline & $\mathrm{k}=4$ & -19.59 & -1.28 & 0.14 & 2.49 & 0.73 & 0.02 \\
\hline & $\mathrm{k}=5$ & -21.94 & -0.81 & 0.08 & 1.29 & 0.37 & 0.00 \\
\hline \multirow{3}{*}{ Stocks } & $\mathrm{k}=1$ & 3.65 & 3.10 & 0.07 & -3.14 & -1.98 & 0.05 \\
\hline & $\mathrm{k}=4$ & 15.37 & 3.08 & 0.23 & -0.02 & -0.86 & 0.00 \\
\hline & $\mathrm{k}=5$ & 18.02 & 3.39 & 0.25 & -0.00 & -0.33 & 0.00 \\
\hline
\end{tabular}


Table 16: Predictability of excess returns and dividend growth with rent-price ratios. Housing versus stocks. 1-lag Newey-West corrected standard errors. Data source: rents data correspond to housing services expenditures (NIPA from BLS) and housing values from the Flow of Funds. Sample from 1960 to 1998.

\begin{tabular}{clccc|cccc}
\hline & & \multicolumn{3}{c}{ Excess Returns } & \multicolumn{3}{c}{ Dividend growth } \\
\cline { 3 - 8 } & Horizon & $\beta$ & t-stat & $R^{2}$ & $\beta$ & t-stat & $R^{2}$ \\
\hline \multirow{3}{*}{ Housing } & $\mathrm{k}=1$ & 1.48 & 4.85 & 0.40 & 0.08 & 0.41 & 0.01 \\
& $\mathrm{k}=4$ & 10.82 & 5.99 & 0.54 & -0.61 & -1.22 & 0.04 \\
& $\mathrm{k}=5$ & 16.01 & 5.28 & 0.50 & -1.06 & -1.54 & 0.08 \\
\hline \multirow{4}{*}{ Stocks } & $\mathrm{k}=1$ & 2.83 & 1.20 & 0.03 & -3.33 & -1.96 & 0.05 \\
& $\mathrm{k}=4$ & 7.75 & 1.15 & 0.04 & -2.38 & -1.42 & 0.02 \\
& $\mathrm{k}=5$ & 11.37 & 1.41 & 0.05 & -4.41 & -2.36 & 0.04 \\
\hline
\end{tabular}


Table 17: Predictability of excess returns and dividend growth with rent-price ratios. Regional analysis and different data sources. Panel A. Predictability of excess returns and dividend growth with rent-price ratios, 1-lag Newey-West corrected standard errors. Data source: price-rent data using annualized quarterly data from 1978 to 2007 on house prices from the Federal Housing Finance Agency (FHFA) and rents from the Bureau of Labor Statistics (BLS). Panel B. Same regressions with rent data from NIPA and value data from Flow of Funds from 1960 to 2007.

Panel A. Data: FHFA

\begin{tabular}{|c|c|c|c|c|c|c|c|}
\hline & \multirow[b]{2}{*}{ Horizon } & \multicolumn{3}{|c|}{ Excess Returns } & \multicolumn{3}{|c|}{ Dividend growth } \\
\hline & & $\beta$ & t-stat & $R^{2}$ & $\beta$ & t-stat & $R^{2}$ \\
\hline \multirow{3}{*}{ U.S. } & $\mathrm{k}=1$ & -3.37 & -1.82 & 0.16 & 0.40 & 0.53 & 0.01 \\
\hline & $\mathrm{k}=4$ & -19.59 & -1.54 & 0.14 & 2.49 & 0.80 & 0.02 \\
\hline & $\mathrm{k}=5$ & -21.94 & -0.98 & 0.08 & 1.29 & 0.34 & 0.00 \\
\hline \multirow{3}{*}{ Midwest } & $\mathrm{k}=1$ & -1.76 & -1.38 & 0.06 & 0.89 & 1.41 & 0.07 \\
\hline & $\mathrm{k}=4$ & -3.97 & -0.46 & 0.01 & 3.49 & 1.50 & 0.12 \\
\hline & $\mathrm{k}=5$ & -2.54 & -0.20 & 0.00 & 3.28 & 1.25 & 0.08 \\
\hline \multirow{3}{*}{ Northeast } & $\mathrm{k}=1$ & -1.36 & -0.83 & 0.03 & -0.84 & -1.19 & 0.08 \\
\hline & $\mathrm{k}=4$ & 8.04 & 0.77 & 0.04 & 1.82 & 0.66 & 0.04 \\
\hline & $\mathrm{k}=5$ & 18.85 & 1.45 & 0.14 & 4.21 & 1.30 & 0.14 \\
\hline \multirow{3}{*}{ South } & $\mathrm{k}=1$ & -3.61 & -2.29 & 0.16 & -0.36 & -0.42 & 0.01 \\
\hline & $\mathrm{k}=4$ & -3.99 & -0.22 & 0.01 & -1.86 & -0.65 & 0.02 \\
\hline & $\mathrm{k}=5$ & 6.80 & 0.30 & 0.01 & -3.32 & -0.89 & 0.04 \\
\hline \multirow{3}{*}{ West } & $\mathrm{k}=1$ & -4.54 & -2.18 & 0.29 & 0.13 & 0.18 & 0.00 \\
\hline & $\mathrm{k}=4$ & -22.27 & -1.43 & 0.17 & -3.81 & -1.14 & 0.05 \\
\hline & $\mathrm{k}=5$ & -21.63 & -0.98 & 0.09 & -8.23 & -2.18 & 0.16 \\
\hline \multirow{3}{*}{ Stocks } & $\mathrm{k}=1$ & 3.92 & 2.65 & 0.08 & -3.24 & -2.07 & 0.05 \\
\hline & $\mathrm{k}=4$ & 17.71 & 3.77 & 0.27 & -0.01 & -0.84 & 0.00 \\
\hline & $\mathrm{k}=5$ & 20.39 & 4.31 & 0.28 & 0.00 & 0.04 & 0.00 \\
\hline
\end{tabular}

Panel B. Data: NIPA and Flow of Funds

\begin{tabular}{lcccc|ccc}
\hline & & \multicolumn{3}{c}{ Excess Returns } & \multicolumn{3}{c}{ Dividend growth } \\
\cline { 3 - 8 } & Horizon & $\beta$ & t-stat & $R^{2}$ & $\beta$ & t-stat & $R^{2}$ \\
\hline \multirow{4}{*}{ Housing } & $\mathrm{k}=1$ & 1.40 & 3.68 & 0.36 & 0.08 & 0.72 & 0.01 \\
& $\mathrm{k}=4$ & 11.91 & 8.24 & 0.62 & -0.63 & -1.60 & 0.06 \\
& $\mathrm{k}=5$ & 19.17 & 9.01 & 0.68 & -0.92 & -1.98 & 0.09 \\
\hline \multirow{3}{*}{ Stocks } & $\mathrm{k}=1$ & 2.58 & 1.50 & 0.03 & -3.04 & -2.35 & 0.05 \\
& $\mathrm{k}=4$ & 7.17 & 1.54 & 0.05 & -3.85 & -2.07 & 0.07 \\
& $\mathrm{k}=5$ & 11.64 & 2.37 & 0.08 & -5.33 & -2.81 & 0.08 \\
\hline
\end{tabular}


Table 18: Predictability of excess returns and dividend growth with rent-price ratios. Metropolitan-level analysis. 1-lag Newey-West corrected standard errors. Data source: quarterly price-rent data from 1978 to 2001 on house prices from the Federal Housing Finance Agency (FHFA) and the Bureau of Labor Statistics (BLS) from 1978 to 2000.

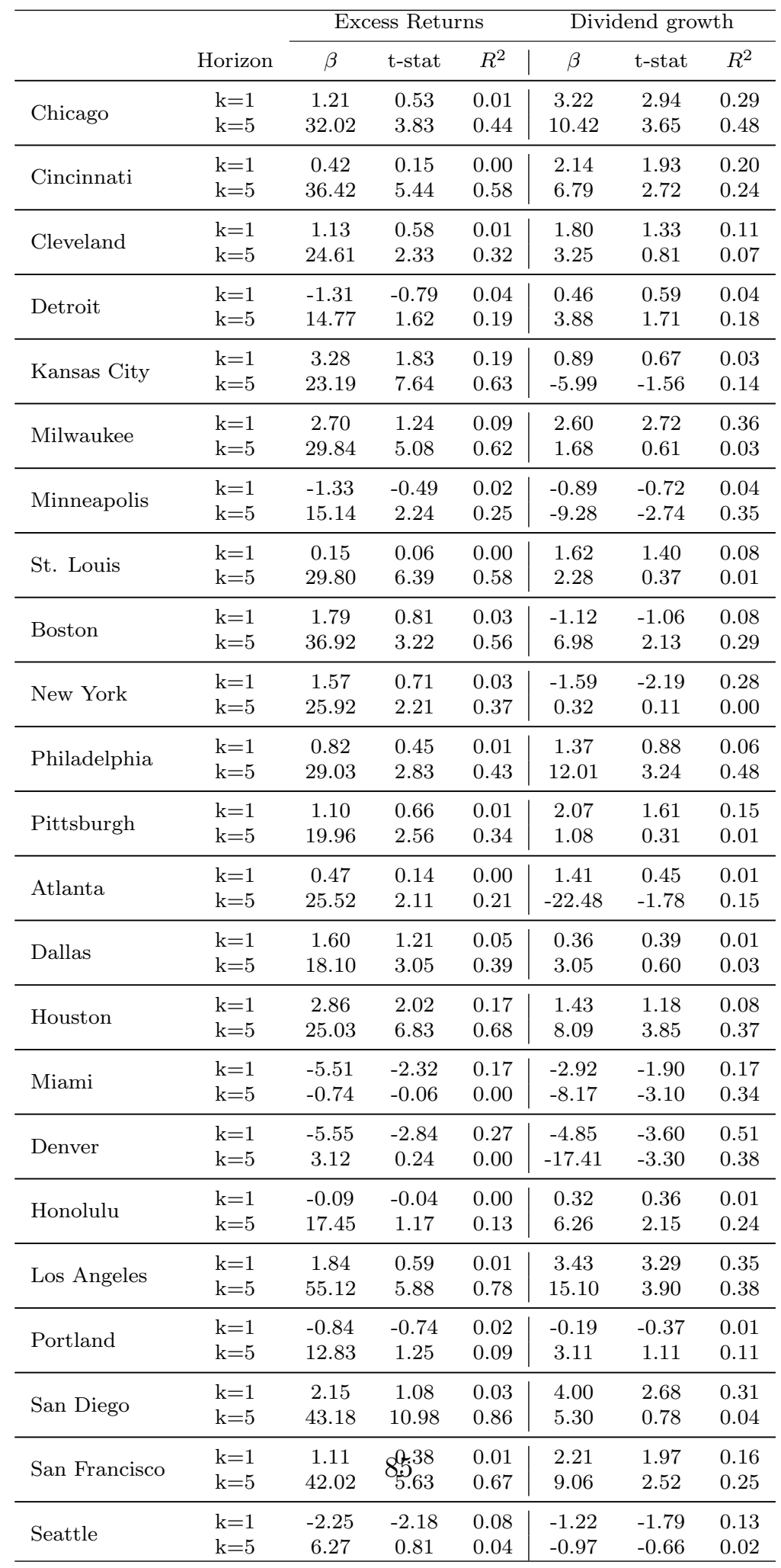


Table 19: Predictability of excess returns and dividend growth with rents-price ratios. Predictability of excess returns and dividend growth with inverse-price ratios in order to test for the predictive power of ignoring rent fluctuations. 4-lag Newey-West corrected standard errors. Data source: price data on house prices from the Federal Housing Finance Agency (FHFA), annualized from 1978 to 2007.

\begin{tabular}{ccccc|cccc}
\hline & & \multicolumn{3}{c}{ Excess Returns } & \multicolumn{3}{c}{ Dividend growth } \\
\cline { 3 - 8 } & Horizon & $\beta$ & t-stat & $R^{2}$ & $\beta$ & t-stat & $R^{2}$ \\
\hline \multirow{4}{*}{$1978-2000$} & $\mathrm{k}=1$ & 1.15 & 4.10 & 0.58 & 0.16 & 1.01 & 0.06 \\
& $\mathrm{k}=2$ & 2.68 & 7.06 & 0.74 & 0.24 & 0.76 & 0.04 \\
& $\mathrm{k}=3$ & 4.36 & 11.79 & 0.84 & 0.13 & 0.30 & 0.01 \\
& $\mathrm{k}=4$ & 5.95 & 15.71 & 0.88 & -0.17 & -0.31 & 0.01 \\
& $\mathrm{k}=5$ & 7.54 & 19.30 & 0.92 & -0.52 & -0.86 & 0.06 \\
\hline \multirow{3}{*}{$1978-2007$} & $\mathrm{k}=1$ & 1.48 & 4.06 & 0.56 & 0.19 & 1.26 & 0.07 \\
& $\mathrm{k}=2$ & 3.40 & 5.77 & 0.70 & 0.29 & 0.98 & 0.06 \\
& $\mathrm{k}=3$ & 5.54 & 7.40 & 0.78 & 0.25 & 0.65 & 0.03 \\
& $\mathrm{k}=4$ & 7.70 & 8.32 & 0.83 & 0.14 & 0.31 & 0.01 \\
& $\mathrm{k}=5$ & 9.90 & 8.87 & 0.86 & 0.04 & 0.08 & 0.00 \\
\hline
\end{tabular}

Table 20: Sensitivity analysis. Columns (1), (2) and (3) display the lower bound, the optimal return point and the upper bound, respectively. The optimal return point represents the wealth-to-housing ratio immediately after a housing purchase. Column (4) is the optimal housing-to-wealth ratio without transaction costs and Column (5) is the corresponding ratio with transaction costs immediately after a housing purchase. Column (6) is the relative risk aversion just after a housing purchase. Column (7) is the average holding of the risky asset, estimated just after a housing purchase. Four scenarios illustrate alternatives to the benchmark: (A) sensitivity to the correlation between the house price and the stock market; (B) sensitivity to the transaction costs associated with moving; (C) sensitivity to the curvature of the utility function; and (D) sensitivity to house price standard deviation.

\begin{tabular}{|c|c|c|c|c|c|c|c|c|}
\hline & Regime & (1) & $(2)$ & $(3)$ & $(4)$ & $(5)$ & $(6)$ & $(7)$ \\
\hline & $i$ & $\underline{z}_{i}$ & $z_{i}^{*}$ & $\bar{z}_{i}$ & $\alpha_{h, i}$ & $1 / z_{i}^{*}$ & $R R A\left(z_{i}^{*}\right)$ & $\frac{E\left(\frac{\hat{\theta}^{*}\left(z^{*}, i\right)}{z^{*}}\right)}{E\left(\tau_{i}\right)}$ \\
\hline U.S. aggregate & High & 0.249 & 0.491 & 1.587 & 2.980 & 2.035 & 2.595 & 0.730 \\
\hline$(1930-2010)$ & Low & 1.575 & 3.870 & 6.739 & 0.340 & 0.258 & 2.071 & 1.098 \\
\hline (A) Correlation $P-S$ & High & 0.212 & 0.429 & 1.286 & 3.950 & 2.328 & 2.663 & 1.213 \\
\hline$\rho_{P S}=-0.25$ & Low & 1.145 & 3.012 & 4.841 & 0.497 & 0.331 & 2.091 & 1.096 \\
\hline (B) Transaction cost & High & 0.265 & 0.557 & 1.678 & 2.980 & 1.792 & 2.686 & 0.718 \\
\hline$\epsilon=0.075$ & Low & 1.653 & 3.346 & 7.549 & 0.340 & 0.298 & 2.153 & 1.080 \\
\hline (C) Curvature & High & 0.490 & 0.802 & 1.515 & 2.138 & 1.245 & 3.448 & 0.536 \\
\hline$\gamma=3$ & Low & 1.866 & 3.567 & 5.544 & 0.324 & 0.280 & 3.156 & 0.730 \\
\hline (D) House price std. dev. & High & 0.174 & 0.353 & 0.866 & 5.208 & 2.828 & 2.788 & 0.629 \\
\hline$\sigma_{P}=0.075$ & Low & 1.546 & 3.021 & 5.240 & 0.374 & 0.330 & 2.170 & 1.051 \\
\hline
\end{tabular}




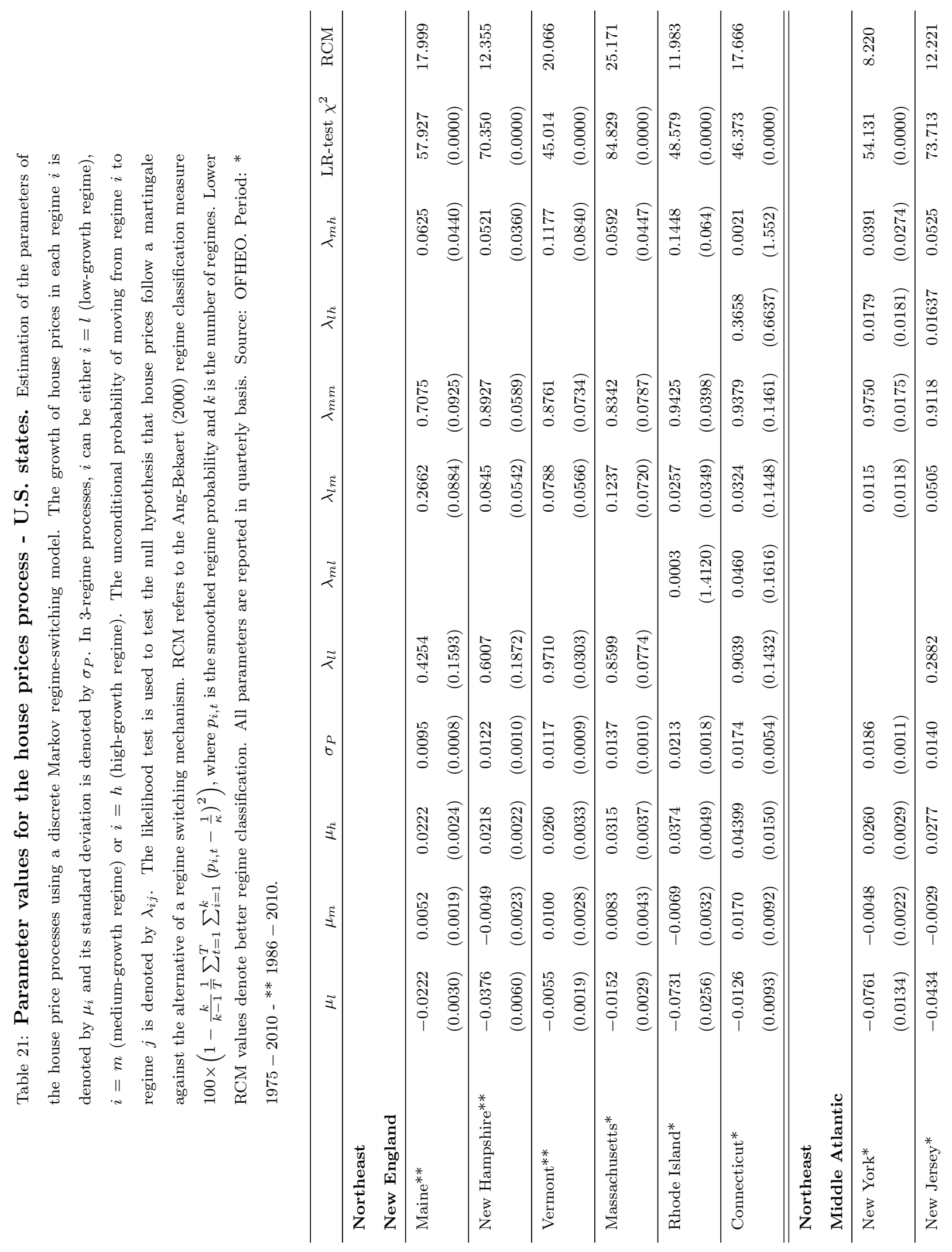




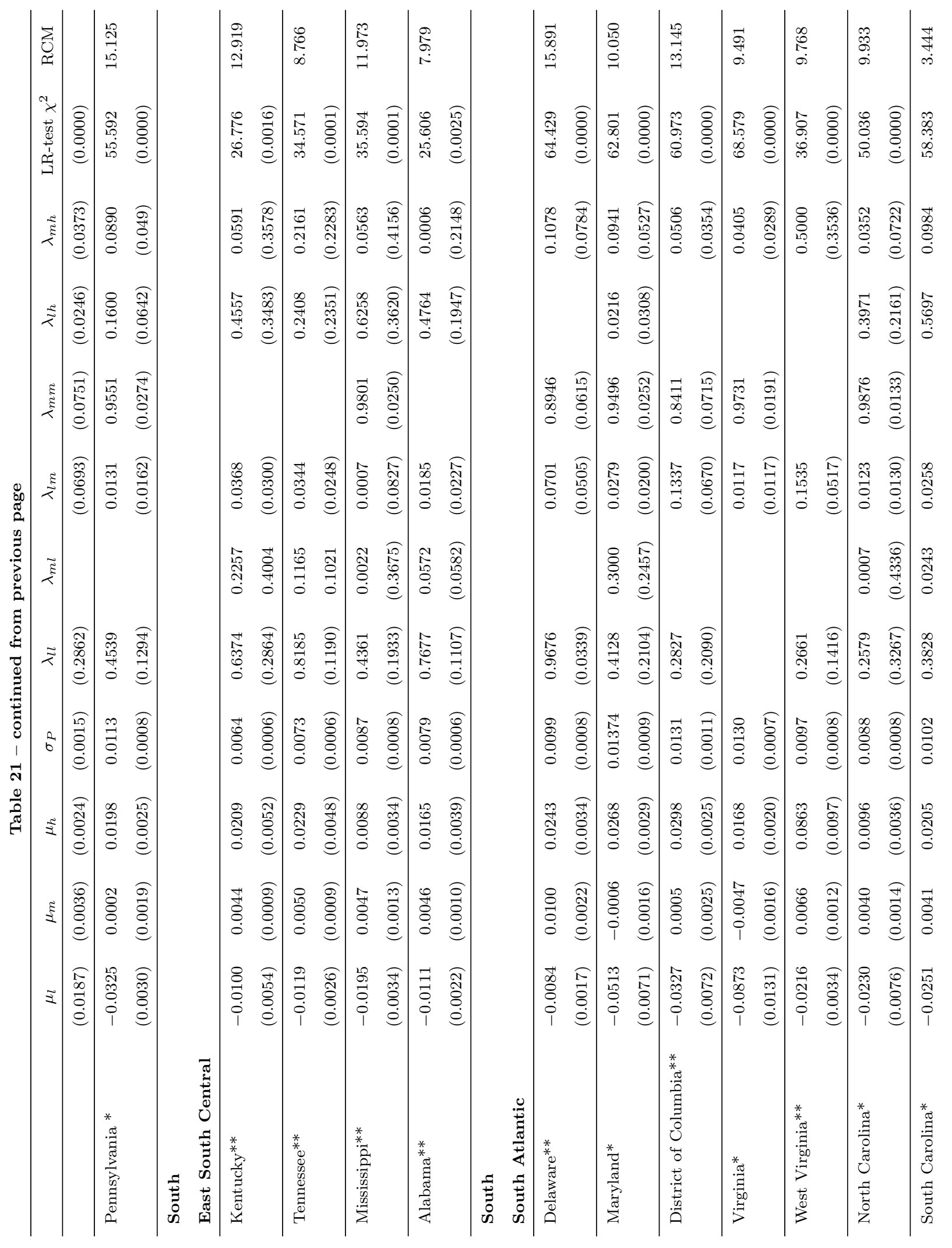




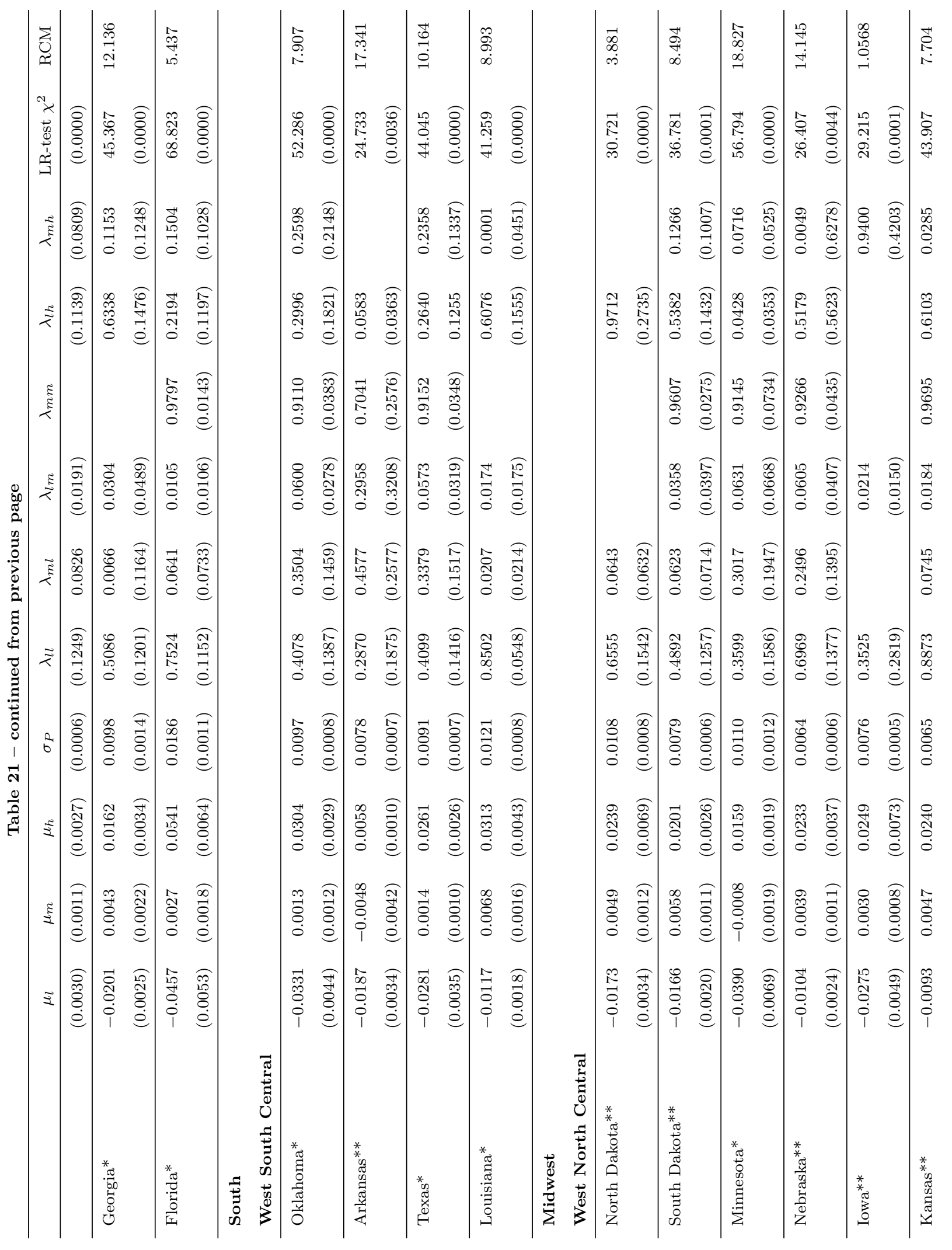




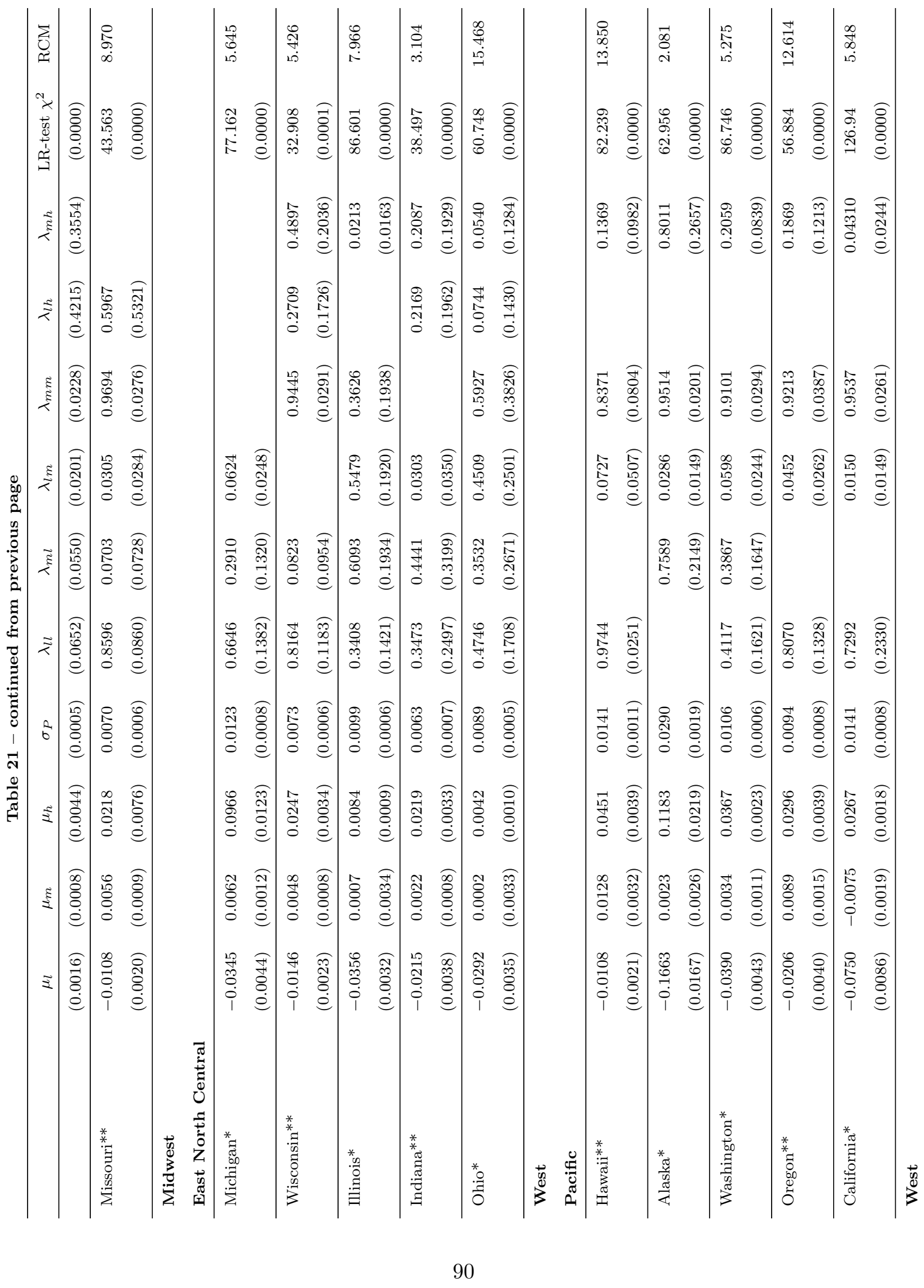




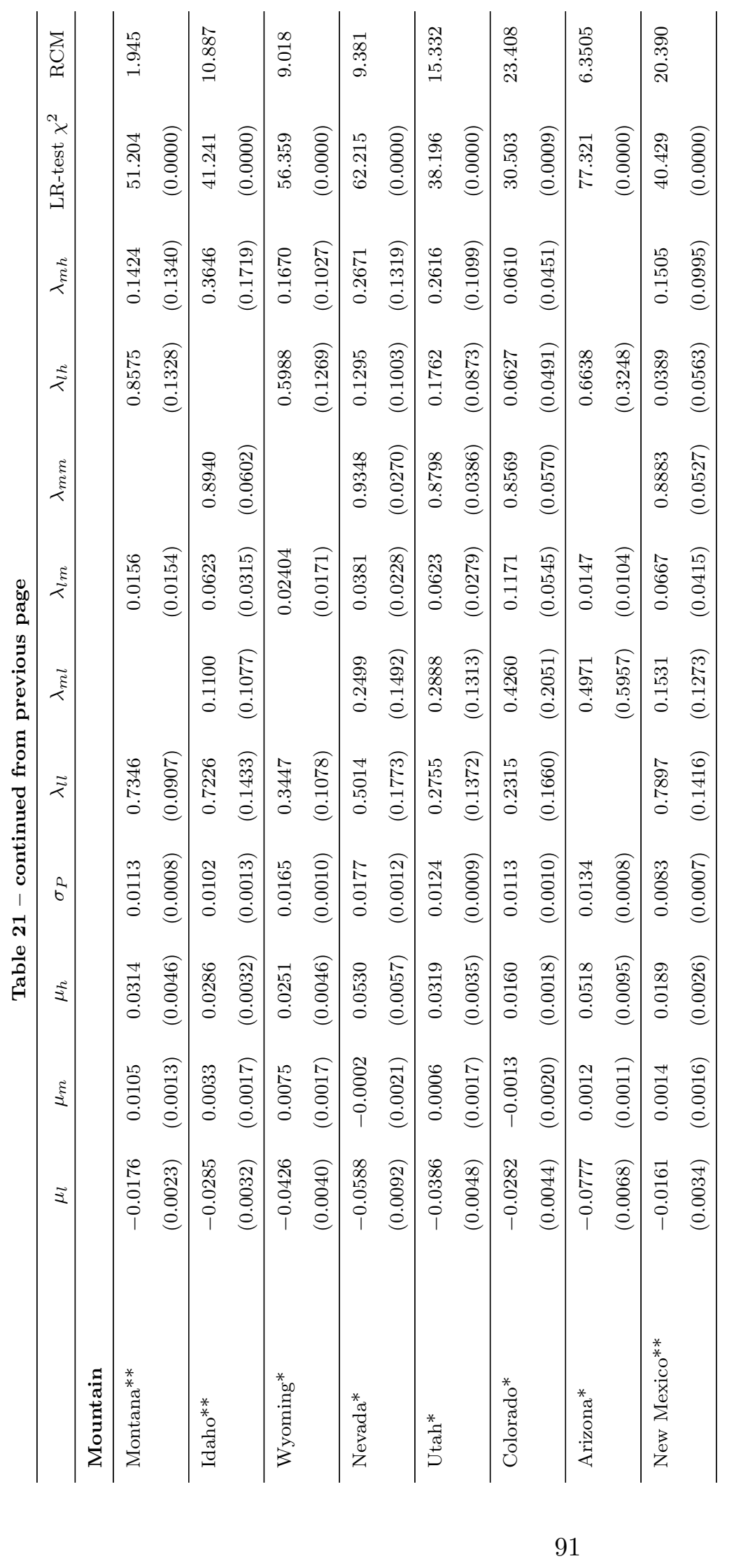


Table 22: Test of Hypothesis 3 - PSID. Coefficients estimated using a standard OLS model and ex-ante (i.e., before moving) values of the ratio of total risky stock holdings relative to liquid wealth, $\widehat{\Theta}_{i t} / \widehat{W}_{i t}$. Risky stock holdings do not include retirement assets. $m_{B I G_{i t}}\left(m_{S M A L L_{i t}}\right)$ is a dummy variable equal to one if the family is increasing (decreasing) its housing holdings (i.e., moving to a bigger (smaller) house). Standard errors are reported in parentheses. ${ }^{* * *}$ denotes significance at the $1 \%$ level, ${ }^{* *}$ at the $5 \%$ level, and ${ }^{*}$ at the $10 \%$ level. The pooled regressions include year dummies. Source: PSID. Period: $1984-2005$.

\begin{tabular}{|c|c|c|c|c|c|c|c|c|}
\hline & All & 1984 & 1989 & 1994 & 1999 & 2001 & 2003 & 2005 \\
\hline \multirow[t]{2}{*}{ constant $\left(\gamma_{0}\right)$} & $0.168^{* * *}$ & $0.153^{* * *}$ & $0.171^{* * *}$ & $0.303^{* * *}$ & $0.199^{* * *}$ & $0.168^{* * *}$ & $0.152^{* * *}$ & $0.168^{* * *}$ \\
\hline & $(0.008)$ & $(0.018)$ & $(0.017)$ & $(0.020)$ & $(0.015)$ & $(0.014)$ & $(0.013)$ & (0.013) \\
\hline \multirow[t]{2}{*}{$m_{B I G}\left(\gamma_{1}\right)$} & 0.010 & 0.006 & 0.028 & 0.025 & 0.001 & 0.016 & 0.014 & -0.003 \\
\hline & $(0.008)$ & $(0.026)$ & $(0.029)$ & $(0.035)$ & $(0.020)$ & $(0.017)$ & $(0.015)$ & $(0.015)$ \\
\hline \multirow[t]{2}{*}{$m_{S M A L L}\left(\gamma_{2}\right)$} & 0.012 & 0.002 & -0.002 & 0.008 & -0.024 & 0.031 & 0.036 & 0.012 \\
\hline & $(0.012)$ & $(0.049)$ & $(0.053)$ & $(0.058)$ & $(0.031)$ & $(0.024)$ & $(0.026)$ & $(0.024)$ \\
\hline \multirow[t]{2}{*}{$\Delta$ Family } & 0.005 & 0.003 & 0.015 & 0.007 & $0.013^{*}$ & 0.005 & -0.005 & 0.001 \\
\hline & $(0.003)$ & $(0.010)$ & $(0.011)$ & $(0.014)$ & $(0.007)$ & $(0.006)$ & $(0.006)$ & $(0.006)$ \\
\hline \multirow[t]{2}{*}{$\Delta$ Married } & 0.010 & -0.009 & -0.089 & -0.008 & 0.017 & -0.052 & $0.076^{*}$ & 0.040 \\
\hline & $(0.015)$ & $(0.049)$ & $(0.058)$ & $(0.068)$ & $(0.035)$ & $(0.033)$ & $(0.030)$ & $(0.031)$ \\
\hline \multirow[t]{2}{*}{$\Delta$ Employment } & $-0.016^{* *}$ & -0.012 & -0.020 & 0.019 & -0.021 & $-0.026^{*}$ & $-0.027^{*}$ & -0.022 \\
\hline & $(0.005)$ & $(0.016)$ & $(0.016)$ & $(0.018)$ & $(0.014)$ & $(0.013)$ & $(0.013)$ & $(0.013)$ \\
\hline \multirow[t]{2}{*}{$A g e_{y<30}$} & $-0.064^{* * *}$ & $-0.051^{* *}$ & $-0.045^{*}$ & $-0.072^{* *}$ & $-0.060^{* *}$ & $-0.070 * * *$ & $-0.045^{* *}$ & $-0.085^{* * *}$ \\
\hline & (0.007) & $(0.020)$ & $(0.022)$ & $(0.027)$ & $(0.020)$ & $(0.018)$ & $(0.017)$ & $(0.016)$ \\
\hline \multirow[t]{2}{*}{ Age $_{30<y<40}$} & $-0.025^{* * *}$ & 0.021 & -0.005 & -0.021 & -0.023 & $-0.030^{*}$ & $-0.047 * * *$ & $-0.041^{* *}$ \\
\hline & $(0.006)$ & $(0.017)$ & $(0.016)$ & $(0.019)$ & $(0.014)$ & $(0.014)$ & $(0.013)$ & $(0.013)$ \\
\hline \multirow[t]{2}{*}{ Age $_{40<y<50}$} & $-0.014^{*}$ & 0.008 & 0.018 & 0.032 & -0.023 & -0.018 & $-0.048^{* * *}$ & $-0.037^{* *}$ \\
\hline & $(0.005)$ & $(0.019)$ & $(0.017)$ & $(0.019)$ & $(0.013)$ & $(0.012)$ & $(0.012)$ & (0.012) \\
\hline \multirow[t]{2}{*}{ Age $_{50<y<60}$} & 0.003 & $0.039^{*}$ & 0.003 & 0.022 & -0.007 & -0.006 & -0.005 & -0.012 \\
\hline & $(0.006)$ & (0.018) & (0.018) & $(0.022)$ & $(0.015)$ & $(0.014)$ & $(0.012)$ & $(0.012)$ \\
\hline \multirow[t]{2}{*}{ Midwest } & $-0.026^{* * *}$ & -0.025 & 0.015 & -0.011 & $-0.055 * * *$ & -0.020 & $-0.032^{*}$ & $-0.042^{* *}$ \\
\hline & $(0.006)$ & $(0.017)$ & $(0.017)$ & $(0.020)$ & $(0.015)$ & $(0.014)$ & $(0.013)$ & $(0.014)$ \\
\hline \multirow[t]{2}{*}{ South } & $-0.053^{* * *}$ & $-0.075^{* * *}$ & $-0.054^{* * *}$ & -0.008 & $-0.083^{* * *}$ & $-0.057 * * *$ & $-0.041^{* * *}$ & $-0.059 * * *$ \\
\hline & $(0.006)$ & (0.016) & $(0.016)$ & $(0.019)$ & $(0.014)$ & $(0.013)$ & $(0.012)$ & (0.013) \\
\hline \multirow[t]{2}{*}{ West } & $-0.014^{*}$ & -0.035 & 0.006 & -0.013 & $-0.036^{*}$ & -0.020 & -0.001 & -0.007 \\
\hline & $(0.006)$ & $(0.018)$ & $(0.019)$ & $(0.023)$ & $(0.016)$ & $(0.015)$ & $(0.014)$ & $(0.015)$ \\
\hline$R^{2}$ & 0.266 & 0.207 & 0.249 & 0.463 & 0.197 & 0.190 & 0.172 & 0.174 \\
\hline Num. Obs. & 19239 & 1938 & 2271 & 2453 & 3065 & 3169 & 3179 & 3164 \\
\hline
\end{tabular}


Table 23: Test of Hypothesis 3 - SIPP. Coefficients estimated using a standard OLS model and ex-ante (i.e., before moving) values of the ratio of total risky stock holdings relative to liquid wealth, $\widehat{\Theta}_{i t} / \widehat{W}_{i t}$. Risky stock holdings do not include retirement assets. $m_{B I G_{i t}}\left(m_{S M A L L_{i t}}\right)$ is a dummy variable equal to one if the family is increasing (decreasing) its housing holdings (i.e., moving to a bigger (smaller) house). Standard errors are reported in parentheses. ${ }^{* * *}$ denotes significance at the $1 \%$ level, ${ }^{* *}$ at the $5 \%$ level, and ${ }^{*}$ at the $10 \%$ level. The pooled regressions include year dummies. Source: SIPP. Period: $1997-2005$.

\begin{tabular}{|c|c|c|c|c|c|c|c|}
\hline & All years & 1997 & 1998 & 1999 & 2002 & 2003 & 2005 \\
\hline \multirow[t]{2}{*}{ constant $\left(\gamma_{0}\right)$} & $0.221^{* * *}$ & $0.159^{* * *}$ & $0.167^{* * *}$ & $0.163^{* * *}$ & $0.150 * * *$ & $0.144^{* * *}$ & $0.068 * * *$ \\
\hline & $(0.021)$ & $(0.006)$ & $(0.006)$ & $(0.006)$ & $(0.006)$ & $(0.005)$ & $(0.003)$ \\
\hline \multirow[t]{2}{*}{$m_{B I G}\left(\gamma_{1}\right)$} & $0.048^{* * *}$ & $0.073^{* * *}$ & $0.064^{* * *}$ & $0.080^{* * *}$ & 0.015 & 0.025 & $0.034^{* * *}$ \\
\hline & $(0.006)$ & $(0.018)$ & $(0.018)$ & $(0.018)$ & $(0.016)$ & $(0.015)$ & $(0.008)$ \\
\hline \multirow[t]{2}{*}{$m_{S M A L L}\left(\gamma_{2}\right)$} & $0.019^{*}$ & 0.033 & 0.022 & -0.018 & $0.058^{* *}$ & 0.015 & 0.002 \\
\hline & $(0.009)$ & $(0.023)$ & $(0.025)$ & $(0.025)$ & $(0.020)$ & $(0.022)$ & $(0.012)$ \\
\hline \multirow[t]{2}{*}{$\Delta$ Family } & 0.003 & $0.013^{* *}$ & 0.005 & -0.007 & -0.001 & 0.006 & 0.001 \\
\hline & $(0.002)$ & $(0.004)$ & $(0.005)$ & $(0.005)$ & $(0.004)$ & $(0.005)$ & $(0.002)$ \\
\hline \multirow[t]{2}{*}{$\Delta$ Married } & -0.015 & -0.014 & $-0.045^{*}$ & -0.038 & -0.007 & -0.013 & 0.009 \\
\hline & $(0.008)$ & $(0.020)$ & $(0.023)$ & $(0.028)$ & $(0.018)$ & $(0.023)$ & $(0.010)$ \\
\hline \multirow[t]{2}{*}{$\Delta$ Employment } & $-0.007^{*}$ & $-0.021^{*}$ & -0.016 & -0.001 & -0.002 & -0.012 & 0.001 \\
\hline & $(0.003)$ & $(0.011)$ & $(0.011)$ & $(0.011)$ & $(0.007)$ & $(0.007)$ & $(0.004)$ \\
\hline \multirow[t]{2}{*}{$A g e_{y<30}$} & $-0.037 * * *$ & $-0.022^{*}$ & $-0.030^{* *}$ & $-0.025^{*}$ & $-0.045^{* * *}$ & $-0.062 * * *$ & $-0.039 * * *$ \\
\hline & $(0.004)$ & $(0.010)$ & $(0.011)$ & $(0.011)$ & (0.009) & (0.009) & $(0.005)$ \\
\hline \multirow[t]{2}{*}{$A g e_{30}<y<40$} & $-0.005^{*}$ & 0.011 & $0.021^{* *}$ & $0.014^{*}$ & $-0.019 * *$ & $-0.035 * * *$ & $-0.025 * * *$ \\
\hline & $(0.002)$ & $(0.006)$ & (0.007) & $(0.007)$ & $(0.006)$ & $(0.006)$ & (0.003) \\
\hline \multirow[t]{2}{*}{ Age $40<y<50$} & 0.002 & $0.019 * *$ & $0.037^{* * *}$ & $0.013^{*}$ & $-0.020 * * *$ & $-0.023^{* * *}$ & $-0.012 * * *$ \\
\hline & $(0.002)$ & $(0.006)$ & $(0.006)$ & $(0.006)$ & $(0.005)$ & $(0.005)$ & (0.003) \\
\hline \multirow[t]{2}{*}{$A g e_{50}<y<60$} & $0.006^{* *}$ & $0.025^{* * *}$ & $0.034^{* * *}$ & 0.013 & -0.003 & $-0.015 * *$ & $-0.012^{* * *}$ \\
\hline & $(0.002)$ & $(0.006)$ & $(0.007)$ & $(0.007)$ & $(0.006)$ & $(0.006)$ & $(0.003)$ \\
\hline \multirow[t]{2}{*}{ Midwest } & -0.001 & 0.002 & -0.003 & 0.001 & -0.003 & 0.001 & -0.002 \\
\hline & $(0.002)$ & $(0.006)$ & $(0.007)$ & $(0.007)$ & $(0.006)$ & $(0.006)$ & $(0.003)$ \\
\hline \multirow[t]{2}{*}{ South } & $-0.029 * * *$ & $-0.033^{* * *}$ & $-0.037^{* * *}$ & $-0.034^{* * *}$ & $-0.032^{* * *}$ & $-0.023^{* * *}$ & $-0.015^{* * *}$ \\
\hline & $(0.002)$ & $(0.006)$ & $(0.007)$ & $(0.007)$ & $(0.006)$ & $(0.006)$ & (0.003) \\
\hline \multirow[t]{2}{*}{ West } & -0.003 & -0.005 & -0.004 & 0.000 & -0.001 & -0.005 & -0.002 \\
\hline & $(0.003)$ & $(0.007)$ & $(0.008)$ & $(0.008)$ & $(0.007)$ & $(0.006)$ & $(0.004)$ \\
\hline$R^{2}$ & 0.213 & 0.229 & 0.242 & 0.230 & 0.206 & 0.192 & 0.095 \\
\hline Num. Obs. & 105257 & 18348 & 17098 & 16405 & 15573 & 15327 & 22506 \\
\hline
\end{tabular}


Table 24: Test of Hypothesis 5 - PSID. Coefficients estimated using a standard OLS model and ex-ante (i.e., before moving) values of the ratio of total risk free asset holdings relative to financial wealth, $B_{i t} / W_{i t}$. Risk free asset holdings do not include debt. $m_{B I G_{i t}}\left(m_{S M A L L_{i t}}\right)$ is a dummy variable equal to one if the family is increasing (decreasing) its housing holdings (i.e., moving to a bigger (smaller) house). Standard errors are reported in parentheses. ${ }^{* * *}$ denotes significance at the $1 \%$ level, ${ }^{* *}$ at the $5 \%$ level, and ${ }^{*}$ at the $10 \%$ level. The pooled regressions include year dummies. Source: PSID. Period: $1984-2005$.

\begin{tabular}{|c|c|c|c|c|c|c|c|c|}
\hline & All & 1984 & 1989 & 1994 & 1999 & 2001 & 2003 & 2005 \\
\hline \multirow[t]{2}{*}{ constant $\left(\gamma_{0}\right)$} & $0.743^{* * *}$ & $0.224^{*}$ & $0.304^{* *}$ & 0.136 & 0.185 & -0.071 & 0.210 & 0.118 \\
\hline & $(0.059)$ & $(0.100)$ & $(0.107)$ & (0.113) & $(0.124)$ & $(0.121)$ & $(0.123)$ & $(0.124)$ \\
\hline \multirow[t]{2}{*}{$m_{B I G}\left(\gamma_{1}\right)$} & 0.013 & $0.375^{* * *}$ & 0.139 & 0.287 & $0.466^{* * *}$ & -0.011 & $-0.224^{*}$ & -0.163 \\
\hline & $(0.060)$ & $(0.145)$ & $(0.176)$ & $(0.197)$ & $(0.172)$ & $(0.153)$ & $(0.142)$ & $(0.143)$ \\
\hline \multirow[t]{2}{*}{$m_{S M A L L}\left(\gamma_{2}\right)$} & $-0.325 * * *$ & 0.182 & -0.236 & -0.439 & -0.061 & $-0.439^{*}$ & -0.433 & $-0.451^{* *}$ \\
\hline & $(0.096)$ & $(0.263)$ & $(0.325)$ & $(0.325)$ & $(0.261)$ & $(0.214)$ & $(0.253)$ & $(0.223)$ \\
\hline \multirow[t]{2}{*}{$\Delta$ Family } & $-0.040^{*}$ & 0.034 & -0.073 & -0.078 & $-0.127^{* *}$ & -0.044 & 0.021 & 0.059 \\
\hline & $(0.022)$ & $(0.052)$ & $(0.063)$ & $(0.078)$ & $(0.057)$ & $(0.054)$ & $(0.055)$ & $(0.055)$ \\
\hline \multirow[t]{2}{*}{$\Delta$ Married } & -0.124 & -0.397 & 0.041 & -0.041 & -0.218 & -0.409 & 0.264 & 0.045 \\
\hline & $(0.115)$ & $(0.277)$ & $(0.366)$ & $(0.378)$ & $(0.291)$ & $(0.286)$ & $(0.283)$ & $(0.285)$ \\
\hline \multirow[t]{2}{*}{$\Delta$ Employment } & -0.045 & 0.035 & -0.091 & -0.027 & -0.134 & 0.041 & -0.038 & 0.110 \\
\hline & $(0.041)$ & $(0.080)$ & (0.092) & $(0.100)$ & $(0.122)$ & $(0.112)$ & $(0.122)$ & $(0.118)$ \\
\hline \multirow[t]{2}{*}{$A g e_{y<30}$} & $-2.627 * * *$ & $-1.608^{* * *}$ & $-1.885^{* * *}$ & $-2.487 * * *$ & $-3.131^{* * *}$ & $-2.933^{* * *}$ & $-3.168 * * *$ & $-3.076^{* * *}$ \\
\hline & $(0.056)$ & $(0.106)$ & $(0.130)$ & $(0.149)$ & $(0.169)$ & $(0.158)$ & $(0.160)$ & $(0.151)$ \\
\hline \multirow[t]{2}{*}{ Age $_{30<y<40}$} & $-1.677^{* * *}$ & $-0.949 * * *$ & $-1.317^{* * *}$ & $-1.587^{* * *}$ & $-2.004^{* * *}$ & $-1.871^{* * *}$ & $-2.019 * * *$ & $-1.897^{* * *}$ \\
\hline & $(0.043)$ & (0.089) & (0.096) & $(0.106)$ & (0.119) & (0.119) & $(0.123)$ & $(0.124)$ \\
\hline \multirow[t]{2}{*}{ Age $40<y<50$} & $-0.924^{* * *}$ & $-0.509 * * *$ & $-0.651^{* * *}$ & $-0.867 * * *$ & $-1.292^{* * *}$ & $-0.951^{* * *}$ & $-1.013^{* * *}$ & $-1.033^{* * *}$ \\
\hline & $(0.041)$ & (0.101) & (0.103) & (0.104) & $(0.110)$ & $(0.109)$ & $(0.112)$ & (0.112) \\
\hline \multirow[t]{2}{*}{$\operatorname{Age}_{50<y<60}$} & $-0.468 * * *$ & $-0.253^{* *}$ & -0.197 & $-0.366^{* *}$ & $-0.645^{* * *}$ & $-0.636^{* * *}$ & $-0.535^{* * *}$ & $-0.500 * * *$ \\
\hline & $(0.044)$ & $(0.093)$ & $(0.109)$ & $(0.125)$ & $(0.129)$ & $(0.120)$ & $(0.118)$ & $(0.115)$ \\
\hline \multirow[t]{2}{*}{ Midwest } & $-0.224^{* * *}$ & $-0.255^{* *}$ & -0.191 & -0.026 & -0.088 & -0.063 & $-0.451^{* * *}$ & $-0.394^{* *}$ \\
\hline & $(0.045)$ & $(0.096)$ & $(0.108)$ & $(0.114)$ & $(0.127)$ & $(0.123)$ & $(0.125)$ & $(0.126)$ \\
\hline \multirow[t]{2}{*}{ South } & $-0.295^{* * *}$ & $-0.279 * *$ & $-0.331^{* * *}$ & -0.152 & $-0.279^{*}$ & -0.112 & $-0.429 * * *$ & $-0.408^{* * *}$ \\
\hline & $(0.042)$ & $(0.089)$ & (0.099) & (0.108) & $(0.119)$ & $(0.115)$ & $(0.117)$ & (0.117) \\
\hline \multirow[t]{2}{*}{ West } & $-0.373^{* * *}$ & -0.186 & $-0.284^{*}$ & -0.102 & $-0.612^{* * *}$ & $-0.291^{*}$ & $-0.596^{* * *}$ & $-0.347^{*}$ \\
\hline & $(0.050)$ & $(0.107)$ & $(0.122)$ & $(0.131)$ & $(0.140)$ & $(0.134)$ & $(0.136)$ & $(0.135)$ \\
\hline$R^{2}$ & 0.312 & 0.222 & 0.228 & 0.287 & 0.331 & 0.327 & 0.356 & 0.353 \\
\hline Num. Obs. & 20172 & 2491 & 2582 & 2459 & 3078 & 3191 & 3190 & 3181 \\
\hline
\end{tabular}


Table 25: Test of Hypothesis 5 - SIPP. Coefficients estimated using a standard OLS model and ex-ante (i.e., before moving) values of the ratio of total risk free asset holdings relative to financial wealth, $B_{i t} / W_{i t}$. Risk free asset holdings do not include debt. $m_{B I G_{i t}}\left(m_{S M A L L_{i t}}\right)$ is a dummy variable equal to one if the family is increasing (decreasing) its housing holdings (i.e., moving to a bigger (smaller) house). Standard errors are reported in parentheses. ${ }^{* * *}$ denotes significance at the $1 \%$ level, ${ }^{* *}$ at the $5 \%$ level, and ${ }^{*}$ at the $10 \%$ level. The pooled regressions include year dummies. Source: SIPP. Period: $1997-2005$.

\begin{tabular}{|c|c|c|c|c|c|c|c|}
\hline & All years & 1997 & 1998 & 1999 & 2002 & 2003 & 2005 \\
\hline \multirow[t]{2}{*}{ constant $\left(\gamma_{0}\right)$} & -0.007 & $0.113^{* *}$ & $0.126^{* *}$ & 0.066 & 0.069 & 0.074 & $0.088^{* *}$ \\
\hline & $(0.166)$ & $(0.040)$ & $(0.046)$ & $(0.044)$ & $(0.044)$ & $(0.045)$ & $(0.034)$ \\
\hline \multirow[t]{2}{*}{$m_{B I G}\left(\gamma_{1}\right)$} & $0.169 * * *$ & $0.229^{*}$ & 0.194 & $0.503^{* * *}$ & 0.084 & -0.197 & $0.191^{*}$ \\
\hline & $(0.048)$ & $(0.123)$ & $(0.130)$ & $(0.124)$ & $(0.126)$ & $(0.122)$ & $(0.090)$ \\
\hline \multirow[t]{2}{*}{$m_{S M A L L}\left(\gamma_{2}\right)$} & 0.025 & 0.062 & 0.043 & 0.084 & -0.133 & 0.066 & 0.022 \\
\hline & $(0.067)$ & $(0.160)$ & $(0.184)$ & $(0.176)$ & $(0.161)$ & $(0.182)$ & $(0.132)$ \\
\hline \multirow[t]{2}{*}{$\Delta$ Family } & -0.018 & -0.044 & $-0.078^{*}$ & -0.008 & 0.026 & 0.002 & -0.006 \\
\hline & $(0.013)$ & $(0.030)$ & $(0.034)$ & $(0.038)$ & $(0.032)$ & $(0.039)$ & $(0.022)$ \\
\hline \multirow[t]{2}{*}{$\Delta$ Married } & -0.103 & -0.111 & -0.198 & -0.303 & -0.097 & 0.016 & -0.001 \\
\hline & $(0.061)$ & $(0.140)$ & $(0.165)$ & $(0.197)$ & $(0.139)$ & $(0.192)$ & $(0.107)$ \\
\hline \multirow[t]{2}{*}{$\Delta$ Employment } & $-0.098 * * *$ & $-0.270^{* * *}$ & $-0.253^{* *}$ & -0.132 & 0.049 & -0.059 & $-0.101^{*}$ \\
\hline & $(0.025)$ & $(0.074)$ & $(0.082)$ & $(0.078)$ & $(0.053)$ & $(0.059)$ & $(0.041)$ \\
\hline \multirow[t]{2}{*}{$A g e_{y<30}$} & $-2.611^{* * *}$ & $-2.644^{* * *}$ & $-2.751^{* * *}$ & $-2.868^{* * *}$ & $-2.408^{* * *}$ & $-2.640^{* * *}$ & $-2.419^{* * *}$ \\
\hline & $(0.028)$ & $(0.066)$ & $(0.079)$ & $(0.075)$ & $(0.070)$ & $(0.073)$ & $(0.053)$ \\
\hline \multirow[t]{2}{*}{$A g e_{30}<y<40$} & $-1.532^{* * *}$ & $-1.578 * * *$ & $-1.715^{* * *}$ & $-1.553^{* * *}$ & $-1.405^{* * *}$ & $-1.488^{* * *}$ & $-1.439^{* * *}$ \\
\hline & (0.018) & $(0.042)$ & $(0.049)$ & $(0.047)$ & $(0.047)$ & $(0.048)$ & $(0.035)$ \\
\hline \multirow[t]{2}{*}{ Age $_{40}<y<50$} & $-0.873^{* * *}$ & $-0.902^{* * *}$ & $-1.001^{* * *}$ & $-0.923^{* * *}$ & $-0.814^{* * *}$ & $-0.855^{* * *}$ & $-0.760 * * *$ \\
\hline & $(0.017)$ & $(0.040)$ & $(0.046)$ & $(0.043)$ & $(0.043)$ & $(0.044)$ & (0.032) \\
\hline \multirow[t]{2}{*}{$A g e_{50<y<60}$} & $-0.454^{* * *}$ & $-0.458 * * *$ & $-0.522^{* * *}$ & $-0.518^{* * *}$ & $-0.430^{* * *}$ & $-0.376^{* * *}$ & $-0.414^{* * *}$ \\
\hline & $(0.018)$ & $(0.044)$ & $(0.050)$ & $(0.046)$ & $(0.046)$ & $(0.046)$ & (0.033) \\
\hline \multirow[t]{2}{*}{ Midwest } & $-0.096^{* * *}$ & 0.002 & -0.007 & 0.018 & $-0.115^{*}$ & $-0.186^{* * *}$ & $-0.262^{* * *}$ \\
\hline & (0.019) & $(0.044)$ & $(0.051)$ & $(0.048)$ & $(0.048)$ & $(0.049)$ & (0.037) \\
\hline \multirow[t]{2}{*}{ South } & $-0.203^{* * *}$ & $-0.184^{* * *}$ & $-0.235^{* * *}$ & $-0.203^{* * *}$ & $-0.180^{* * *}$ & $-0.187^{* * *}$ & $-0.231^{* * *}$ \\
\hline & $(0.018)$ & $(0.042)$ & $(0.049)$ & $(0.046)$ & $(0.046)$ & $(0.046)$ & (0.035) \\
\hline \multirow[t]{2}{*}{ West } & $-0.346^{* * *}$ & $-0.375^{* * *}$ & $-0.364^{* * *}$ & $-0.308^{* * *}$ & $-0.378 * * *$ & $-0.314^{* * *}$ & $-0.349^{* * *}$ \\
\hline & $(0.020)$ & $(0.049)$ & $(0.056)$ & $(0.053)$ & $(0.052)$ & $(0.053)$ & $(0.040)$ \\
\hline$R^{2}$ & 0.231 & 0.236 & 0.218 & 0.233 & 0.215 & 0.231 & 0.262 \\
\hline Num. Obs. & 105154 & 18322 & 17086 & 16386 & 15564 & 15319 & 22477 \\
\hline
\end{tabular}

